\title{
دور إدارة المعرفة فِّ تطوير المحتوى الإعلامي لقطاع الإعلام السعودي ِِّ ظل تحولات البيئة الرقمية
}

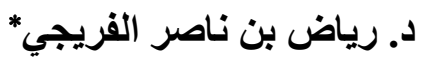

تعد المملكة العربية السعودية من بين أوائل الدول العربية التي بدأت في توظيف

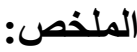

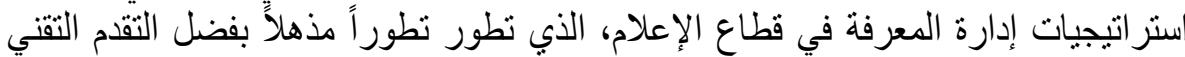

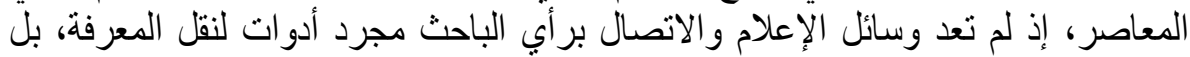

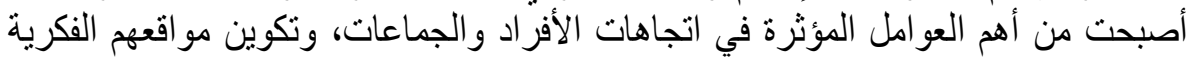
و الاجتماعية في كافة المجتمعات.

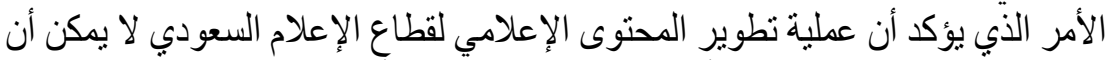

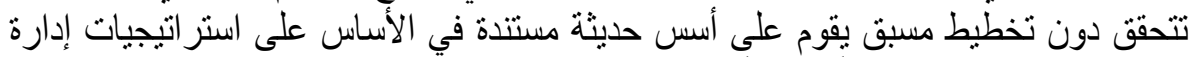

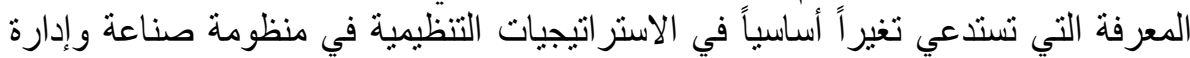

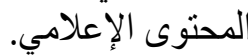

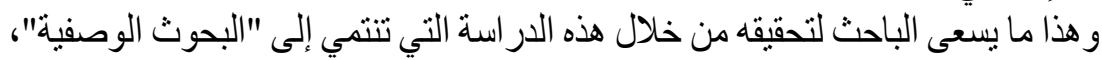

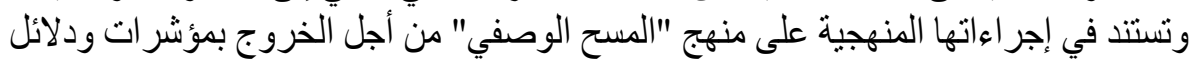
حول دور إدارة المعرفة في تطوير المحتوى الإعلامي لقطاع الإعلام السعودي في ظل تحو لإلات

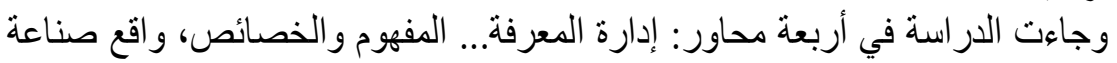
البيئة الرقمية.

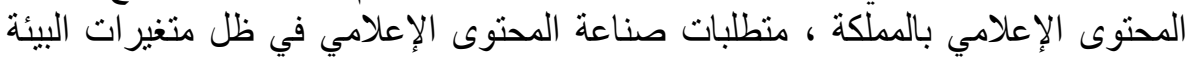

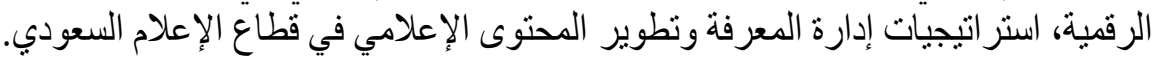

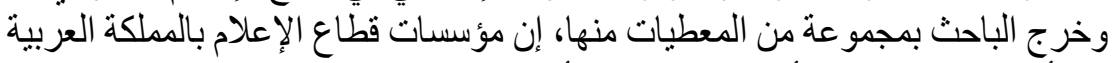

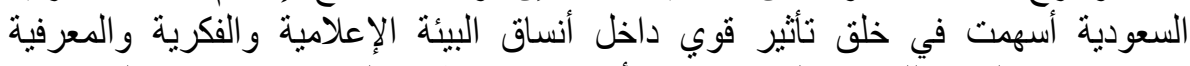

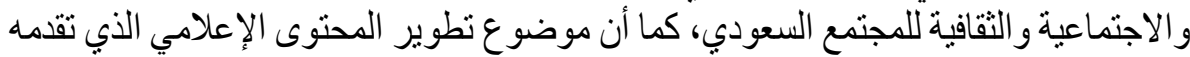

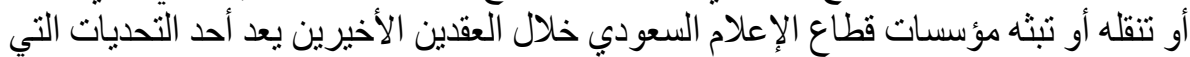
تو اجه المملكة.

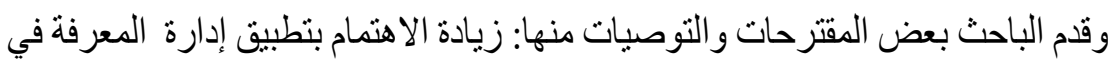

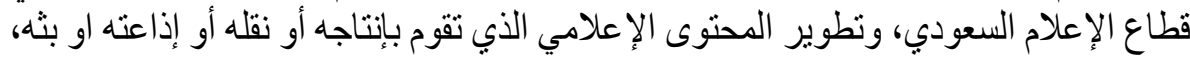

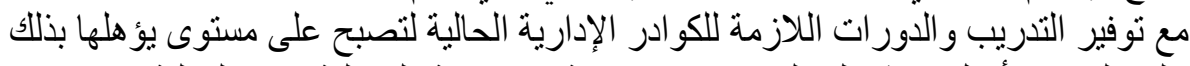

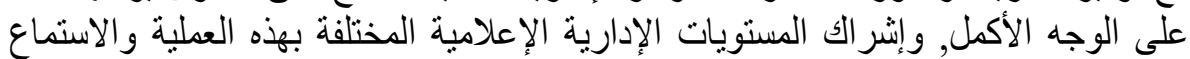

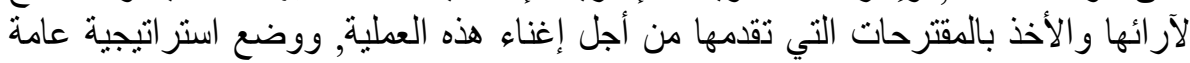

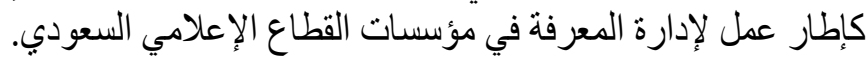

* جامعة الإمام محمد بن سعود الإسلامية ،المملكة العربية السعودية،الرياض * 


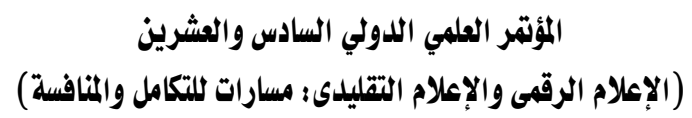

\title{
The role of knowledge management in developing media content for the Saudi media sector in light of the transformations of the digital environment - a reading in the imperative of use and the problem of implementation Riyadh Naseer Mohammed Al Furaiji
}

\begin{abstract}
The Kingdom of Saudi Arabia is among the first Arab countries to start employing knowledge management strategies in the media sector, which has developed an amazing development thanks to contemporary technical progress.Individuals and groups, and the formation of their intellectual and social positions in all societies.

This confirms that the process of developing media content for the Saudi media sector cannot be achieved without prior planning that is based on modern foundations and is mainly based on knowledge management strategies that require a fundamental change in organizational strategies in the media content industry and management system.

This is what the researcher seeks to achieve through this study, which belongs to "descriptive research," and its methodological procedures are based on the "descriptive survey" approach in order to come up with indicators and indications about the role of knowledge management in developing the media content of the Saudi media sector in light of the transformations of the digital environment.

The study came in four axes: knowledge management ... the concept and characteristics, the reality of the media content industry in the Kingdom, the requirements for media content industry in light of the digital environment variables, knowledge management strategies and the development of media content in the Saudi media sector.

The researcher came up with a set of data, including that the institutions of the media sector in the Kingdom of Saudi Arabia have contributed to creating a strong influence within the modes of the media, intellectual, knowledge, social and cultural environment for the Saudi society, and the issue of developing media content presented, transmitted or broadcast by the institutions of the Saudi media sector during the last two decades is considered One of the challenges facing the Kingdom.

The researcher presented some proposals and recommendations, including: Increasing interest in implementing knowledge management in the Saudi media sector, developing media content that you produce, transmitting, broadcasting or broadcasting, while providing training and necessary courses for current administrative cadres to become at a level that fully qualifies them, and involving administrative levels. The various media organizations involved in this process, listen to their views and take into account the proposals they make in order to enrich this process, and develop a general strategy as a framework for knowledge management in the institutions of the Saudi media sector.
\end{abstract}




\section{المؤتقر العلمي اللدولي السادس والعشرين}

(الإعلام الرقمى والإعلام التقليدى : مسارات للتكامل والمتافسة)

مقدمة:

لعل أبرز وأهم صفة تميز المجتمعات المعاصرة عن سابقتها هي البيئة

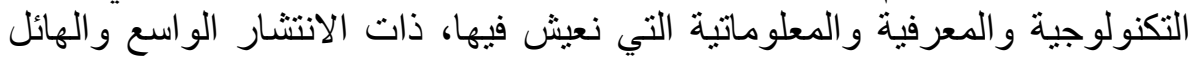

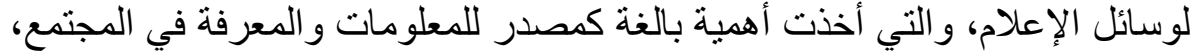

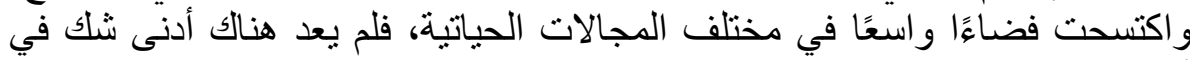

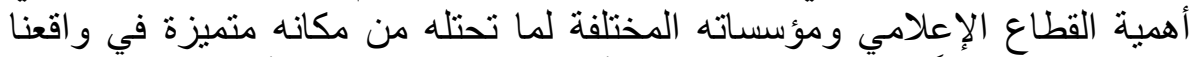

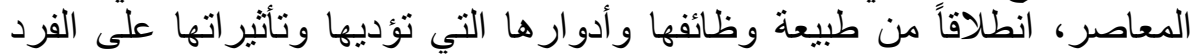

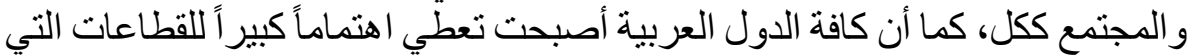

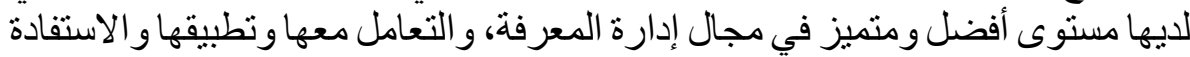
منها، والتي باتت بدورها تشكل أحد أهم التطورات الفكرية المعاصرة التهرة التي تهتم بالمعلومات و البيانات و الأنشطة المعرفية وبخاصة في مجال الاتصال و الإعلام.

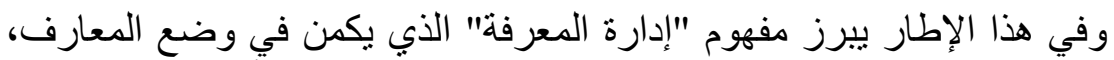

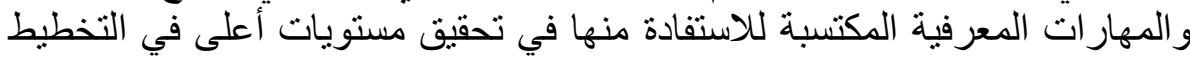

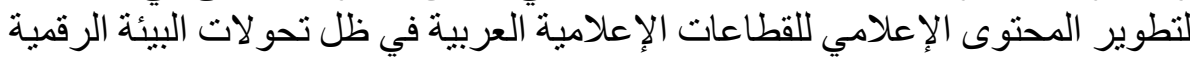

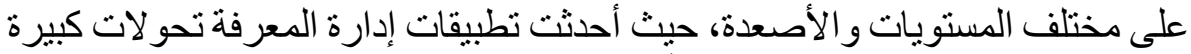
في نمط الحياة الحديثة، وخلقت فرصاً هائلة لتحقيق أهداف التنمية الإدارية والإنة الإنتاجية في كافة المؤسسات و الأنشطة الحياتية.

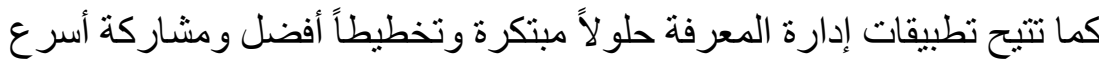

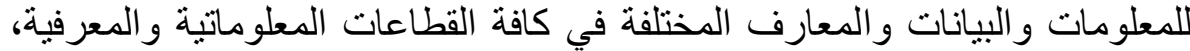

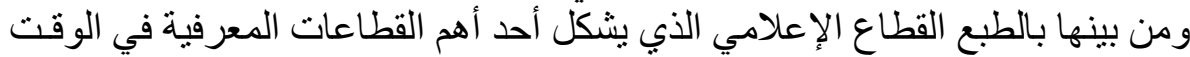

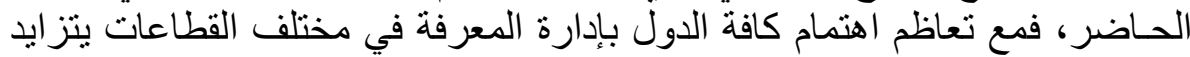

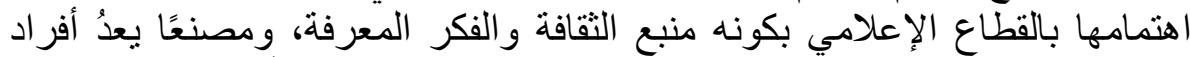

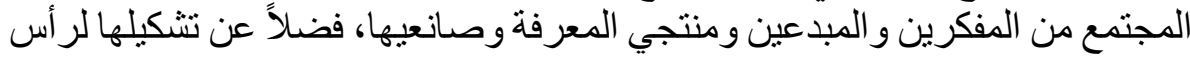
المال الفكري الذي يقع على عاتقه تحقيق العملية التنموية للمجتمع بمختلف جو انبها.

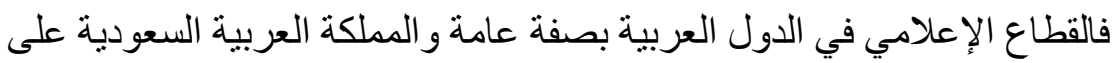

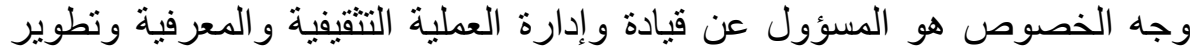

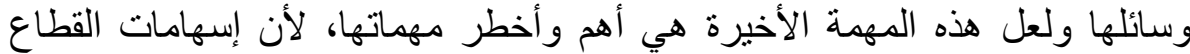

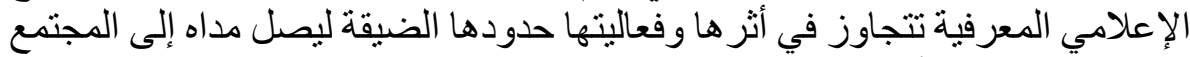

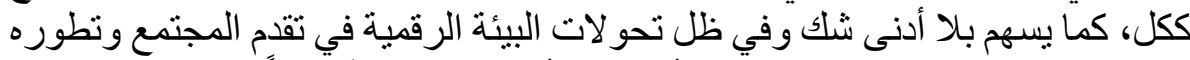

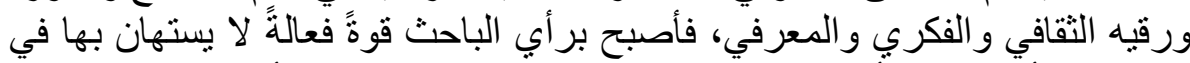

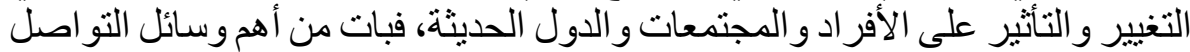

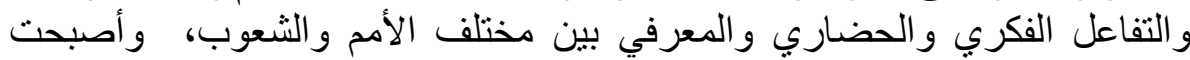




\section{المؤتقر العلمي اللدولي السادس والعشرين}

(الإعلام الرقمى والإعلام التقليدى : مسارات للتكامل والمتافسة)

المؤسسات الإعلامية بمختلف أنو اعها و أنماط ملكيتها مؤسسات فعالة، تساهم في

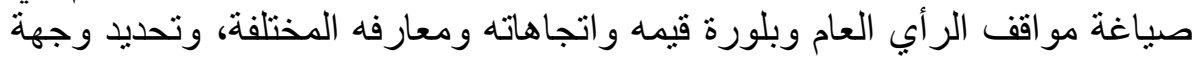

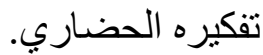

وبما أن قطاع العمل الإعلامي لا يتسم بالجمود، فإن انتشار وسائله على نطاق

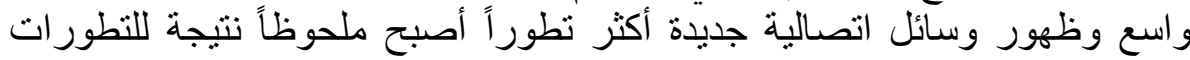
التكنولوجية الحاصلة، إذ يشهد ميدان صناعة المحتوى الإعلامي وتقنيات التهات الاتصال

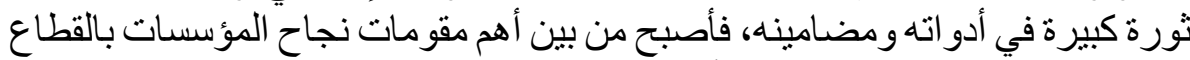

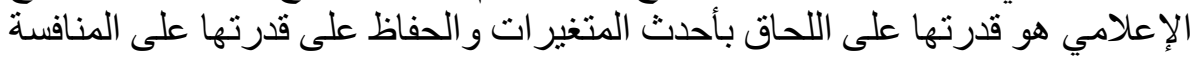

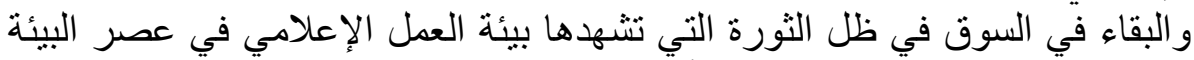

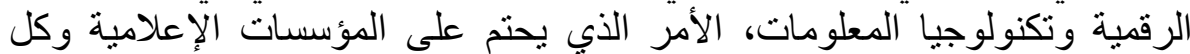

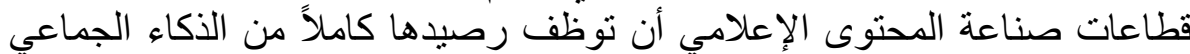
للاستفادة القصوى تطبيقات إدارة المعرفة تحقيق أهدافها الإستراتيجية من عملية

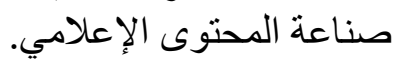

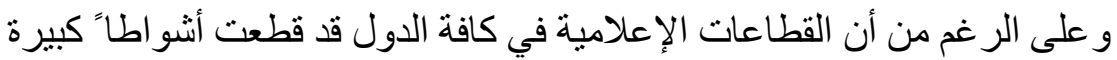

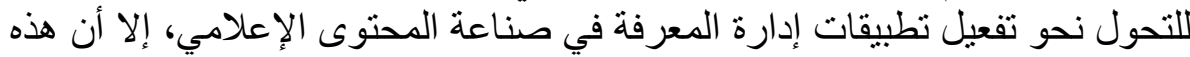

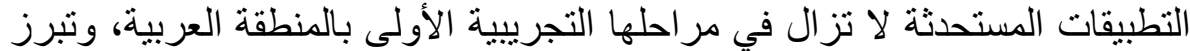

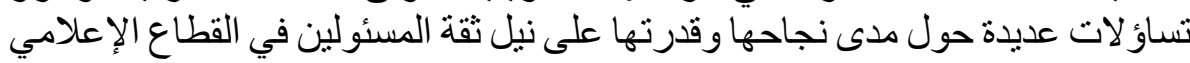

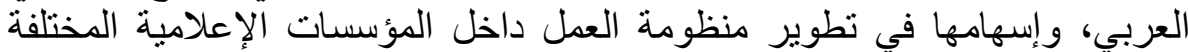

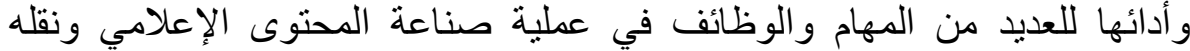

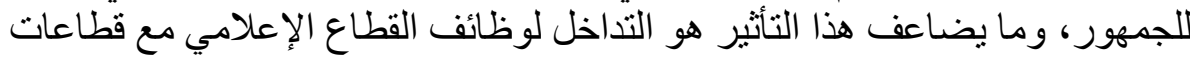

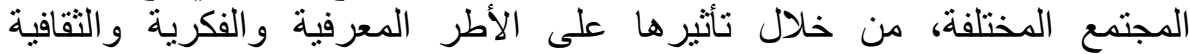

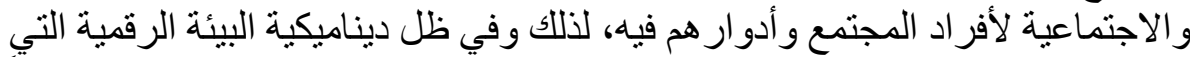

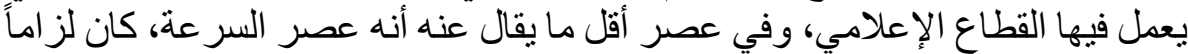

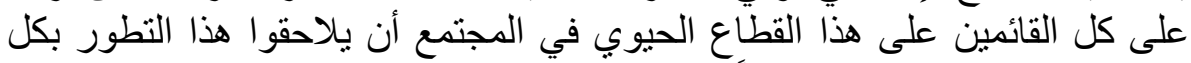

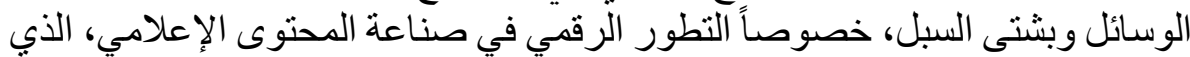

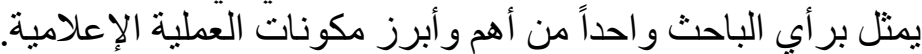

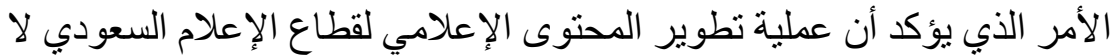

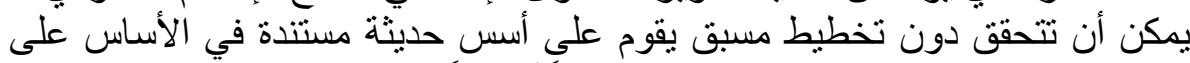

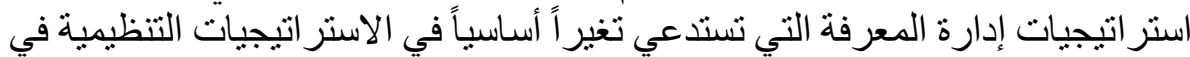

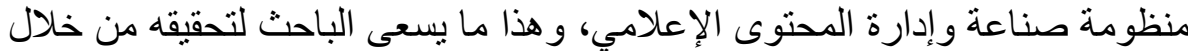

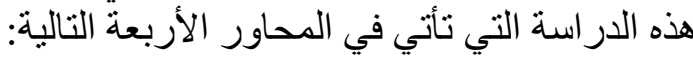
- - - إدارة المعرفة .... ماهيتها وأهميتها. 


\section{المؤتقر العلمي اللدولي السادس والعشرين}

(الإعلام الرقمى والإعلام التقليدى : مسارات للتكامل والمتافسة)

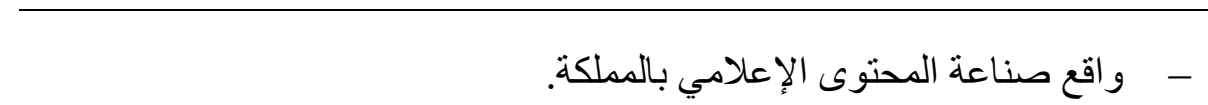

- - منطلبات صناعة المحتوى الإعلامي في ظل متغير ات البيئة الرقمية.

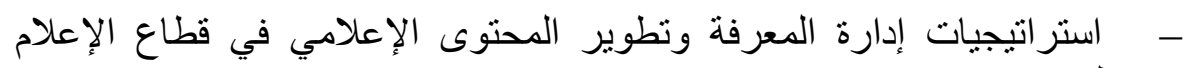
السعودي.

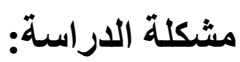

لم تعد تقنيات إدارة المعرفة بر أي الباحث بعيدة عن تطوير مجال العمل الإعلامي

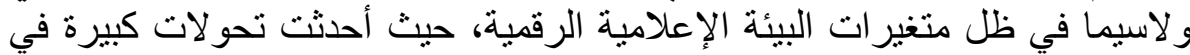

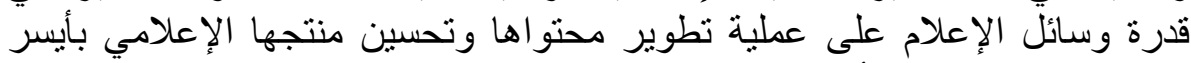

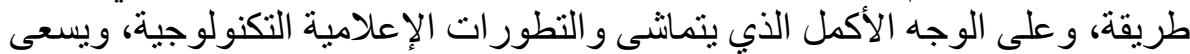

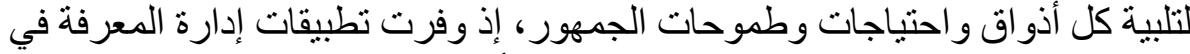

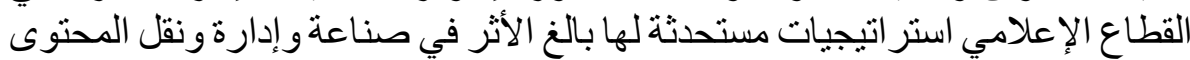

الإعلامي إلى المتلقي(1).

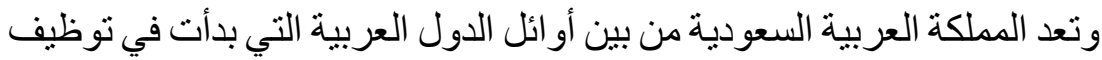

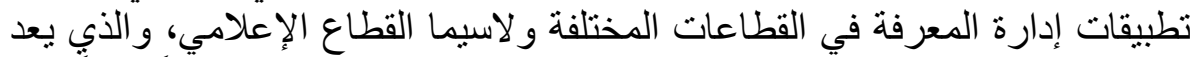

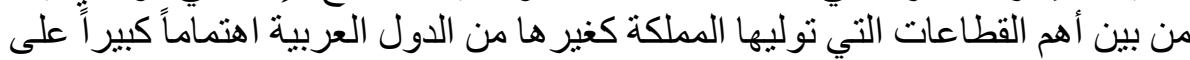

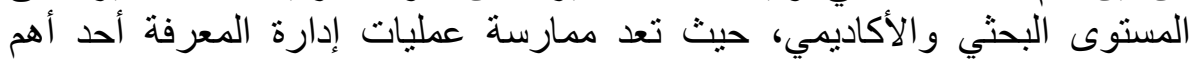

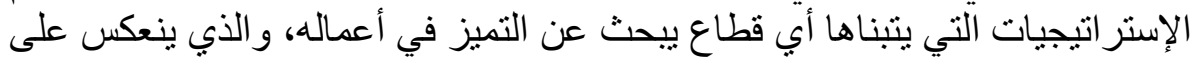

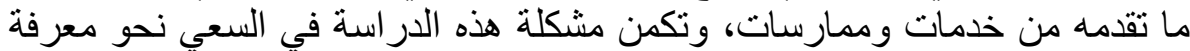

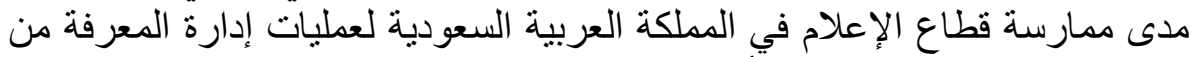

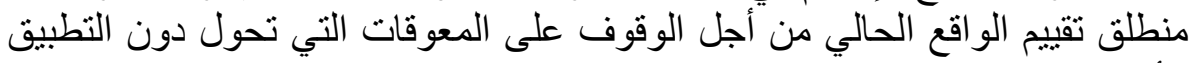

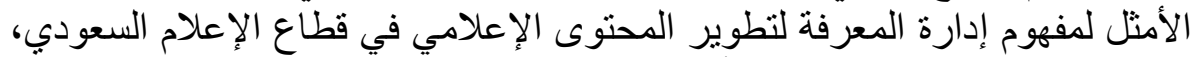

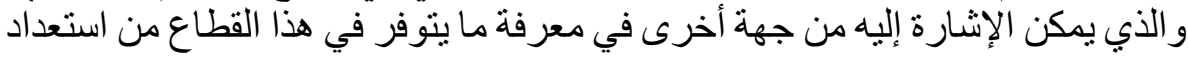

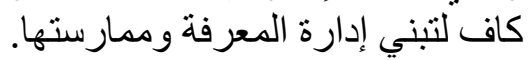

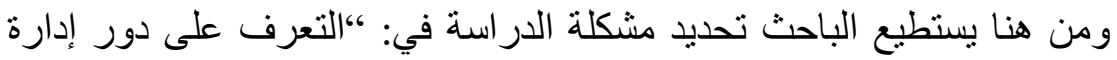

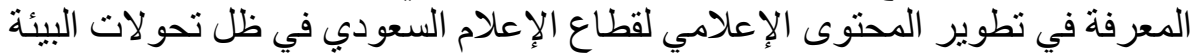

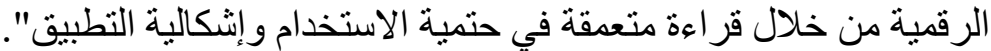

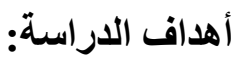

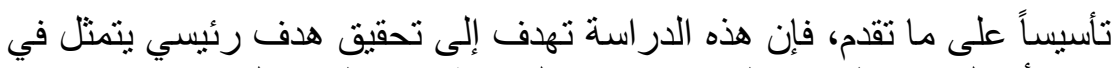

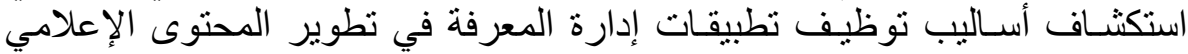

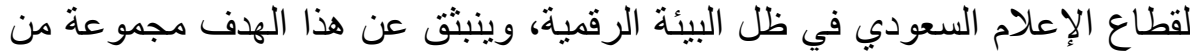
الأهداف الفرعية الأخرى وآلتي تأتي على النئة النحو التالي: 


\section{المؤتقر العلمي اللدولي السادس والعشرين}

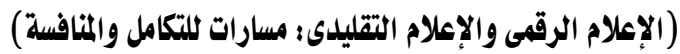

التعرف على مفهوم إدارة المعرفة كمفهوم إداري معاصر يؤثر في قدرة مؤسسات

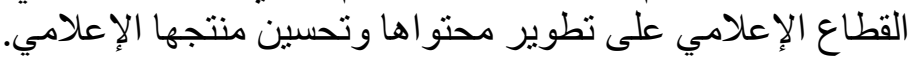

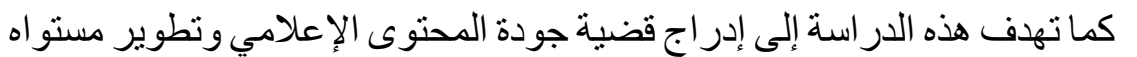

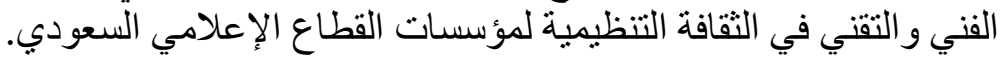

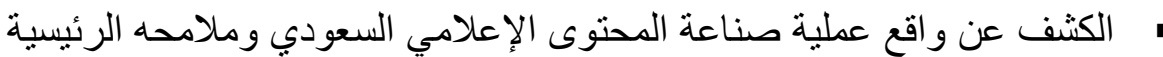
في ظل متغير ات بيئة العمل الإعلامي الرقمية. إبراز الدور الذي يمكن أن تلعبه إدارة المعرفة في عملية تطوير المحتوى

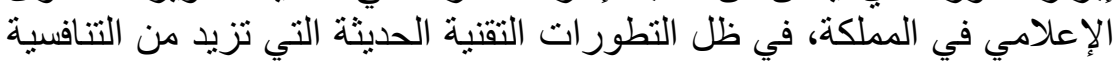
و السباق المحموم بين المؤسسات لتحقيق الريادة الإعلامية.

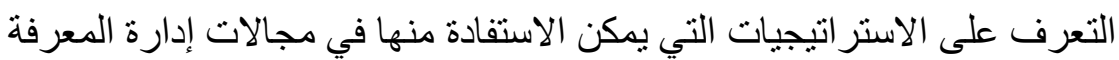

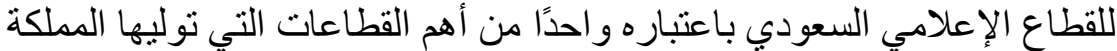

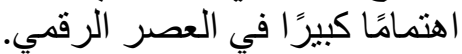

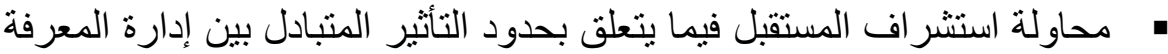

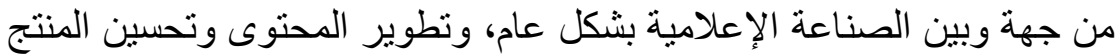
الإعلامي بشكل خاص من جهة أخرى.

تأتي أهمية هذه الدراسة في كون موضو عها جاء ضمن التوجهاء التهاء الذي تسعى إليه

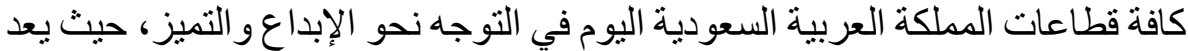

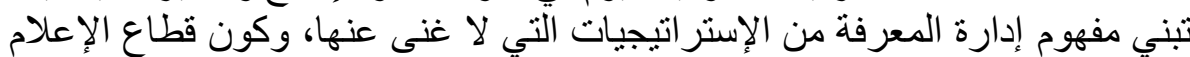

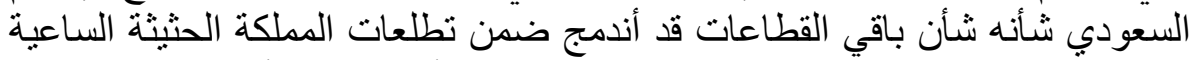

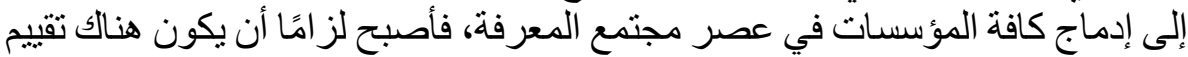

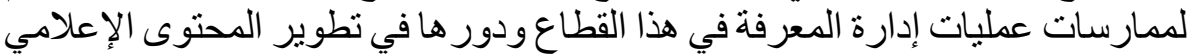

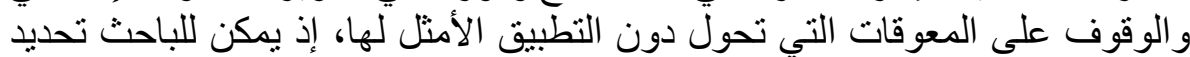
أهمية هذه الار اسة في مجمو عة النقاط النقاط التالية:

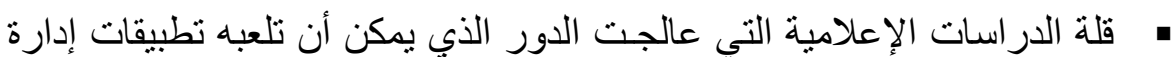

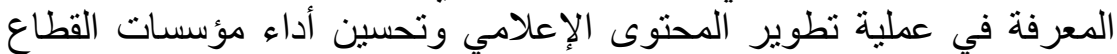
الإعلامي في المملكة العربية السعودية.

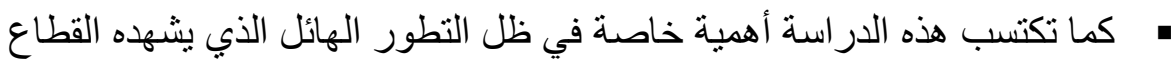
الإعلامي السعودي، وحداثة مفهوم إدارة المعرفة وتطبية النيقاتها الحديثة. 


\section{المؤتقر العلمي اللدولي السادس والعشرين}

(الإعلام الرقمى والإعلام التقليدى : مسارات للتكامل والمتافسة)

تبرز أهمية الدراسة في ضوء ما حظيت به إدارة المعرفة باهتمام بحثي

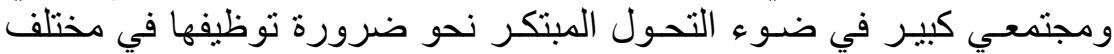

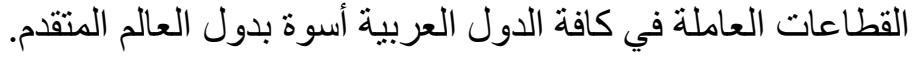

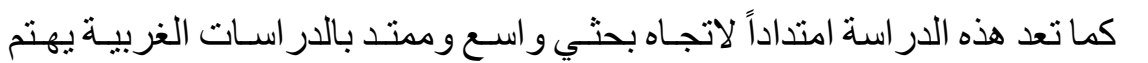
برصد تأثثير تطبيقات إدارة المعرفة والتقنيات الرقمية الحديثة على الإنى الأداء

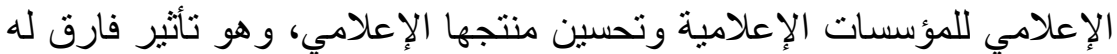

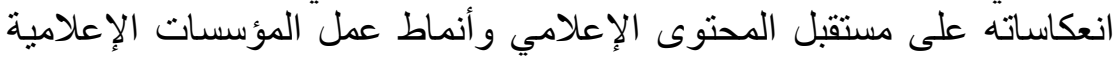

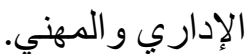
اتجاه بعض المؤسسات الإعلامية السعودية للاستفادة من إدارة المعرفة في تطوير

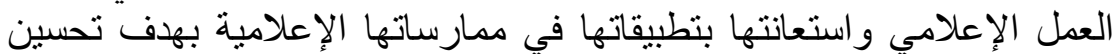
منتجها وتطوير محتو الإعا الإعلامي.

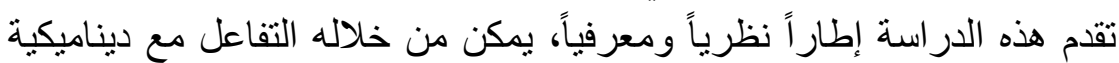

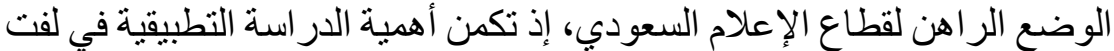

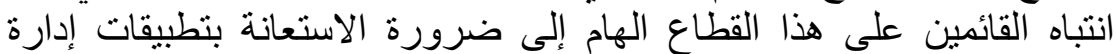

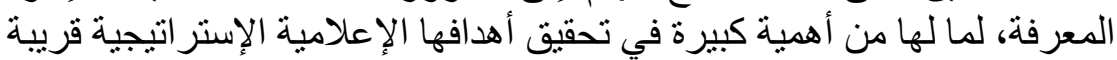

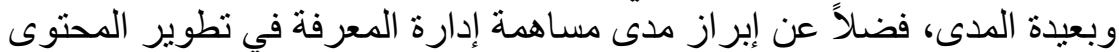
الإعلامي في ظل البيئة الإعلامية الرقية المية الحديثة.

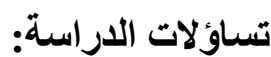
تسعى هذه الدر اسة للإجابة على التساؤل الرئيس التالي:

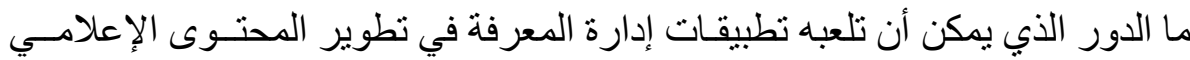

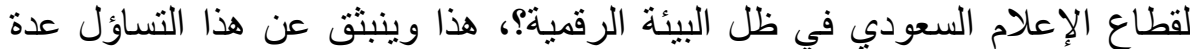
تساؤلات فر عية أخرى ئأتي من بين أهمها:

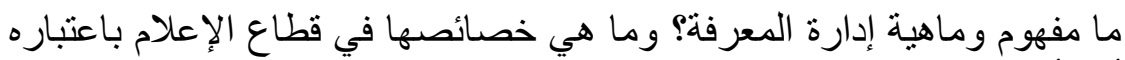
أحد أهم القطاعات المؤثرة في المجتمع؟

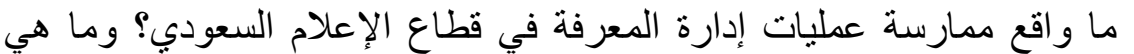

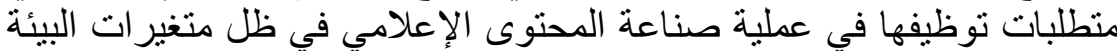
الرقمية؟

ما مدى مساهمة تطبيقات إدارة المعرفة في دعم خطط القطاع الإعلامي السعودي

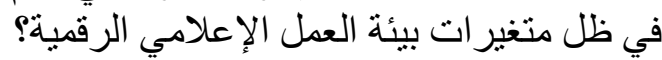

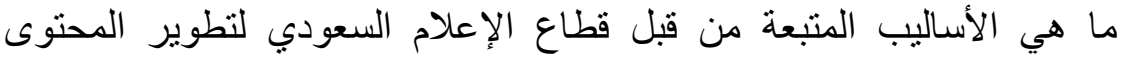

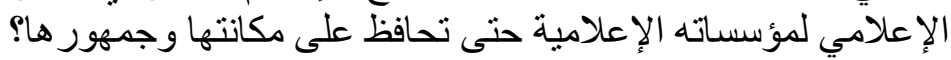




\section{المؤتقر العلمي اللدولي السادس والعشرين}

(الإعلام الرقىى والإعلام التقليدى : مسارات للتكامل والمنافسة)

ما هي الميزات والإضافات التي تقدمها تطبيقات إدارة المعرفة لقطاع الإعلام العربي بصفة عامة والسعودي الإني على وجه الخصات الخصوص لتحسين أداءه الإعلامي

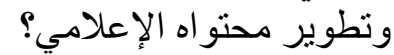

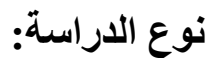

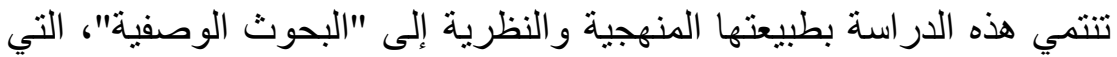

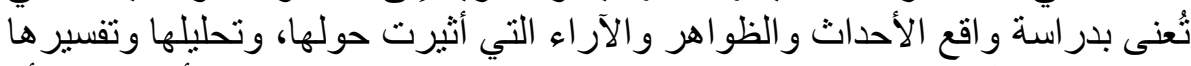

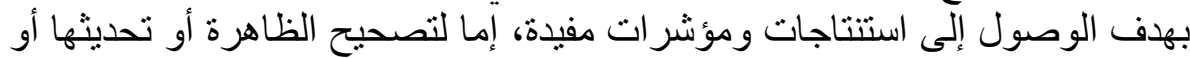

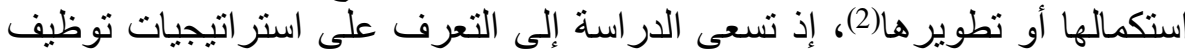

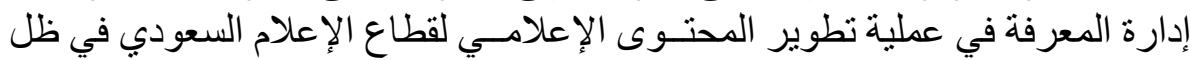

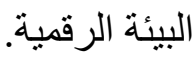

$$
\text { المنهج المستخدم في الاراسة: }
$$

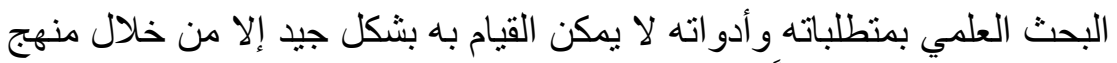

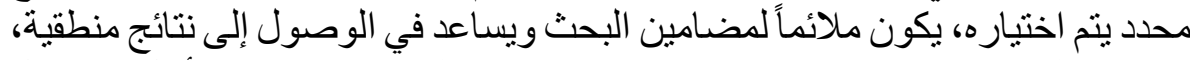

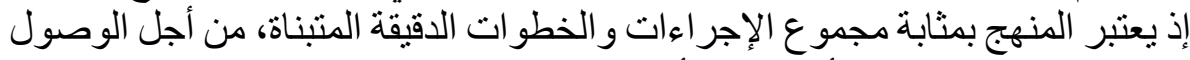

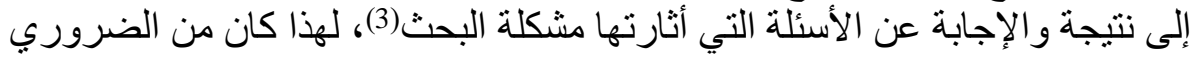

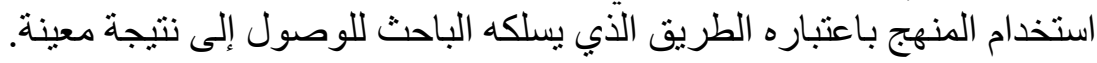

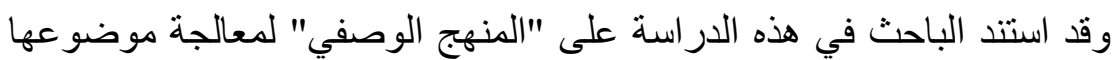

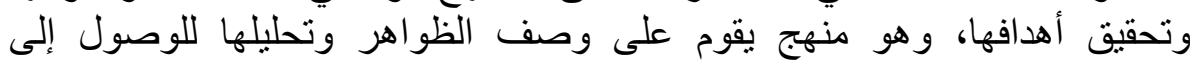
استنتاجات تمكّن من إيجاد حلول لمشكلة الدر اسة، تقوم على أساس وصف ولف معطيات

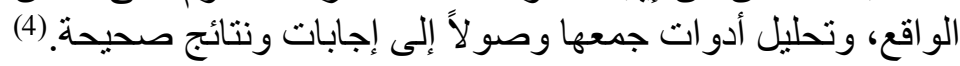

\section{مصطلحات الدراسة ومفاهيمها الإجرائية:}

نظر اً لكثرة المفاهيم وتشعبها وتداخلها أحياناً، ومن أجل التحكم في عناصها

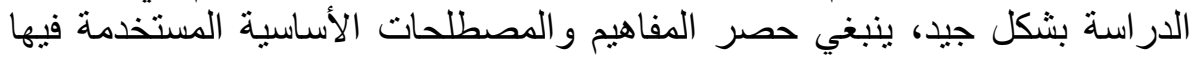

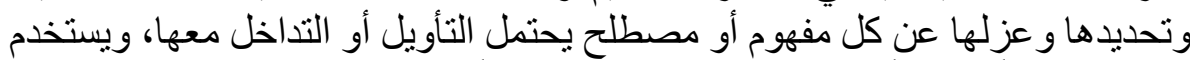

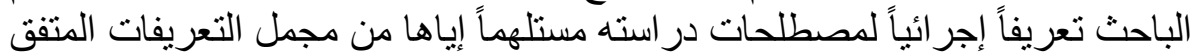
عليها علمياً بالثكل التالي:

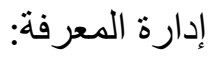

هناك من تناول إدارة المعرفة من زاوية المنظمات و المجتمعات و القطاعات، و أشار

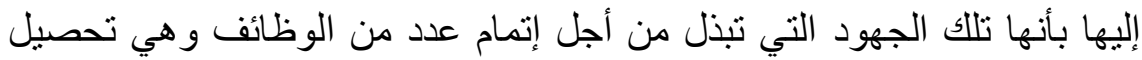

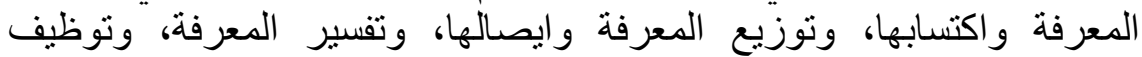
و واستثمار المعرفة، حيث باتت إدارة المعرفة من التوجهات التي يهتم بها علم الإدارة 


\section{المؤتقر العلمي اللدولي السادس والعشرين \\ (الإعلام الرقمى والإعلام التقليدى : مسارات للتكامل والمتافسة)}

التي تز امن الاهتمام بها مع تداول مفهوم ر أس المال الفكري منذ منتصف سبعينيات

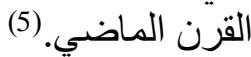
ويعرفها آخرون بأنها: "مجموعة المعارف، والمهارات المعرفية المكتسبة التي المي

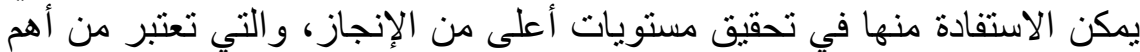

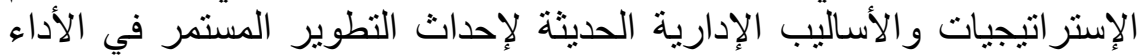

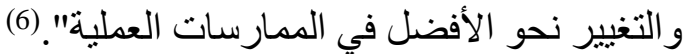
أي أنها مصطلح حديث متعدد التعريفات ومتشعب الفي المفاهيم إذ يمكن تعريفه أيضاً

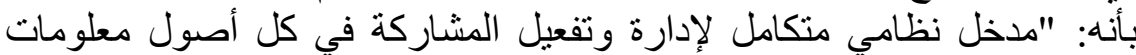

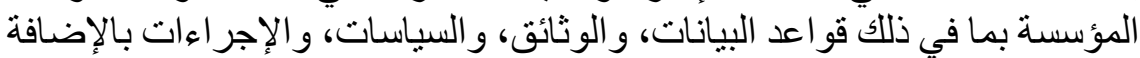

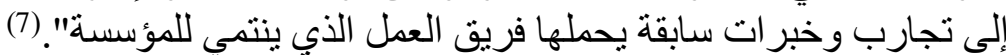
ويقصد بها الباحث إجر ائياً في هذه الدر اسة: "جميع العمليات التي تساعد مؤسسات التهات

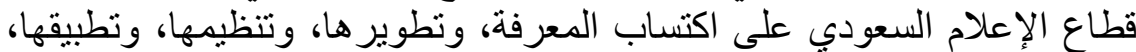

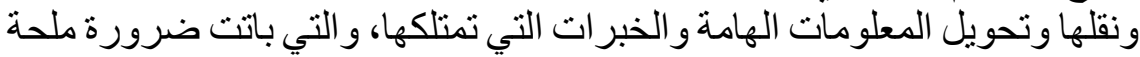
من ضروريات العمل الإعلامي في ظل التحولات التات الرقمية التي تفرضها تقنيات البيئة الإعلامية الحديثة".

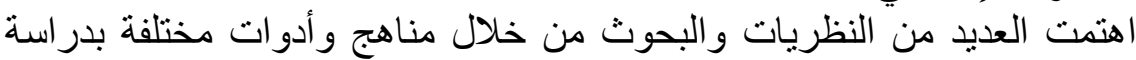

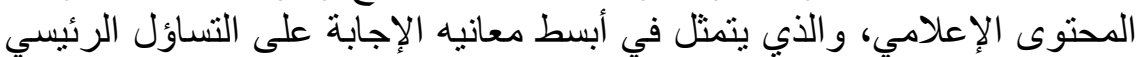

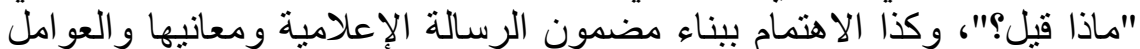

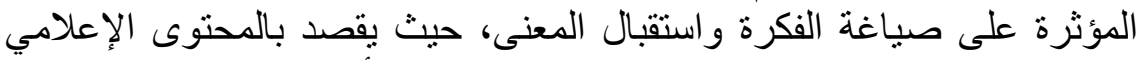

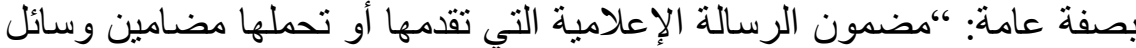

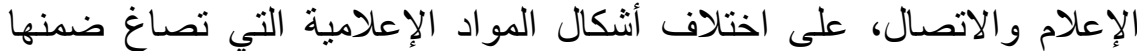

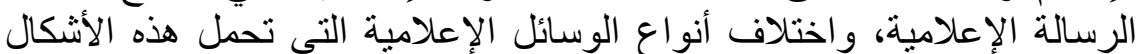

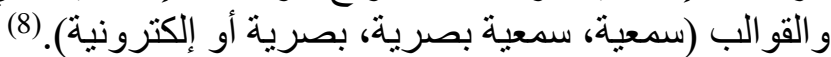
ويقصد به الباحث إجر ائياً في هذه الدر اسة: " كل ما تتضمنه الرسالة الإعلامية التي التي التئي تقدمها أو تنتجها أو تبنها كافة مؤسسات قطاع الإعلام السعودي المقاعة المقروءة

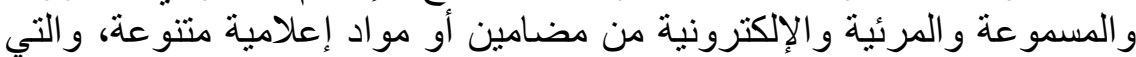

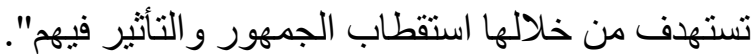

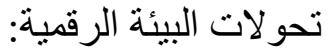

تعرف البيئة الرقية بأنها :"البيئة التي تعتمد بشكل كبير على التكنولوجيا الرقمية

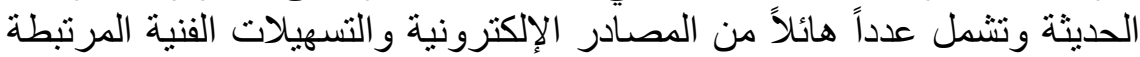

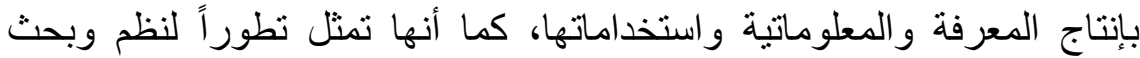

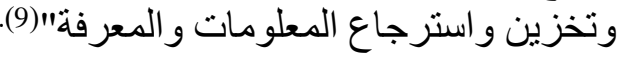




\section{المؤتقر العلمي الدولي السادس والعشريز \\ (الإعلام الرقمى والإعلام التقليدى : مسارات للتكامل والمذافسة)}

كما ينظر لتحو لات البيئة الرقمية على أنها: "مجموعة التغير ات التكنولوجية و التقنية

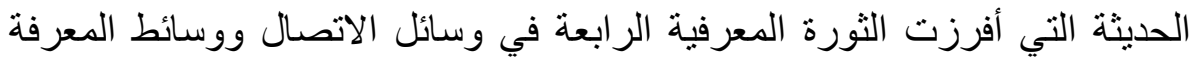

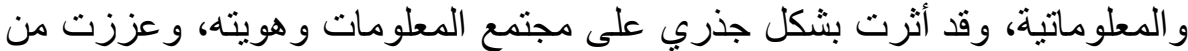
قيمة المعرفة واختراق الأنساق المعلوماتية المختلفة لمختلف القطات القطاعات و المؤسسات" (10) ويقصد بها الباحث إجر ائياً: "التحول الرقمي و التكنولوجي الذي يعتمد بصورة أساسية

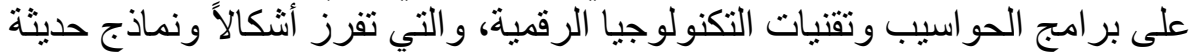

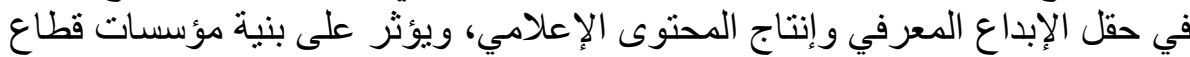

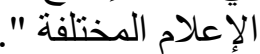

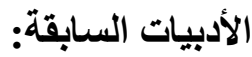

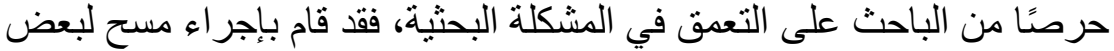

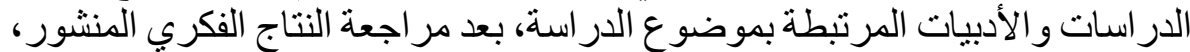

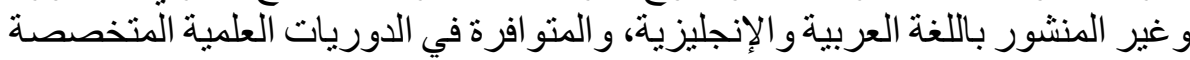

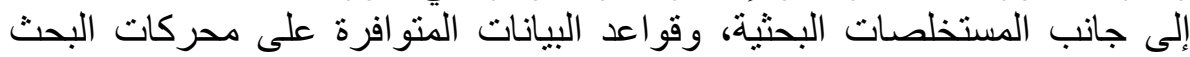

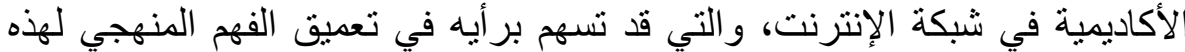

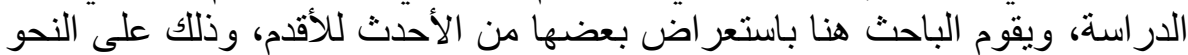

• دراسة عمرو محمد محمود عبدالحميد (2020):(11) والتي استهدفت رصد توظيف تطبيقات الذكاء الاصطناعي في إنتاج المحتوى الإعلامي، وإدي إدر الك عينة

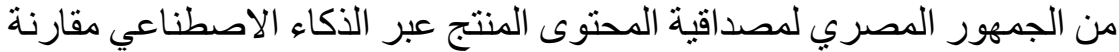

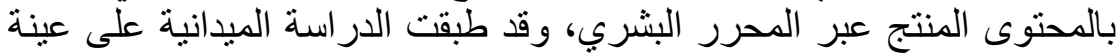

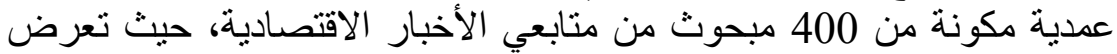

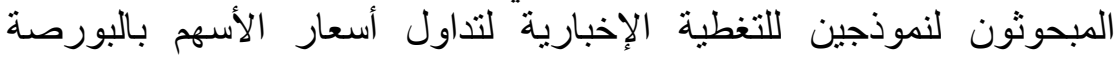

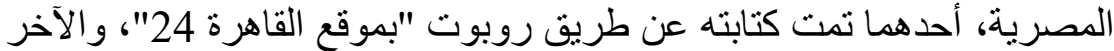

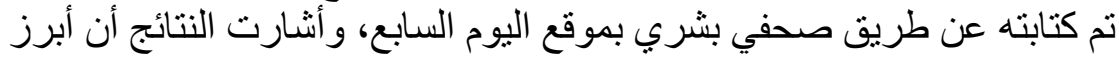

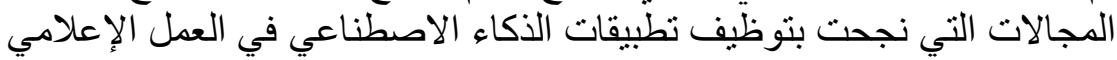
هي الدردشة الآلية عبر المواقع الإلكترونية وشبكات التواصل اصل الاجتماعي، يليه

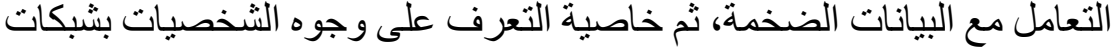
التواصل الاجتماعي، وجاءت في الترتيب الرابع التراتئ الترجمة الآلية.

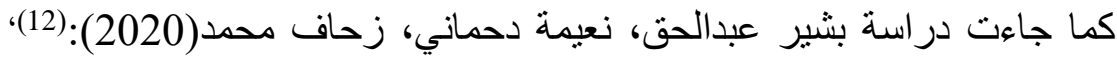

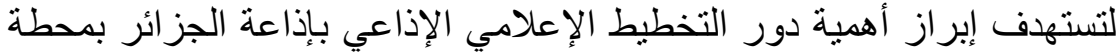

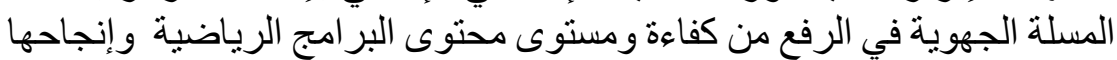
من خلال الثبكة البر امجية المعتمدة والأساليب المنتهجة، ولتحقيق التحة ذلك استخدم 


\section{المؤتقر العلمي اللدولي السادس والعشرين}

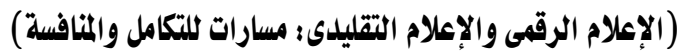

الباحث المنهج الوصفي لملائمته لهذه الدراسة، والتي طبقها الباحثون على عينة

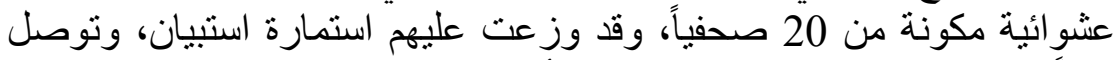
بناءاً على آراء الصحفيين بالإذاعة إلى أن التخطيط الإعلامي الإذاعي له دور

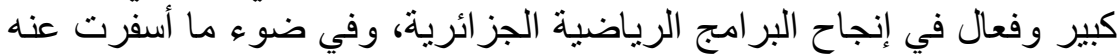

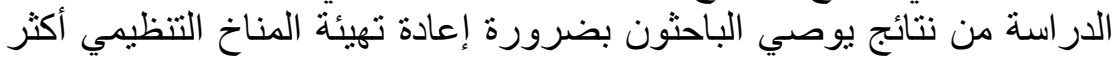
داخل الإذاعة المحلية لضمان تخطيط ناجح يتماثى ويرتبط باحتياجيات الجمهور

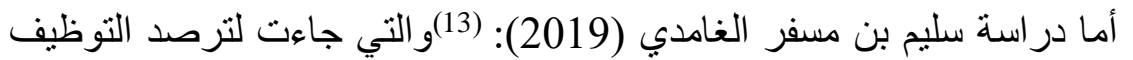

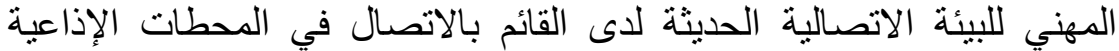

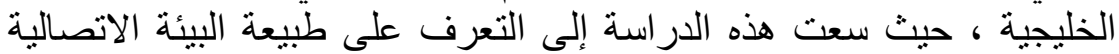

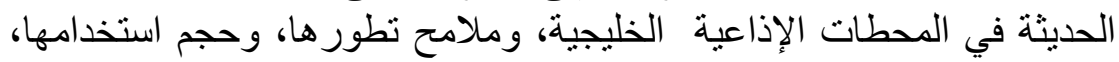
ومعرفة مدى توظيف القائم بالاتصال في المحطات الإذاعية الخليجية لهذه البيئة الئة

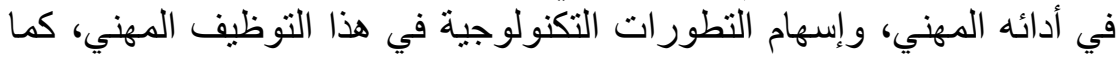

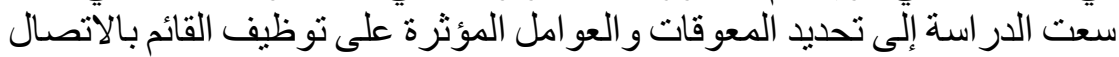
للتطورات التكنولوجية في بيئة الاتصال داخل المونيد المحطات الإذاعية الخليجية،

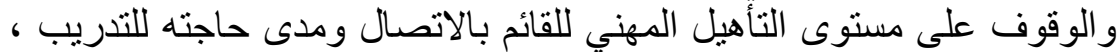

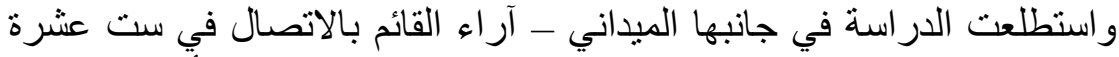

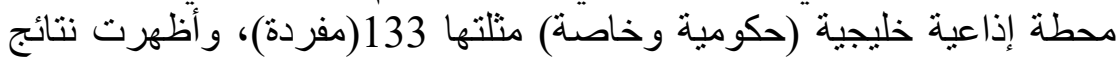

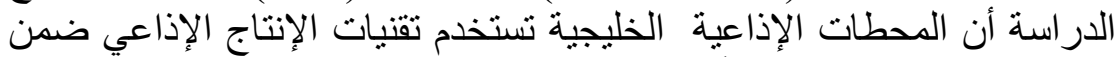

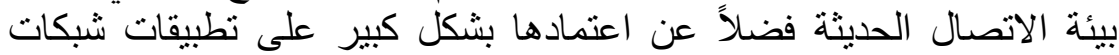

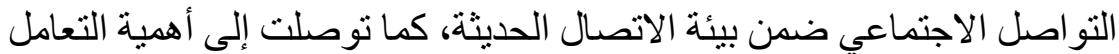

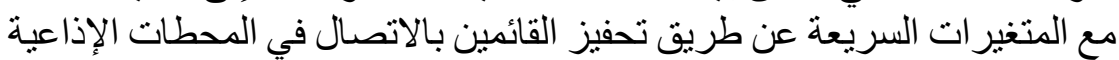

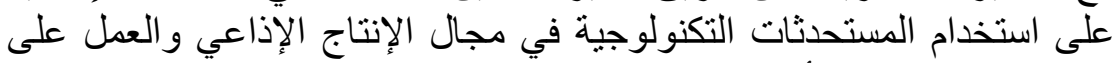
تدريبهم لرفع مستوى أدائهم.

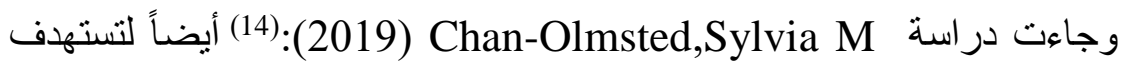
قياس درجة اعتماد الثركات العاملة في قطاع الإعلام الياباني على أدوات الات الذكاء

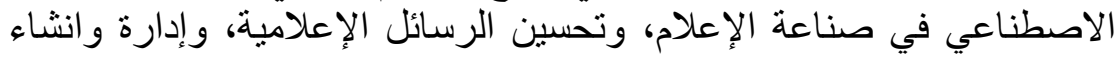

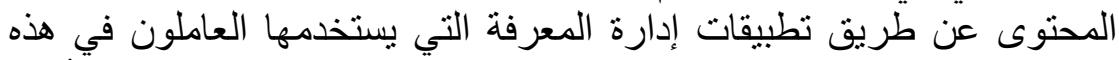

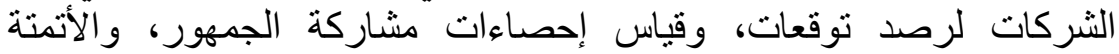

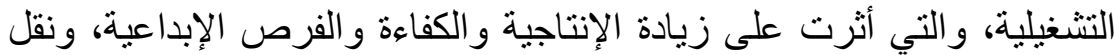

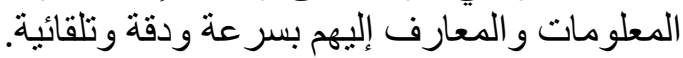

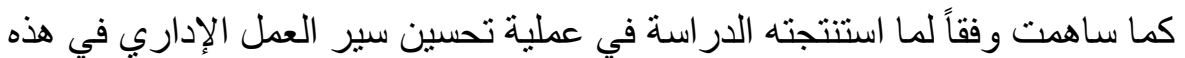

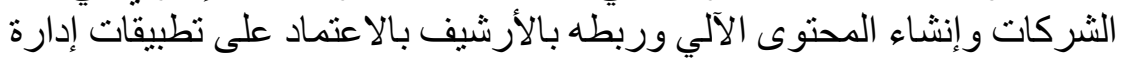




\section{المؤتقر العلمي اللدولي السادس والعشرين}

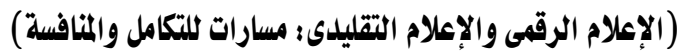

المعرفة وتقنيات الذكاء الاصطناعي الحديثة في عمليات إنتاج الفيديوهات

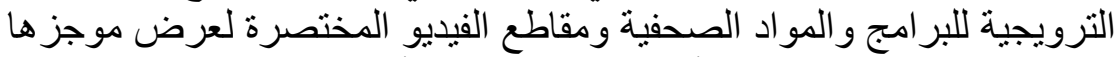

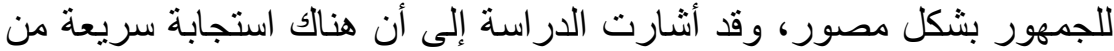
إدارات الثركات اليابانية العاملة في قطاع الإعلام لتطبيق هذه التألت التقنيات

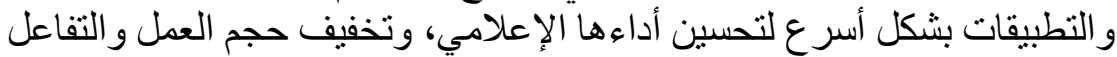

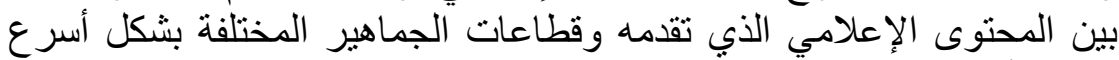

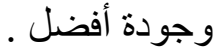

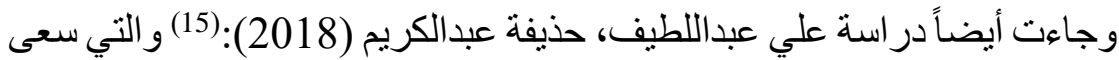

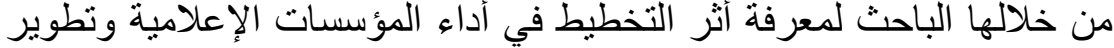

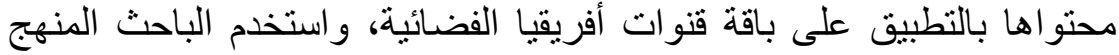
الوصفي التحليلي، واستفاد الباحث كذلك من المنهج التاريخي في استعر اض اضن تطور

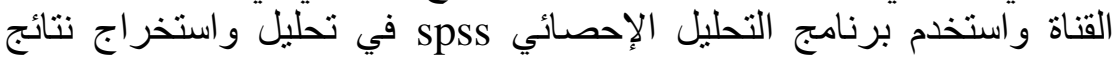
الدر اسة الميدانية واختبار فرضيات البحث.

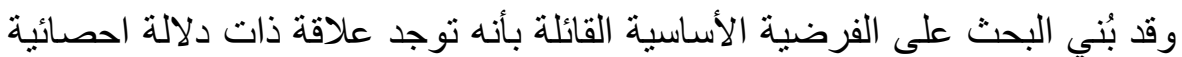

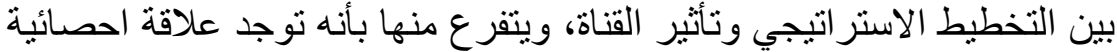

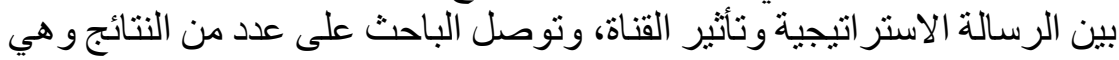

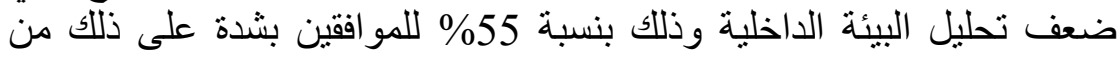
المبحوثين، وضعف تحليل البيئة الخارجية، و عدم وجود تحليل دائم للمتغير التئ لات

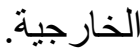

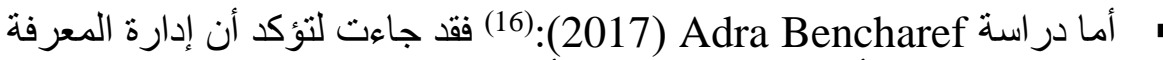

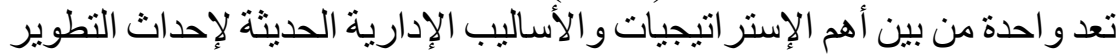

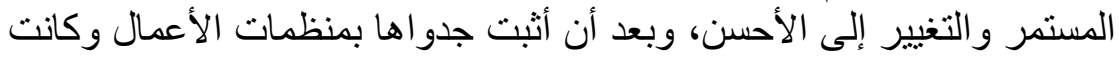

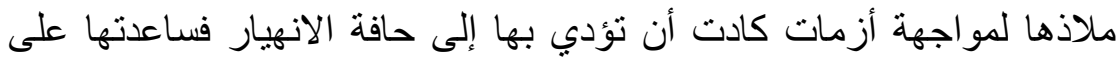

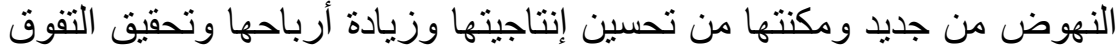
و التميز على مثنيلاتها بوقت فيد قياسي. ولهذا جاءت هذه الدراسة للوقوف على الفوائد التي ستحققها أقسام علم المكتبات

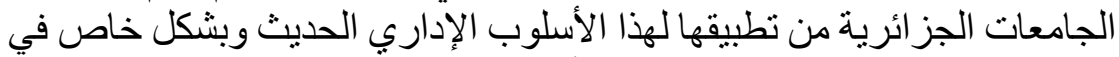

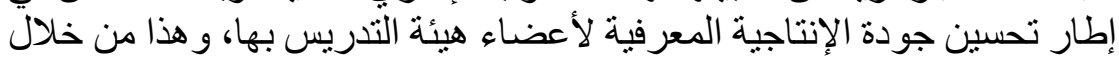

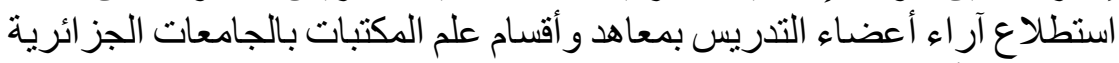

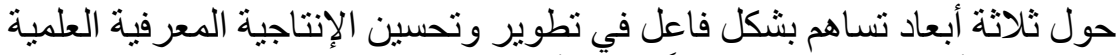

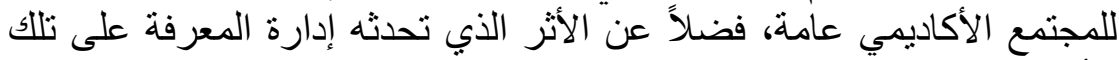

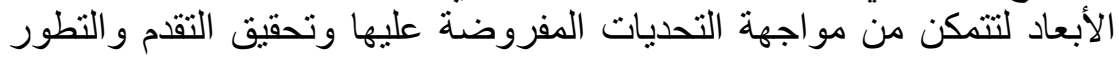
و التميز في جميع مهامها وبشكل خاص وظيفة التيفة إنتاجها للمعرفة. 


\section{المؤتقر العلمي اللدولي السادس والعشرين}

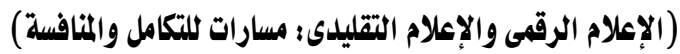

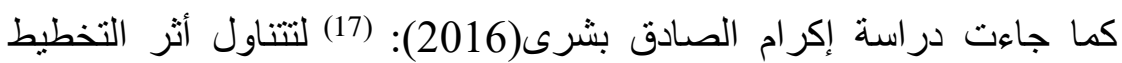

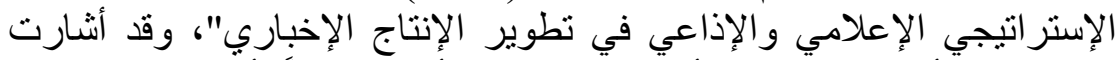

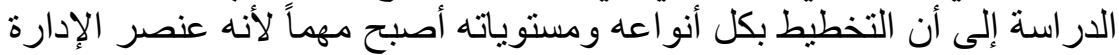

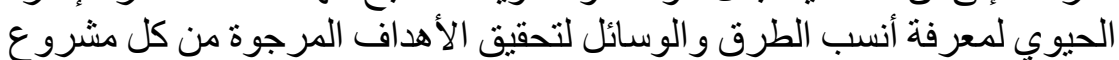

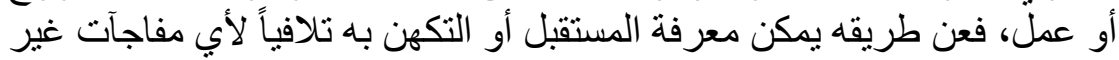

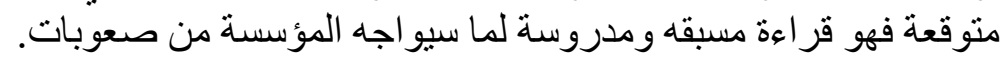

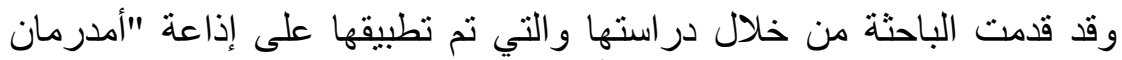

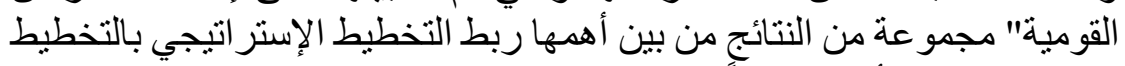

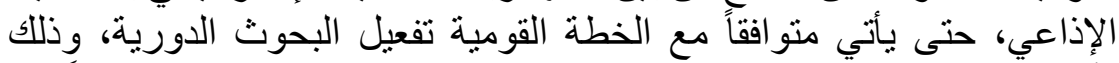

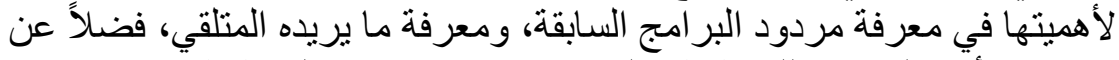

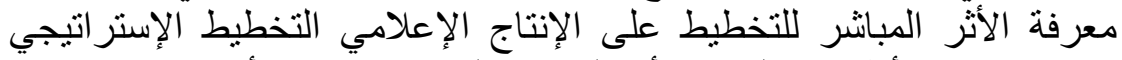

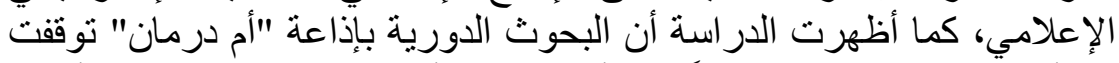

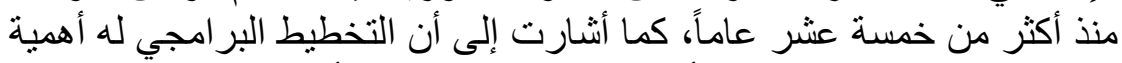

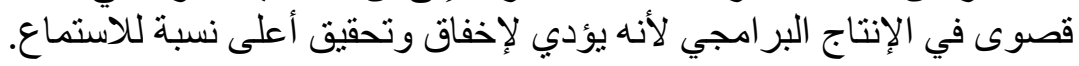

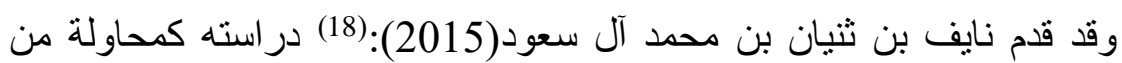

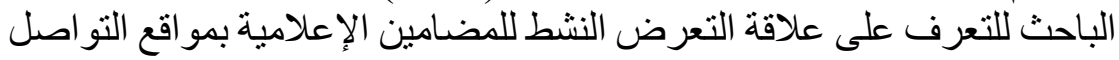

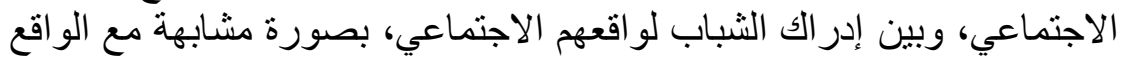

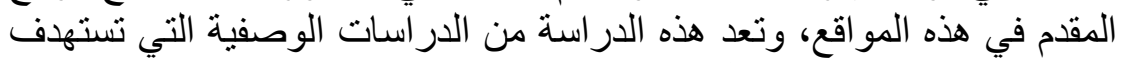

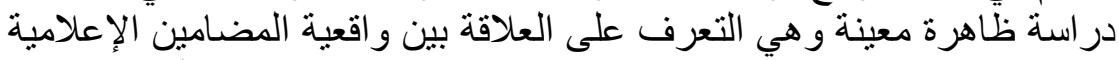

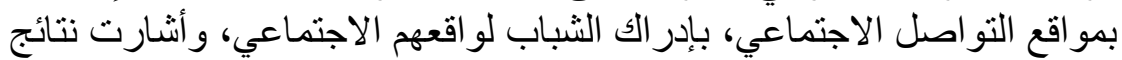

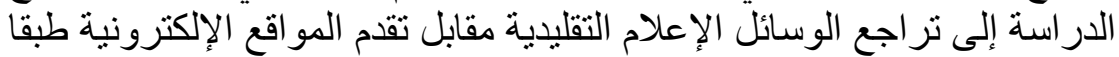

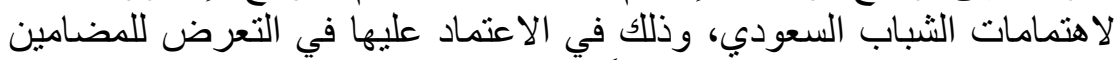

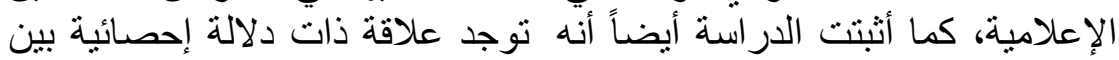

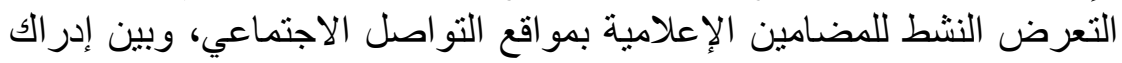

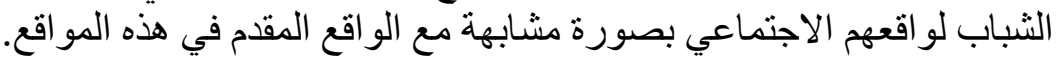

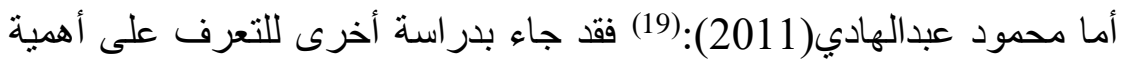

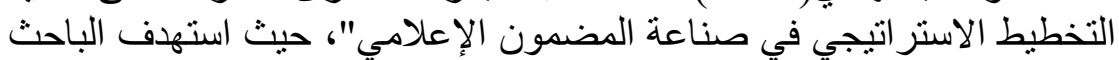

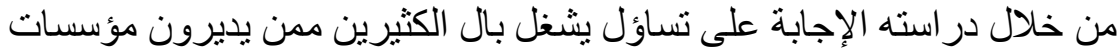

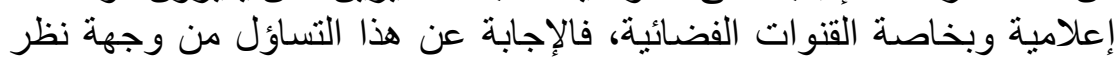

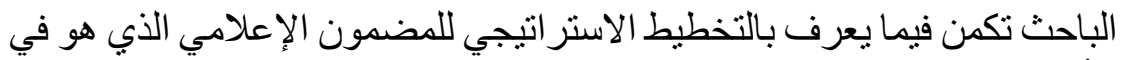

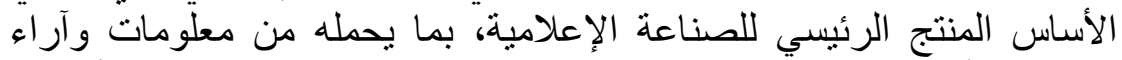
و ومواقف وأفكار وقيم وسلوكيات، وهو الذي يترجم رسالة القناة ورؤيتها و أهدافها 
المؤتقر العلمي اللدولي السادس والعشريز

(الإعلام الرقمى والإعلام التقليدى : مسارات للتكامل والمنافسة)

الاستر اتيجية لجميع الكوادر المسئولة عن التخطيط للمضمون و إدارته و إنتاجه

وتنويقه.

كما أثشار الباحث أن تحقيق هذا الطموح ليس بالمهمة السهلة، ولكنه في نفس الوقت

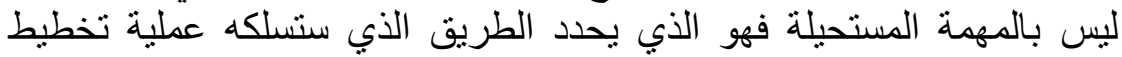

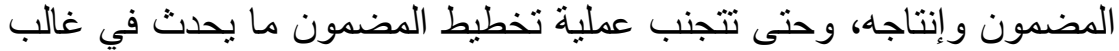
الأحيان من ارتجال أو ضبابية، أوصت الدر اسة بضرورة تورة وضع الأسس المعيارية

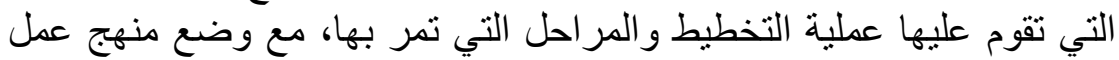

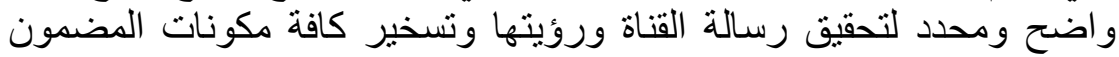
لصالحها.

وجاءت در اسة Aidemark, J (2010): (20) أيضاً لتستهدف التعرف على الطئ الفجوة بين النظرية والتطبيق في إدارة المعرفة، وصياغة إطار متكامل لحل المشاكل

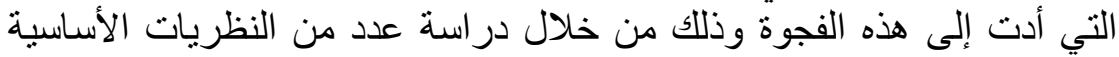

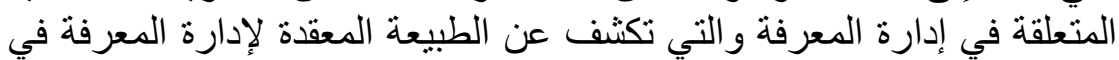
المنظمات.

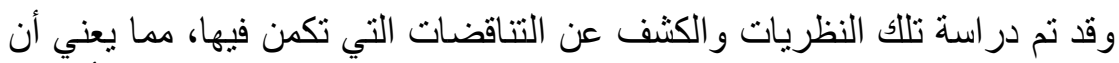

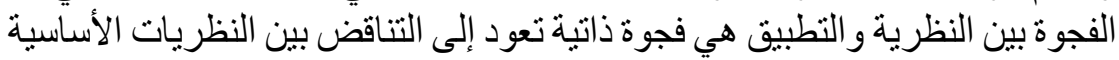

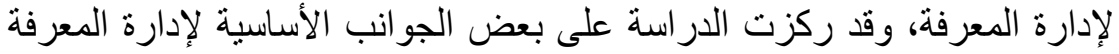

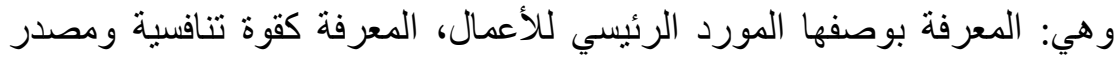

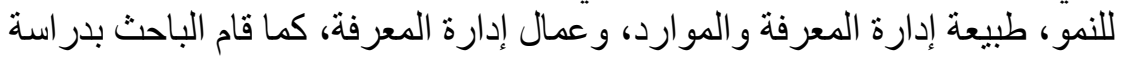

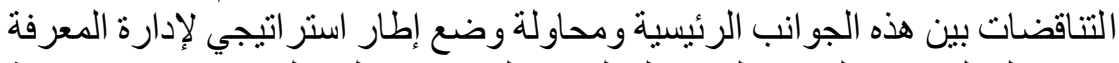

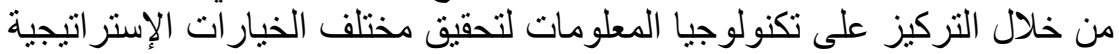

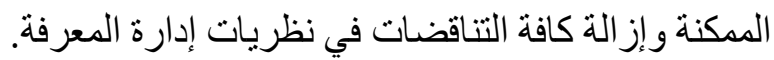

وجاءت دراسة Khandekar \& Sharma (2009):(21) بهدف التعرف على التى

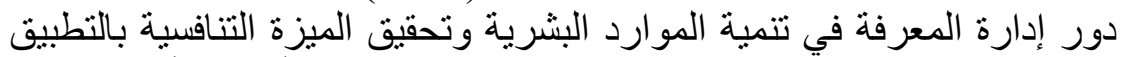

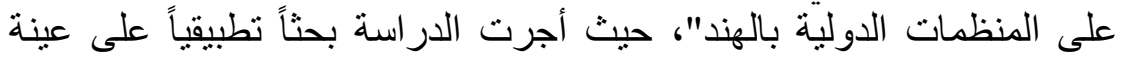

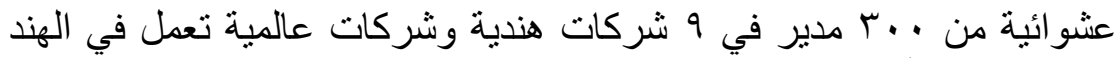

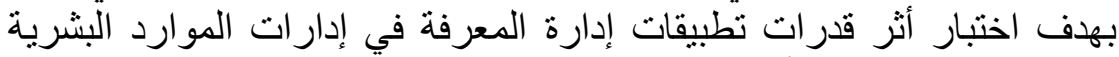

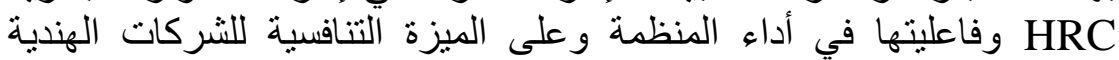

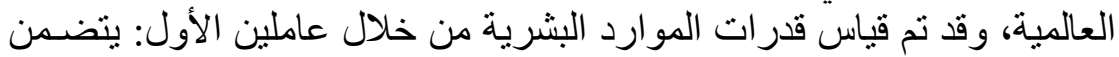

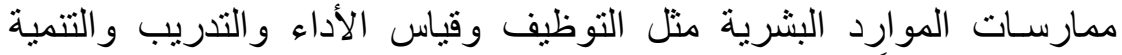

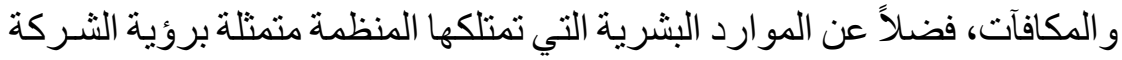

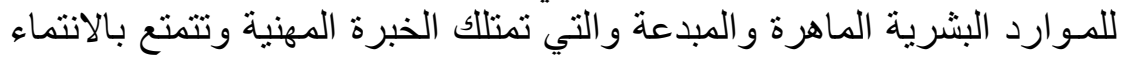

على أنها مصادر للميزة التنافسية. 


\section{المؤتقر العلمي اللدولي السادس والعشرين}

(الإعلام الرقىى والإعلام التقليدى : مسارات للتكامل والمنافسة)

وقد أكدت الدر اسة من خلال الدليل الإحصائي أن الاستثمار في قدرات الموارد

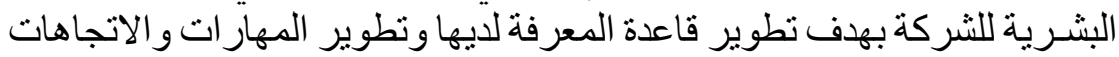

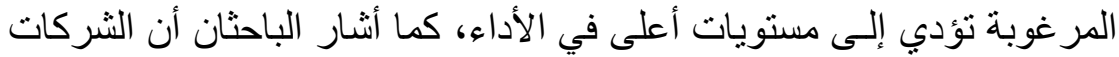

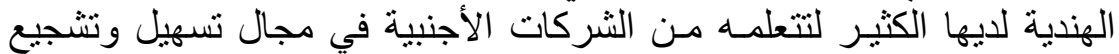

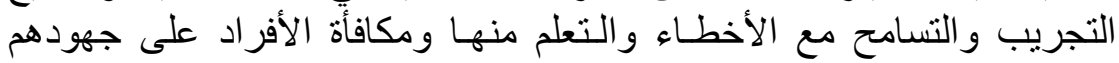
بالشكل الملائم.

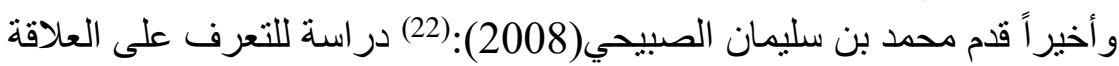

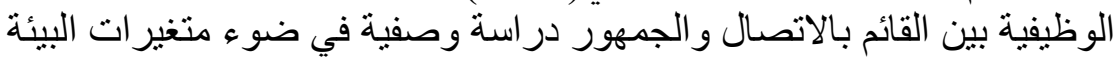

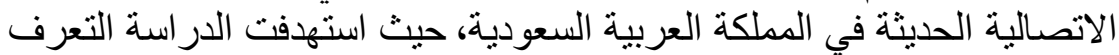
على طبيعة العلاقة الوظيفيَّة بين القائم بالاتصال والجية الجمهور في وسائل الإعلام

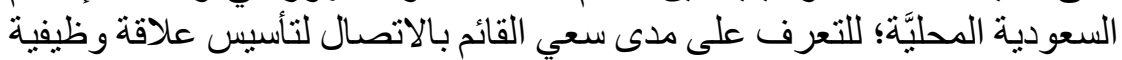

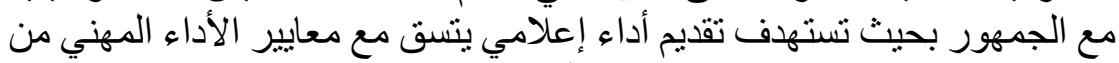

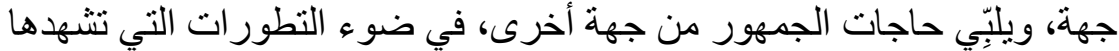

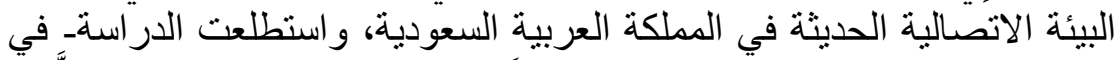

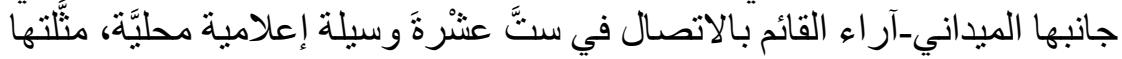

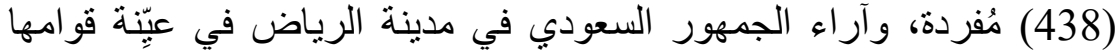

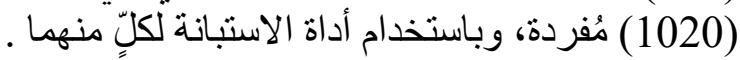

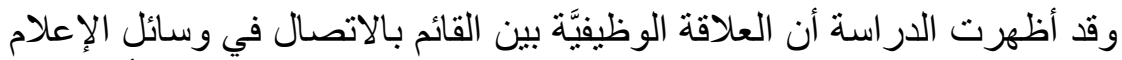

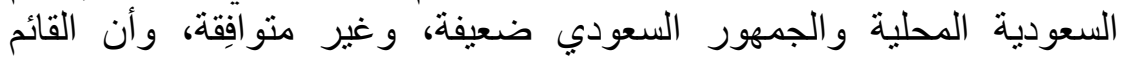

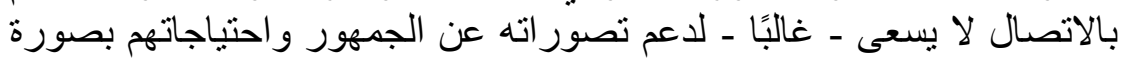

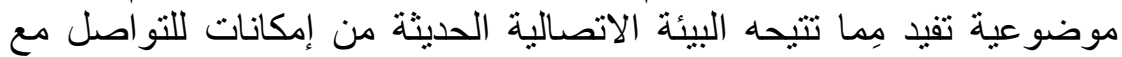

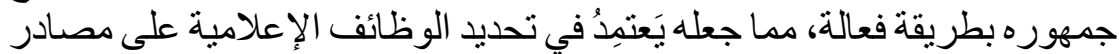

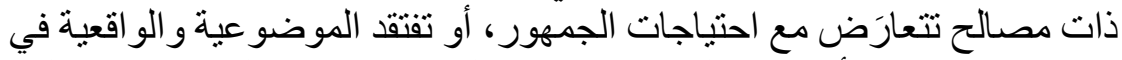

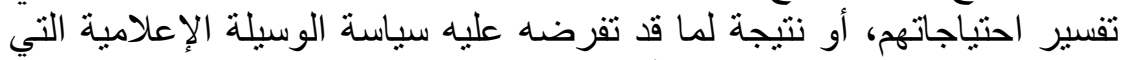

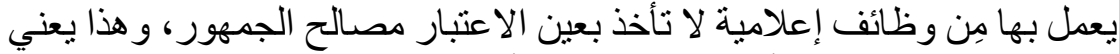
وجود خلل وظيفي في الأداء الإعلامي بين أهم عنصرين الاعتئ في في العملية الاتصالية.

تعقيب الباحث على الدراسات السابقة، وأوجه الاستفادة منها:

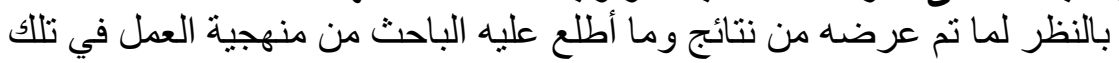

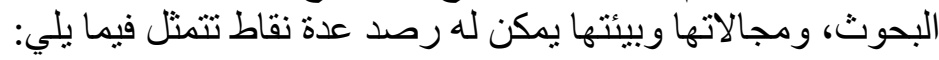

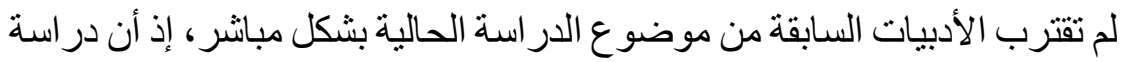

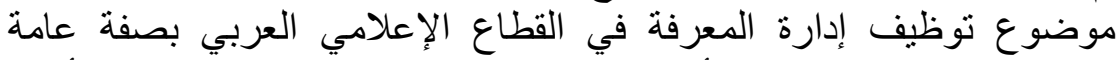

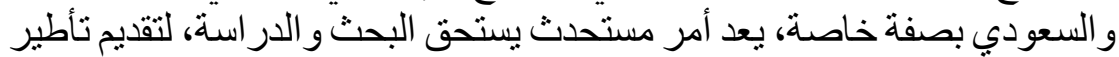

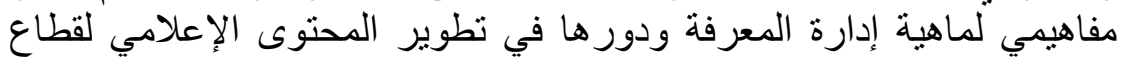




\section{المؤتقر العلمي اللدولي السادس والعشرين}

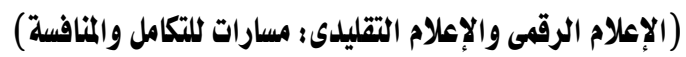

الإعلام بالمملكة، في ظل المتغير ات الرقمية المتلاحقة في بيئة سوق العمل

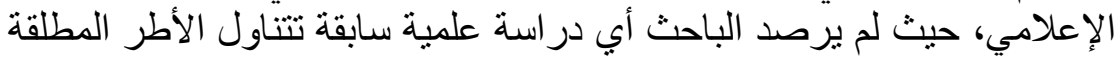
لهذا الموضوع.

يتضح من خلال العرض السابق للار اسات المتعلقة بموضو ع الأل الدار اسة مدى اتفاقها

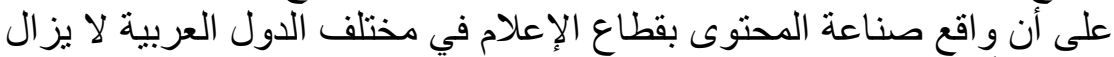

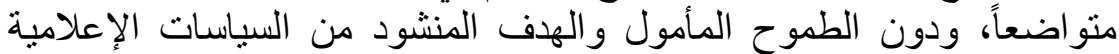

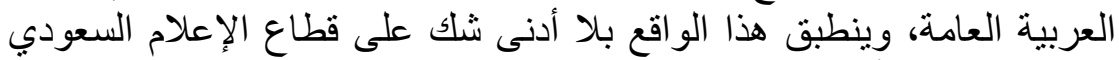

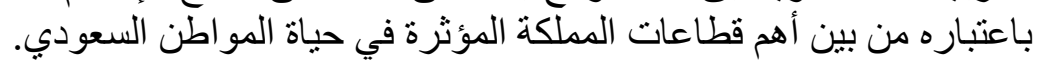

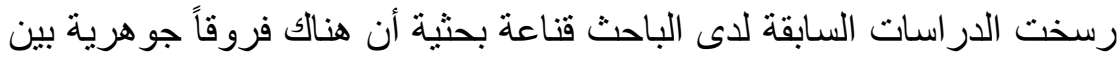

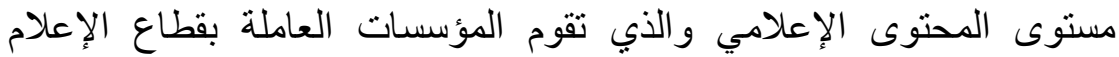

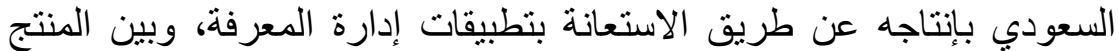

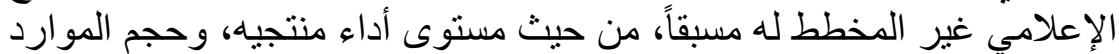

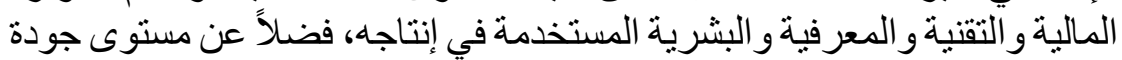

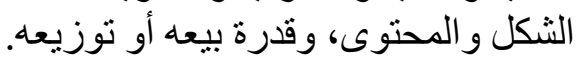

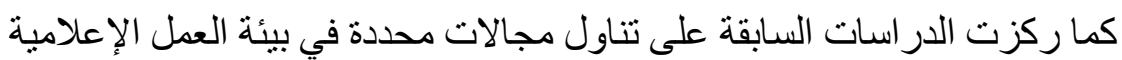

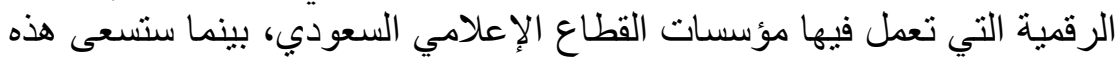

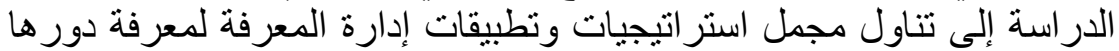

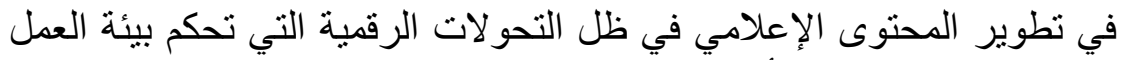
الإِعلامي في السنوات الأخيرة.

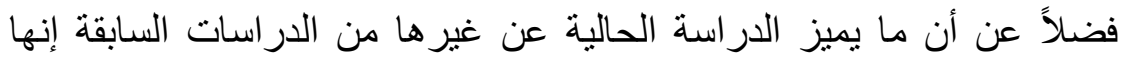

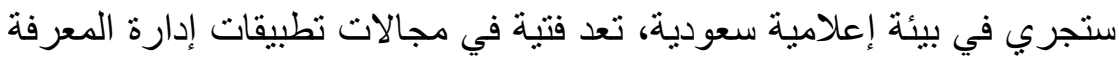

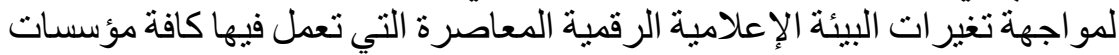
القطاع الإعلامي السعودي، مقارنة بما توصلت إليه مثيلاتها في دول التهات العالم التهات

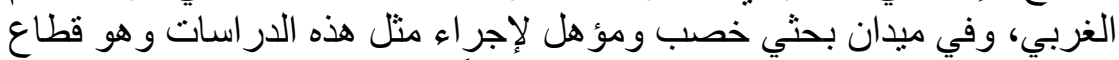

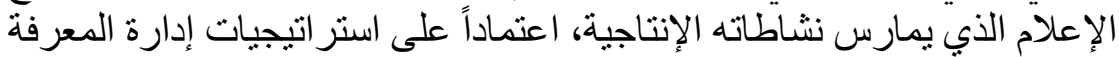

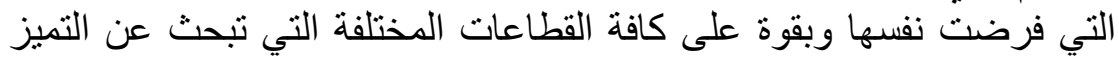

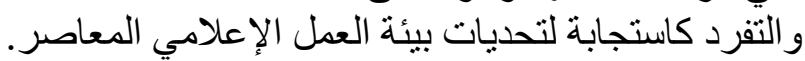

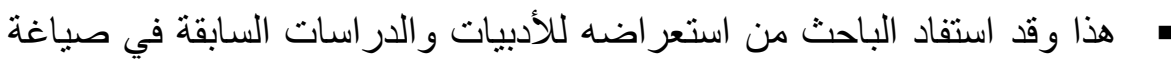

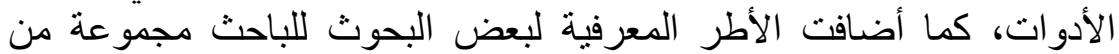

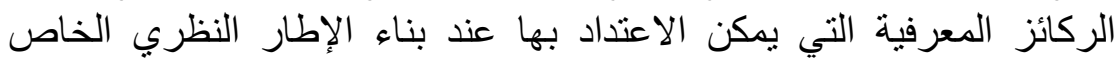

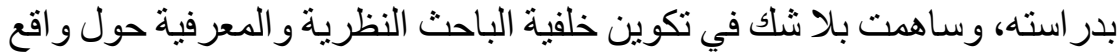
استخدامات تطبيقات إدارة المعرفة في نطوير المحتوى الإعلامي لقطاع الإعلام 


\section{المؤتقر العلمي اللدولي السادس والعشرين}

(الإعلام الرقمى والإعلام التقليدى : مسارات للتكامل والمتافسة)

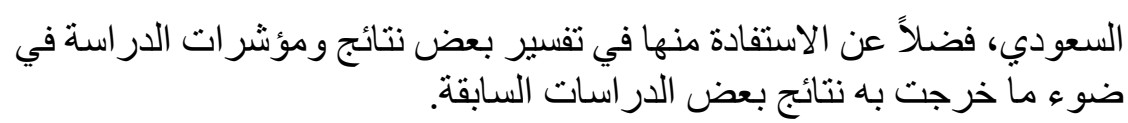

المنطلق النظري للاراسة:

بما أن الدر اسة الر اهنة تعمل على توصيف الدور الذي يمكن أن تقوم به تطبيقات

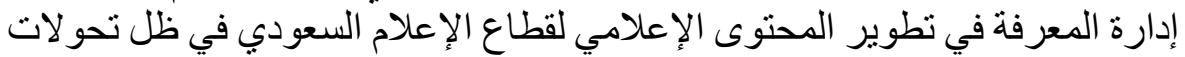

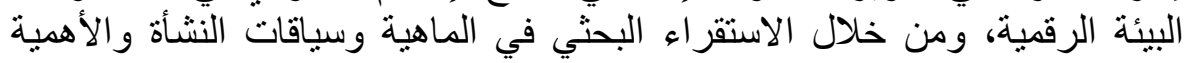

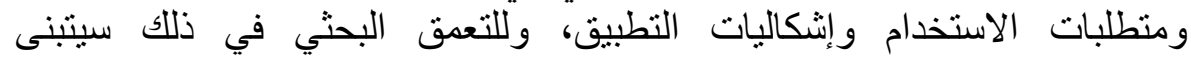

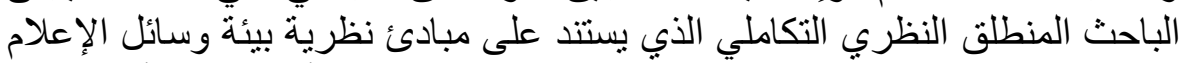

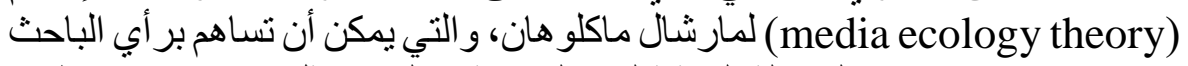

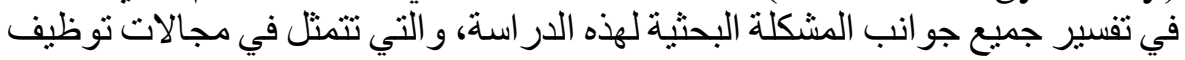
إدارة المعرفة في تطوير المحتوى الإعلامي بقطاع الإعلام السعودي.

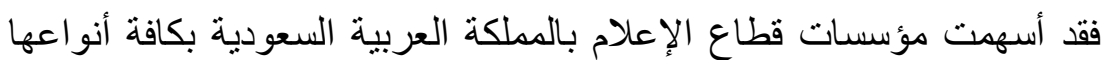

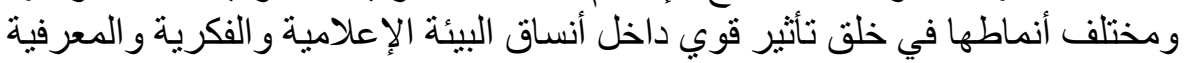

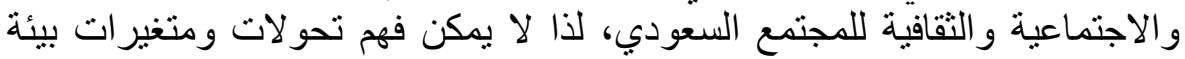

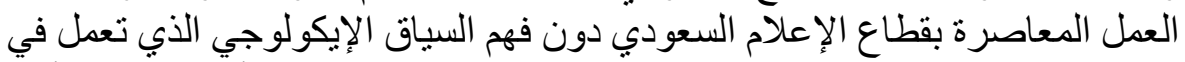

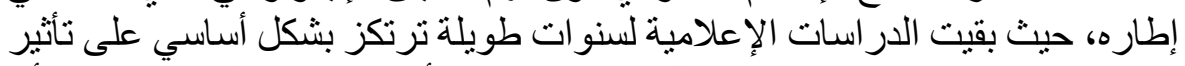

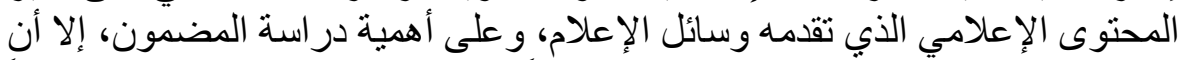

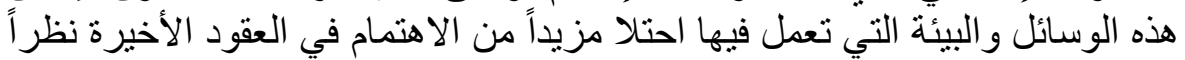

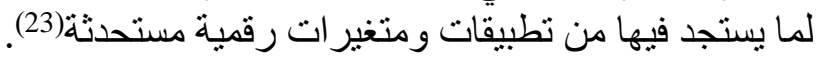

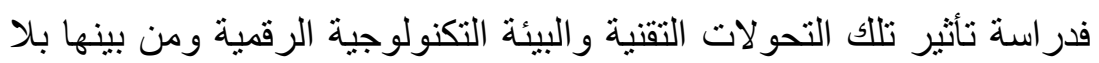

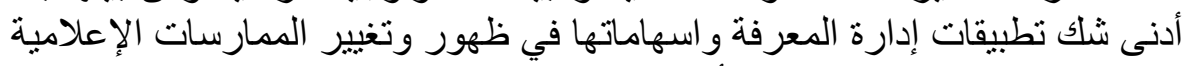

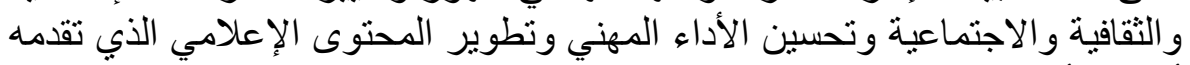

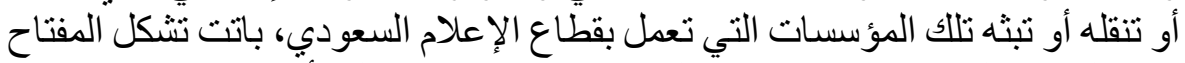

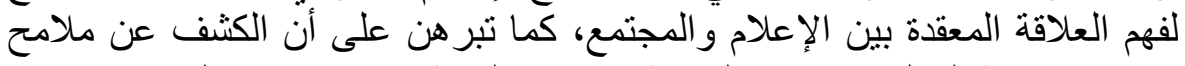

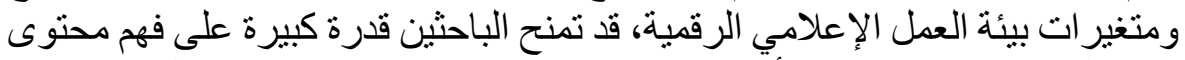

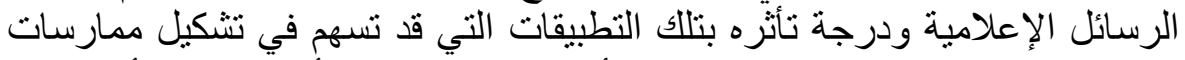

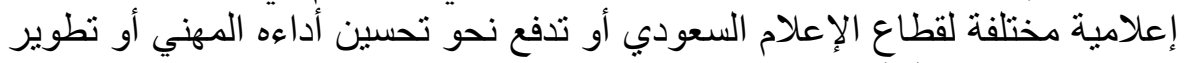

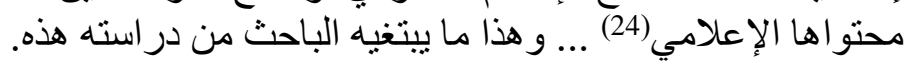

وتذهب النظرية التاريخية للوسائط (The Medium Theory)، أو نظرية

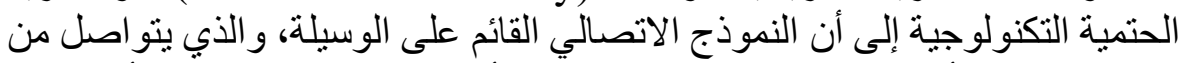

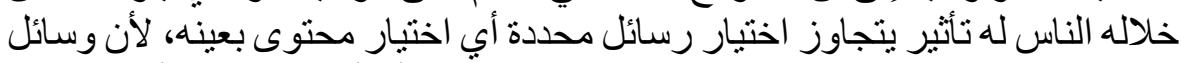

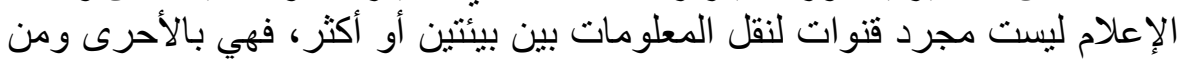




\section{المؤتتر العلمي الدولي السادس والعشرين

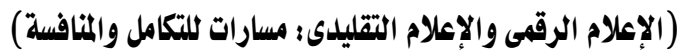

وجهة نظر الباحث بيئات ينمو فيها المحتوى ويتشكل ويتطور وتتحدد خصائصه

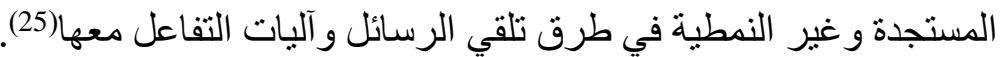

و هذا ما فسره "مارشال ماكلو هان Marshall McLuhan عام 1964 في 196 في

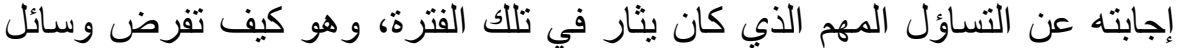

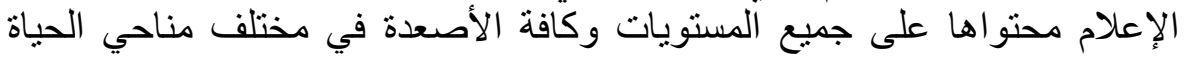

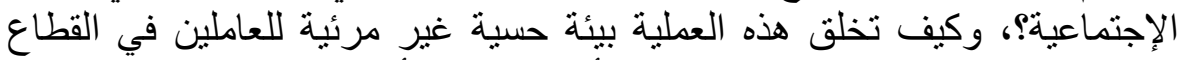

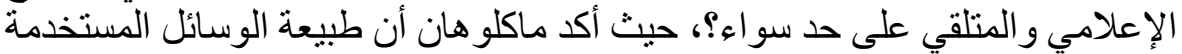

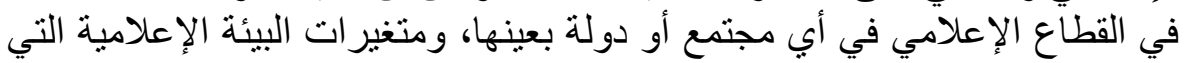

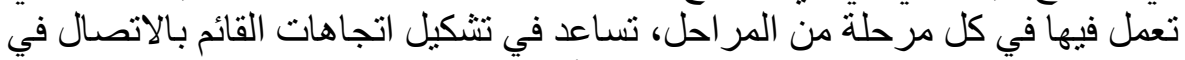

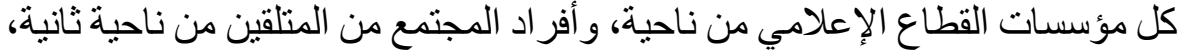

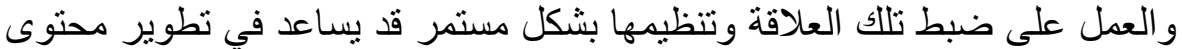

تلأك الوسائل(26).

\section{المنطلق الفكري للاراسة:}

ينطلق الباحث فكرياً في دراسته هذه عبر عدة محاور رئيسية تأتي على النحو التالي: المحور الأول: إدارة المعرفة...ماهيتها وأهميتها:

تعد إدارة المعرفة وكما أشثار الباحث في مقدمه هذه الدراسة من أحدث المفاهيم

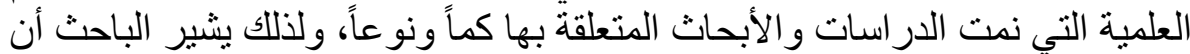

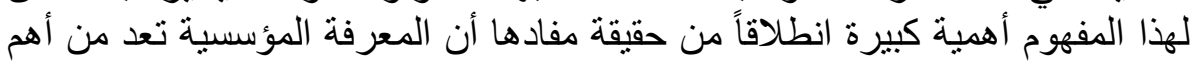

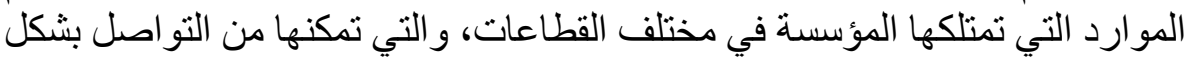
فعال مع محيطها.

وقد جذبت إدارة المعرفة اهتمامات العديد من المختصين في مجالات متعددة،

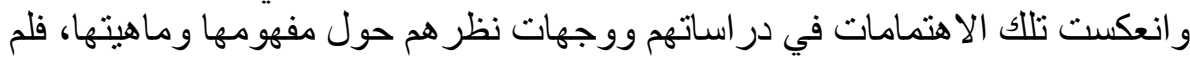

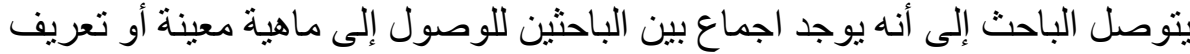

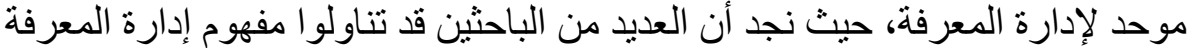

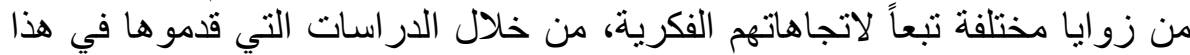

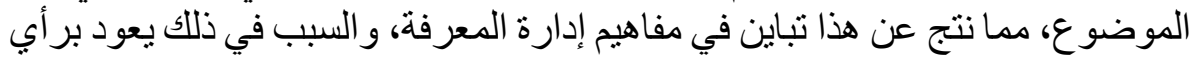

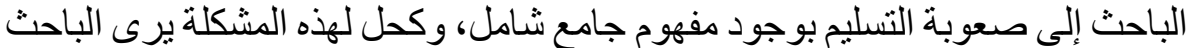

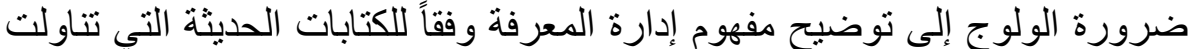

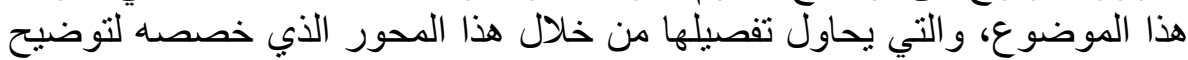
ماهية وأهمية إدارة المعرفة بالنسبة للمؤسسات العاملة في القطاع الإعلامي السعودي بكافة أنشطتها وتنوع أهمية محتو اهـا الإعلامي(27). 


\section{المؤتقر العلمي اللدولي السادس والعشرين}

(الإعلام الرقمى والإعلام التقليدى : مسارات للتكامل والمتافسة)

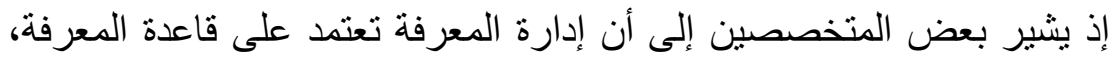

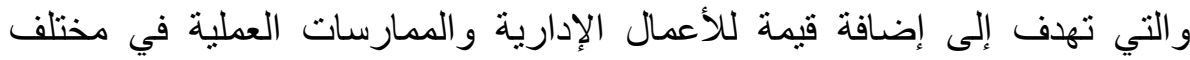
المؤسسات، و لا سيما تلك التي تعتمد على البيانات و المعلومات كات كالمؤسسات الإل الإعلامية،

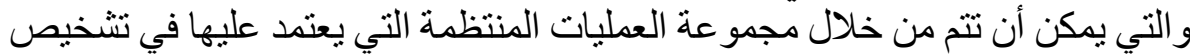

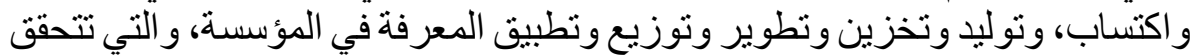

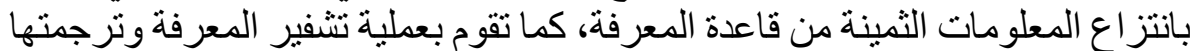

قاعدة بيانات (28)

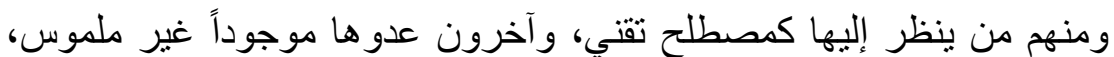

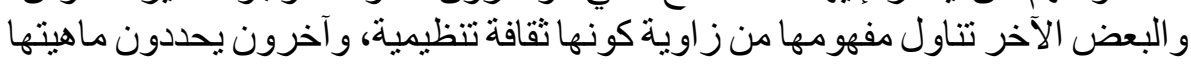

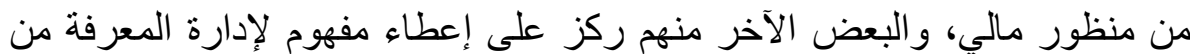

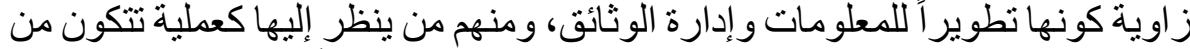

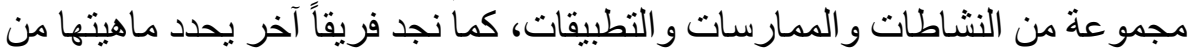

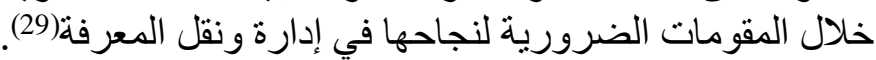

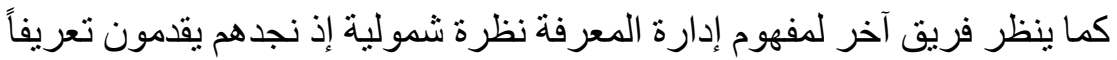

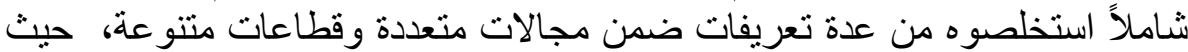

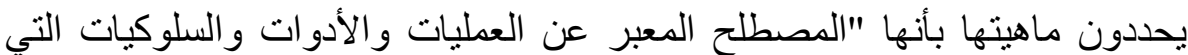

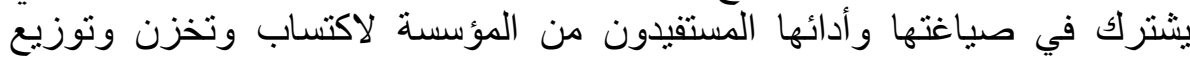
المعرفة، لتتعكس على عمليات الأعمال، بهدف الوصول الكول إلى أفضل التطبيقات لتحقيق المنافسة طو يلة الأمد" (30).

ويعرفها آخرون بأنها: "مجمو عة عمليات منظمة من خلالها يتم ايجاد القيمة التي

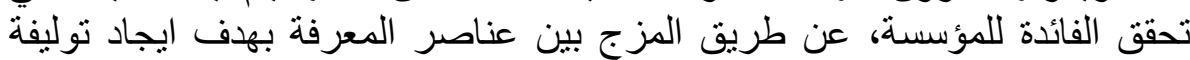
معرفية تحسن أداء المؤسسة بشكل أفضل، وتطور من من عملية تقديم منتجاتها وخدماتها

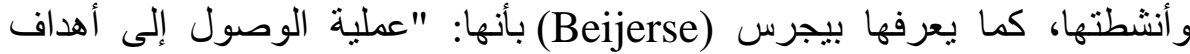

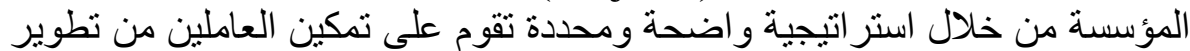

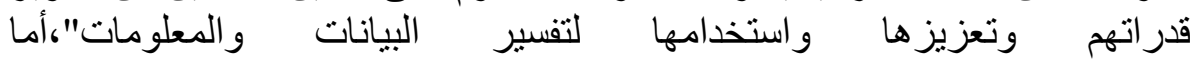

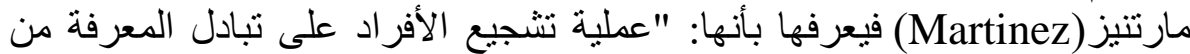

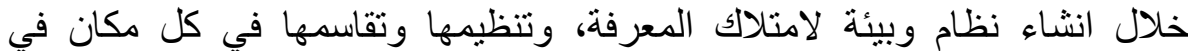

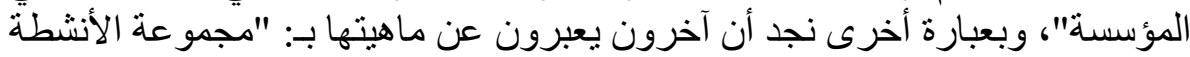

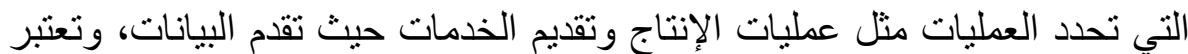

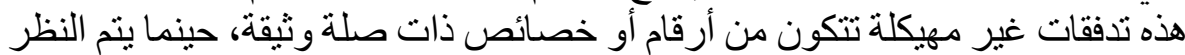

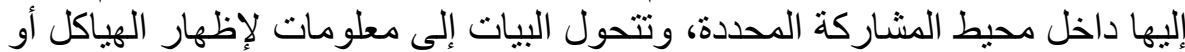

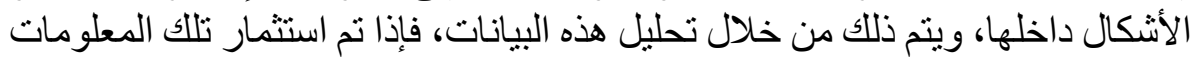

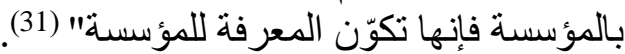




\section{المؤتقر العلهي الدولي السادس والعشريز \\ (الإعلام الرقمى والإعلام التقليدى : مسارات للتكامل والمتافسة)}

كما يعرفها تايلور (Taylor) بأنها: "عملية التأكد من تلبية الاحتياجات المعرفية

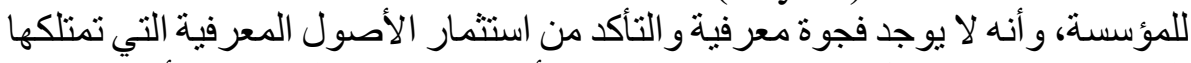

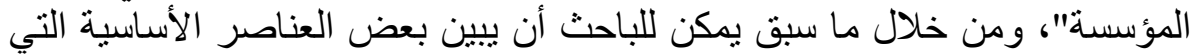

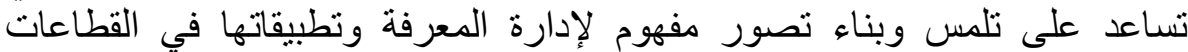
الإعلامية المختلفة وهي(32):

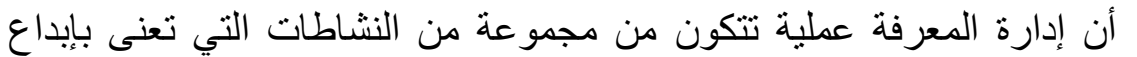

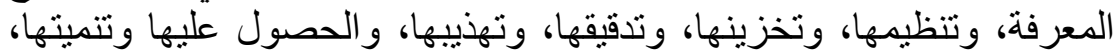
ونشر ها، وتطبيقها.

أن هنالك مجموعة من المقومات والضروية الضرورية لتنفيذ نشاطات إدارة المعرفة في

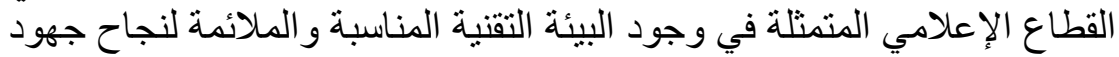
إدارة المعرفة في تطوير المحتوى الإعنامي الإعلامي.

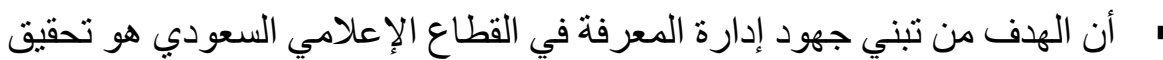

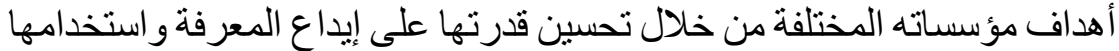

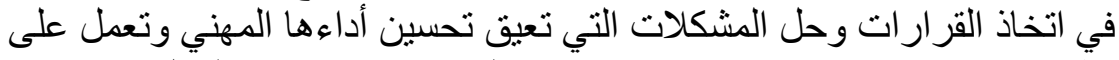

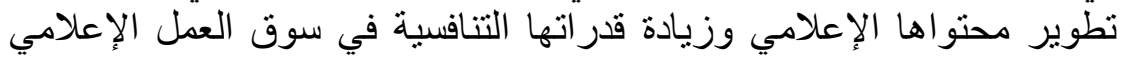

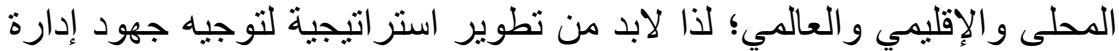
المعرفة في ذلك و هذا ما سيفرد له الباحث محور خاص في هذه الدر اسة.

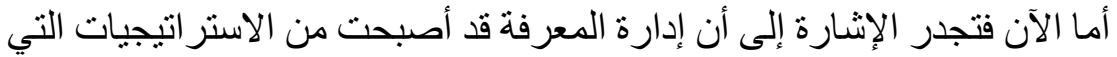

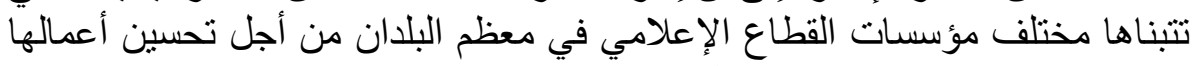

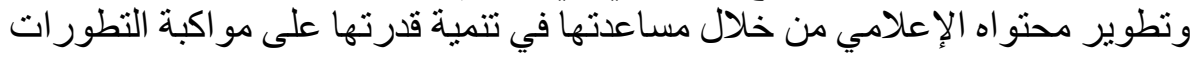

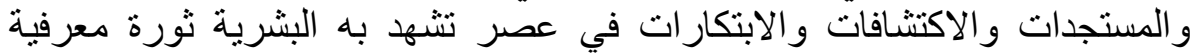

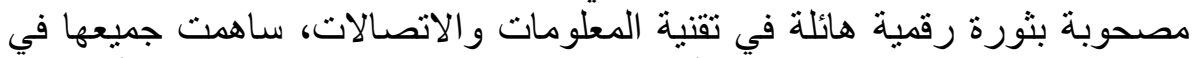

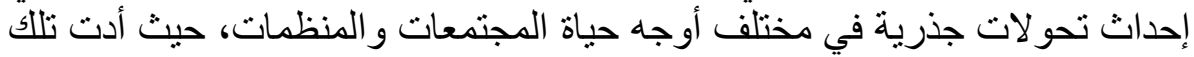

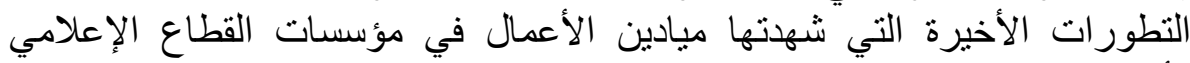

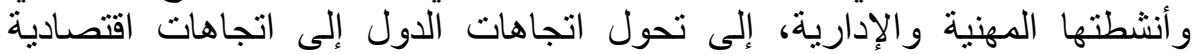
وممارسات إدارية قو امها المعرفة والية، (33).

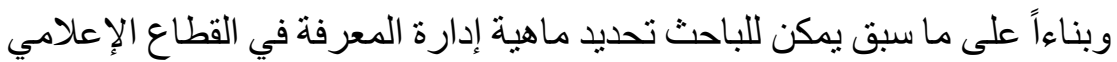

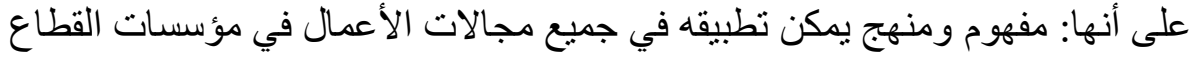

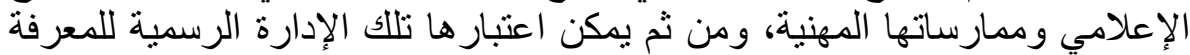

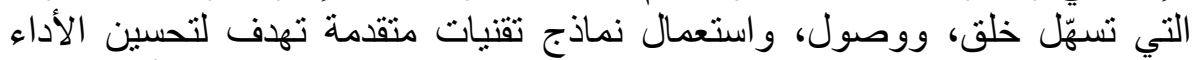

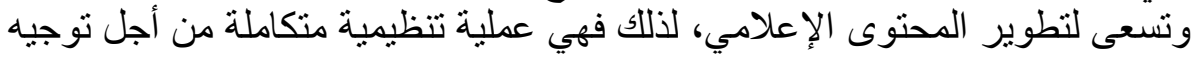

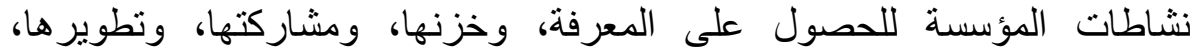




\section{المؤتقر العلمي اللدولي السادس والعشرين}

(الإعلام الرقمى والإعلام التقليدى : مسارات للتكامل والمتافسة)

و واستخدامها من قبل الأفراد و الجماعات من أجل تحقيق أهداف على كافة المستويات

ومختلف الأصعدة(34).

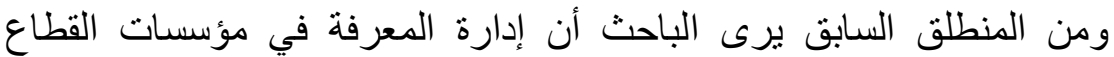

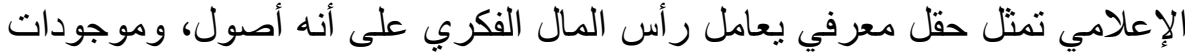

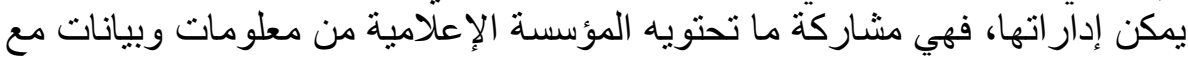

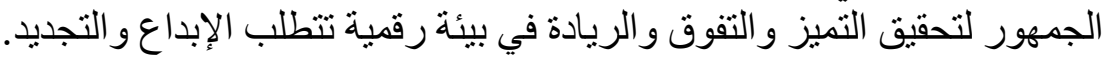

ويرى الباحث أن أهمية إدارة المعرفة في القطاع الإعلامي تتمثل في مساهمتها

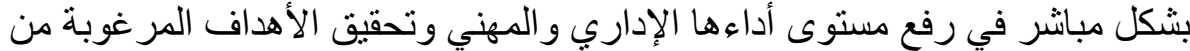

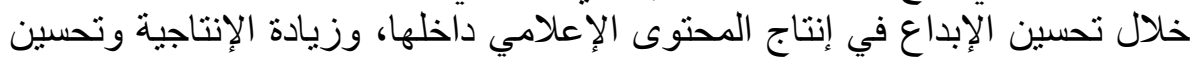

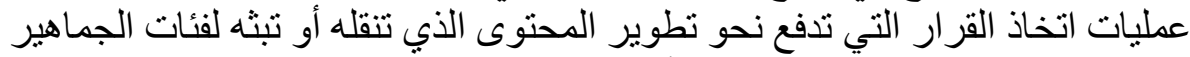

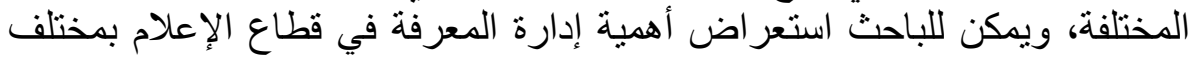

أنشطته ومؤسساته الإعلامية على النحو التالي (35):

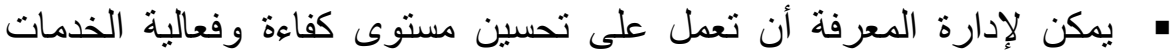

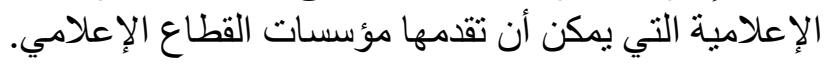

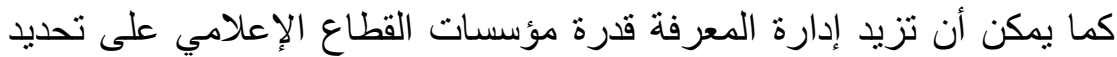

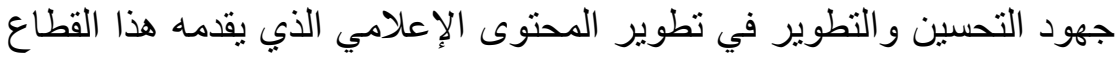

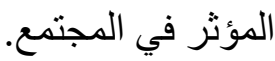

كما يمكنها أن نساهم في تحسين مستوى كفاءة وفعالية وجودة المنتجات الإعلامية

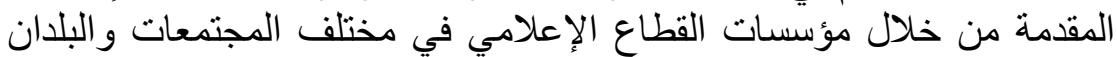

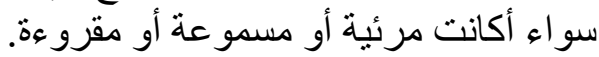

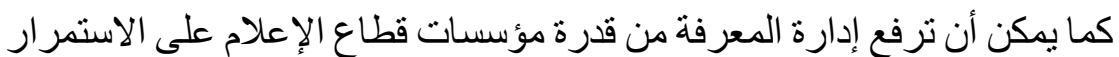

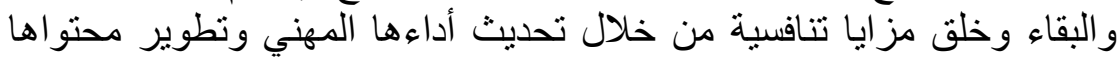

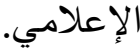

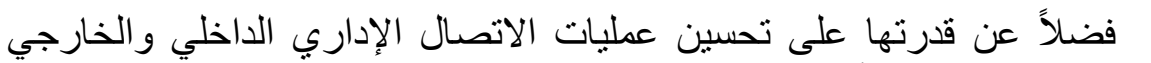

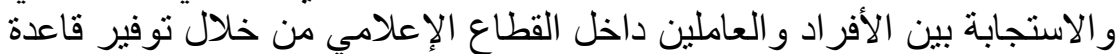

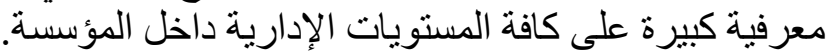

\section{المحور الثاني: واقع صناعة المحتوى الإعلامي بالمملكة}

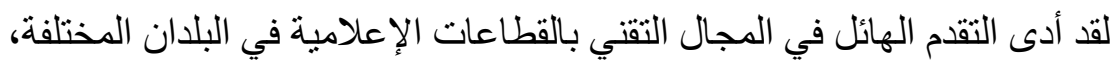

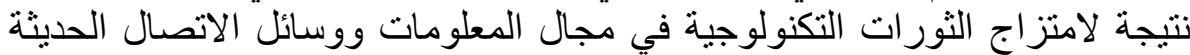

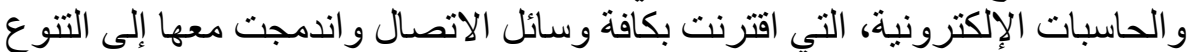

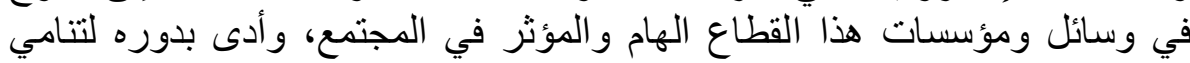




\section{المؤتقر العلمي اللدولي السادس والعشرين}

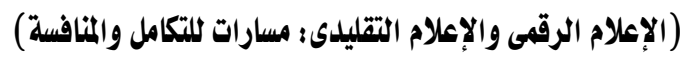

قار اتها الاتصالية في نقل محتواها الإعلامي من أقصى الأرض لأدناها ومن أدناها

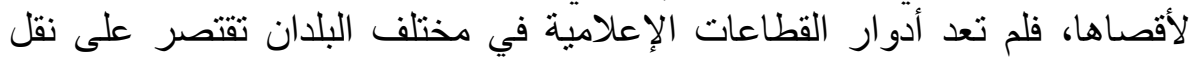

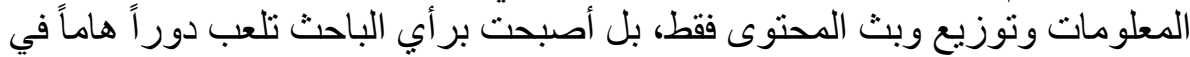

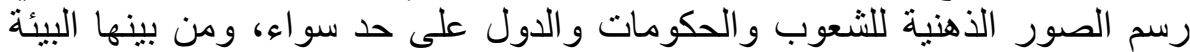

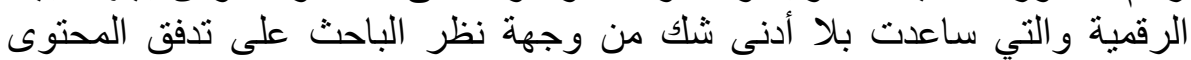
الإعلامي ونقلّه من مكان لآخر بكل حرية ويسر (36).

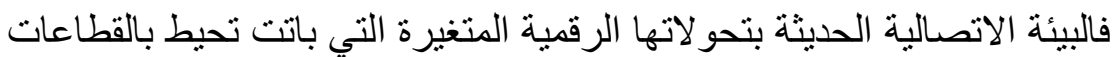

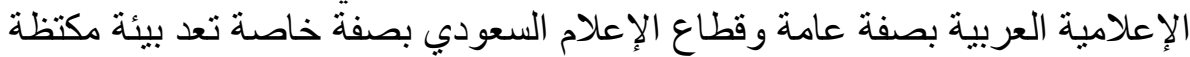

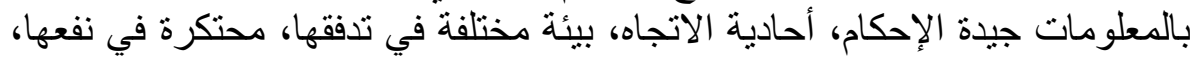

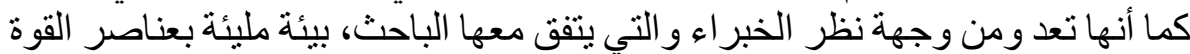

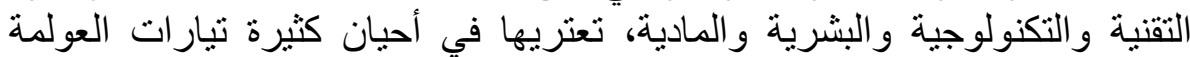
بمفاهيمها الغربية و أبعادها الاقتصادية و السياسية و الثقافية و الإعلامية (37).

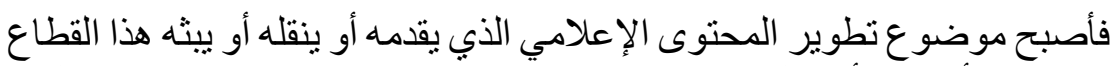

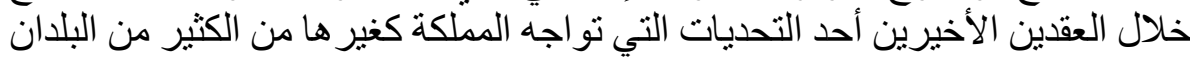

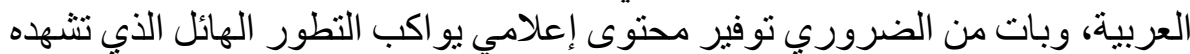

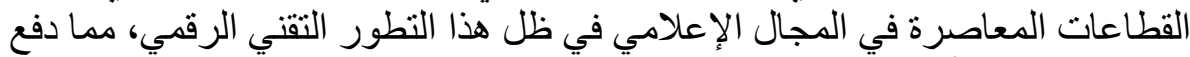

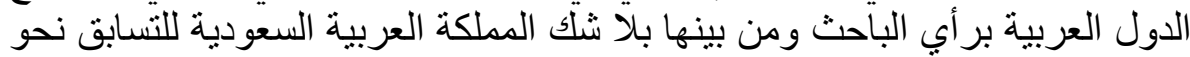

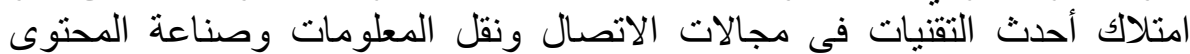

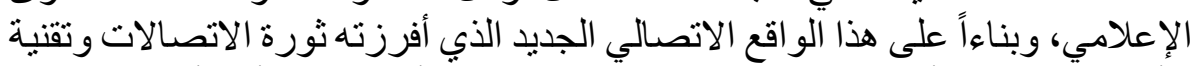

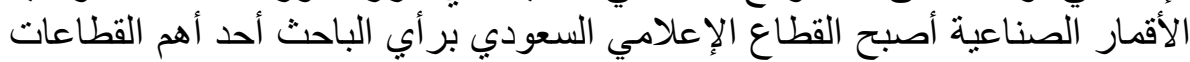

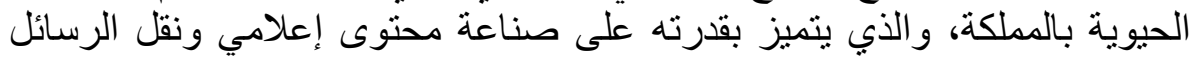

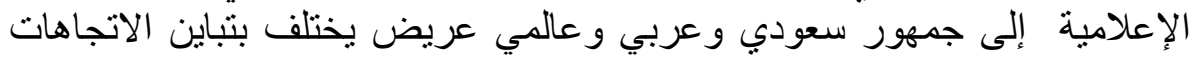
و المستويات بسر عة متناهية وفورية مدهشة وآنية وآنية خطيرة، مع مقدرته على على التعبئة

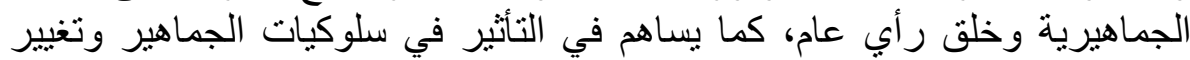
اتجاهاتهم تجاه العديد من القضايا الهامة في الّيا لمتمع (38).

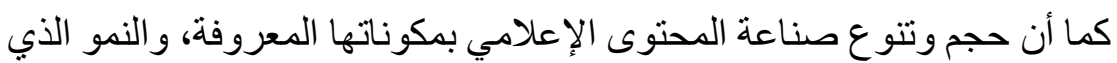

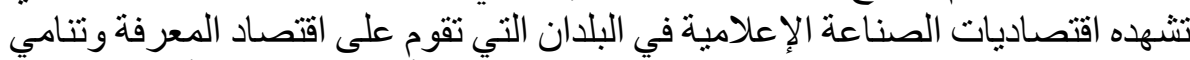

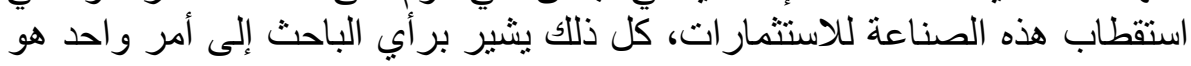

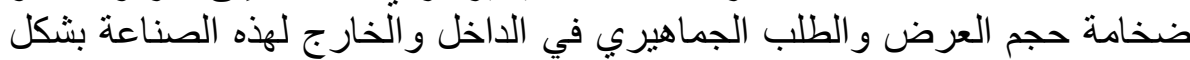

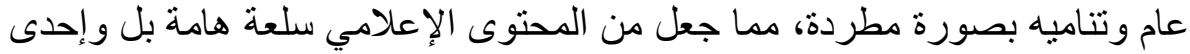

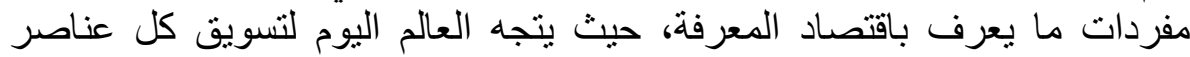

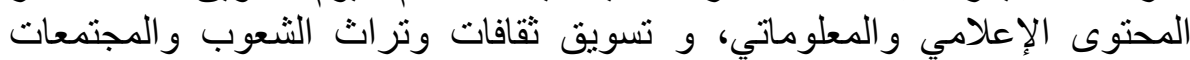
و مختلف مخرجات الإبداع الفكري الإعلامي و الثقافي، وبأثنكال وقو الب سلعية متعددة 


\section{المؤتقر العلمي الدولي السادس والعشريز \\ (الإعلام الرقمى والإعلام التقليدى : مسارات للتكامل والمتافسة)}

يتم تصنيعها في مؤسسات إعلامية متخصصة بصناعة المحتوى في القطاع الإعلامي

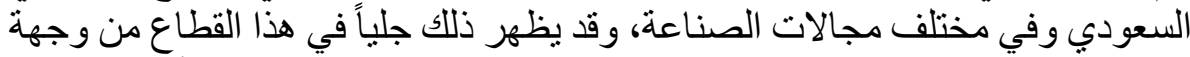
نظر الباحث في نمو صناعة الإعلام، وصناعة الدر اما و السينما وصناعة ألعاب العاب الفيديو

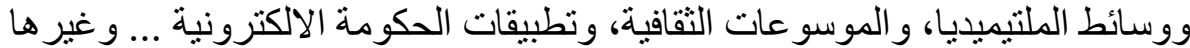

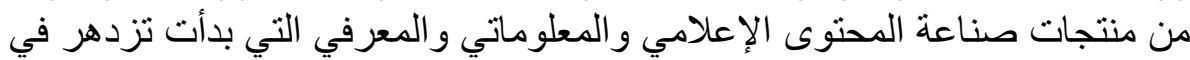
جميع ربوع المجتمع السعودي في السنوات الأني الأخيرة.

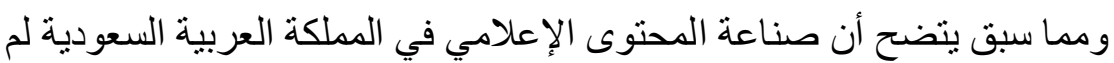
تعد محصورة في الثق الإعلامي أو في جو انب محدودة الإني في مؤسساته الرسمية النمطية،

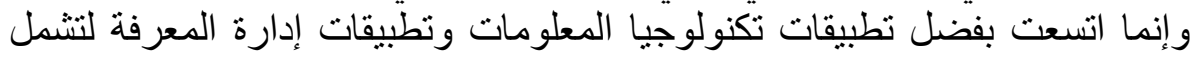

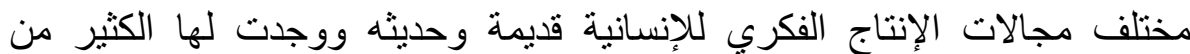

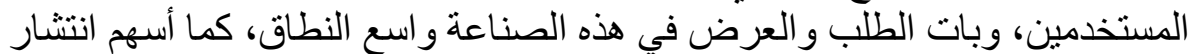

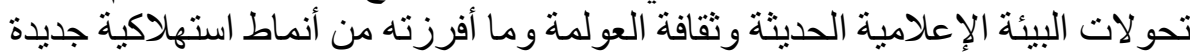

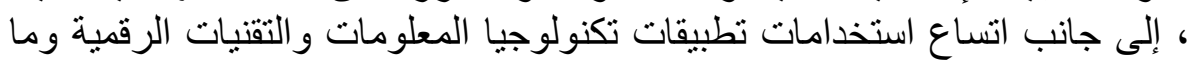

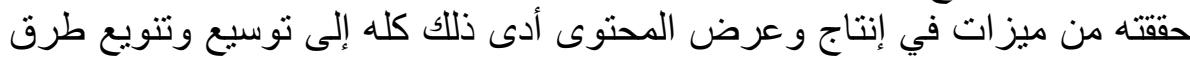

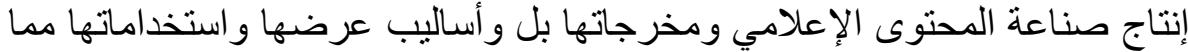

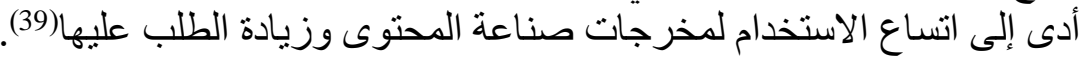

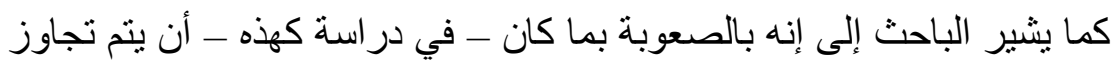

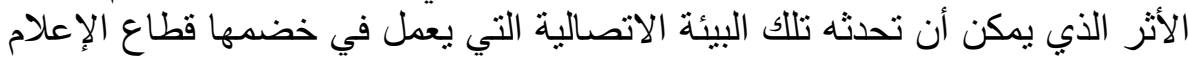

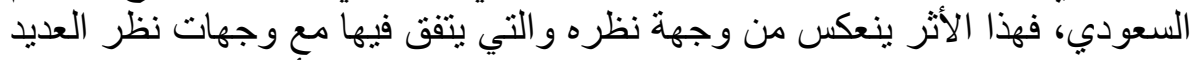

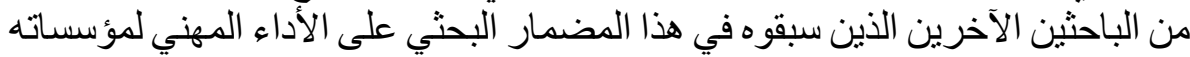

ومحتو اها الإعلامي من خلال الجاهين الثنين يستطيع إجمالهما على النى النحو التّالي (40):

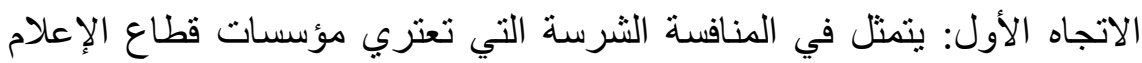

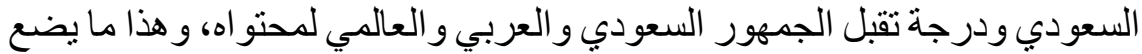

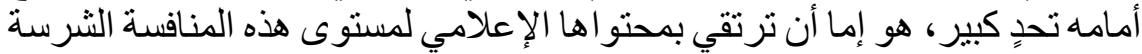

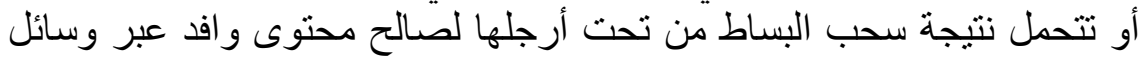

$$
\text { إعلامية ووسائط اتصالية ومنصات رقية رقمية خارجية. }
$$

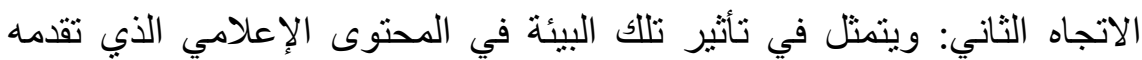

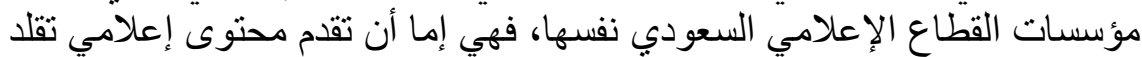

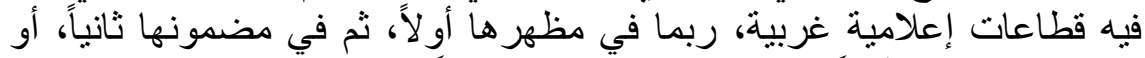
تستقل بشخصيتها أولاً، ثم تحمل زبلة زمام آلمبادرة ثنانياً.

ونتيجة لما سبق طرحه يرى الباحث أنه لم بعد بمقدور المسئولين عن قطاع

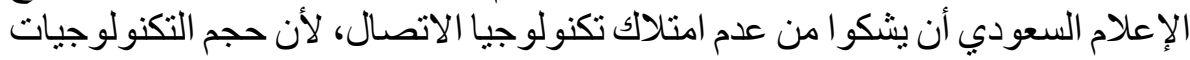




\section{المؤتقر العلمي اللدولي السادس والعشرين}

(الإعلام الرقمى والإعلام التقليدى : مسارات للتكامل والمتافسة)

الرقمية المحيطة ببيئة العمل الإعلامي المستخدمة في إنتاج المحتوى الإعلامي

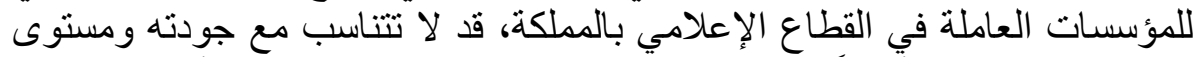

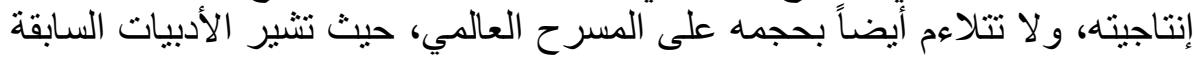

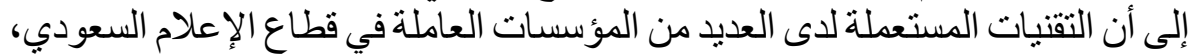

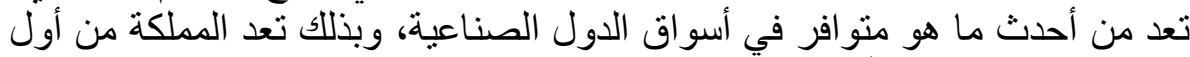

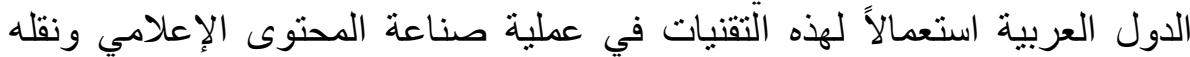

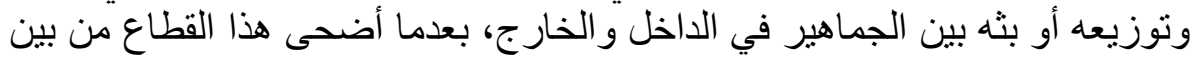

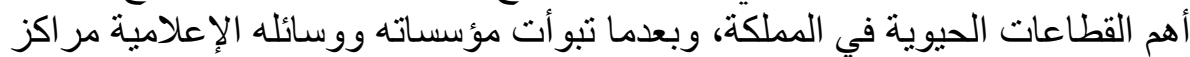

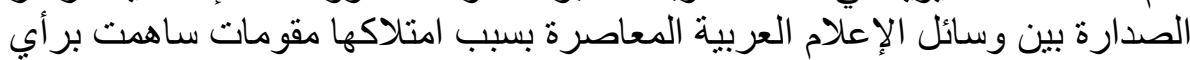

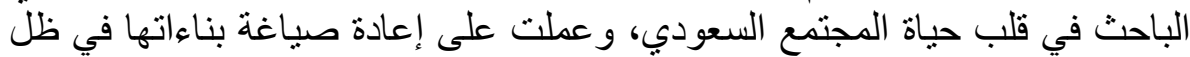
التحو لات التكنولوجية الحديثة(41).

ونتيجة لذلك فقد باتت عملية صناعة المحتوى الإعلامي جزءعاً لا يتجز أ من مهام

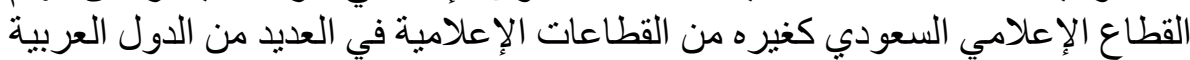

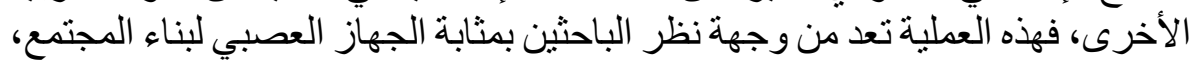

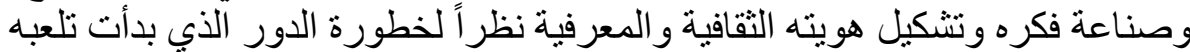

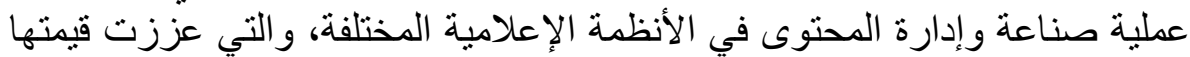

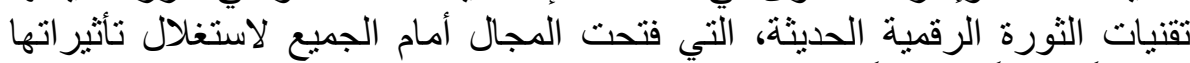
إعلامياً وثقافياً ومعرفياً. (42) الترفئة

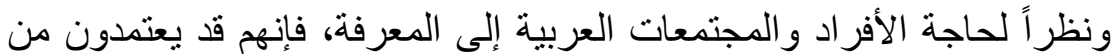

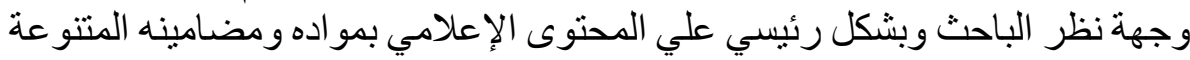

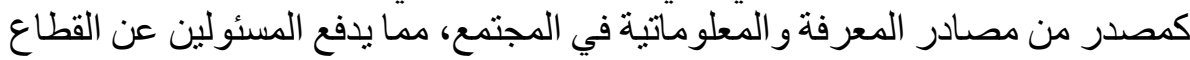

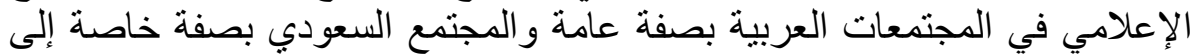

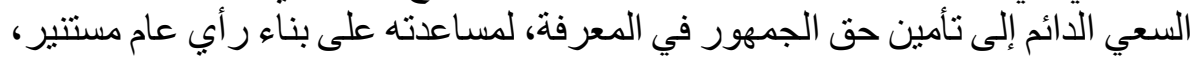

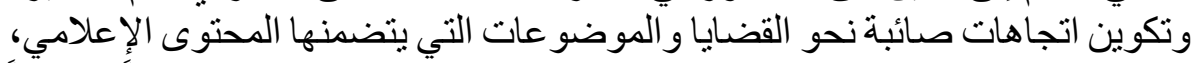

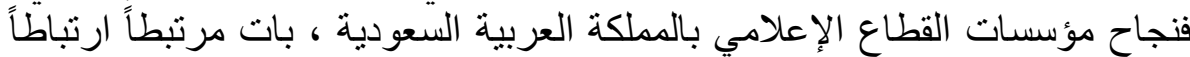

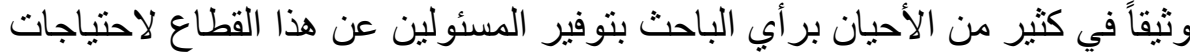

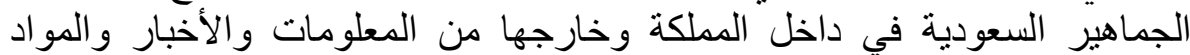

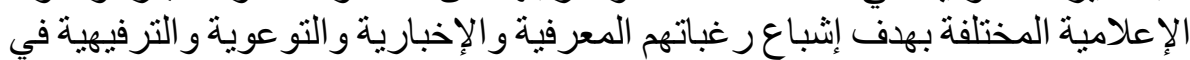

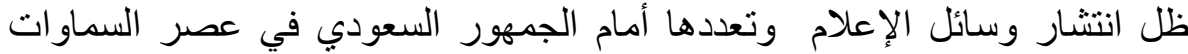
المفتوحة و المنصات الرقية الرعات المتعددة(43).

فالمتتبع لو اقع عملية صناعة المحتوى الإعلامي بقطاع الإعلاعة إنام بالمملكة العربية

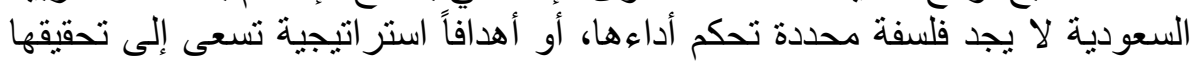
بالر غم من تحديد المسئولين عنه لمجمو عة أهداف، ولكن لا تلمس ذللك بر أي الباحث 


\section{المؤتقر العلمي الدولي السادس والعشريز \\ (الإعلام الرقمى والإعلام التقليدى : مسارات للتكامل والمتافسة)}

بشكل واقعى، حتى أن بعض المؤسسات الإعلامية بصفة عامة والتلفزيونية بصفة

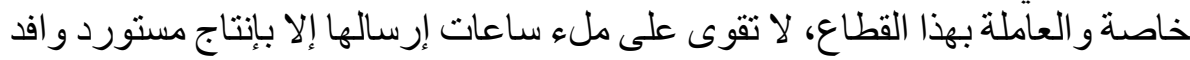
لا يعبر عن هوية المجتمع السعودي و لا يعكس ثقافته العربية.

وبقر اءة متعقة في و اقع صناعة المحتوى الإعلامي بالمملكة يرى الباحث أن أن إعل

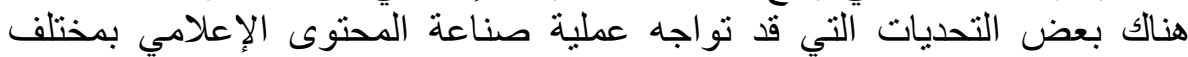

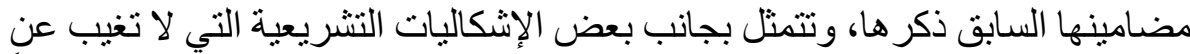

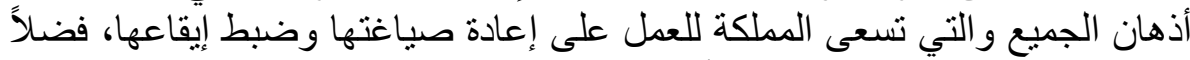

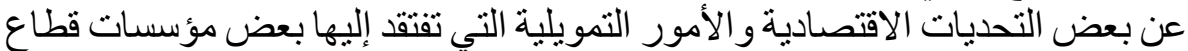

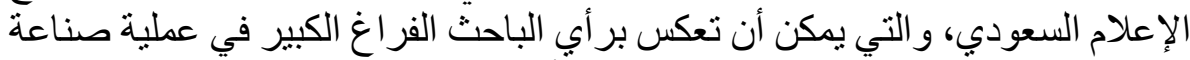

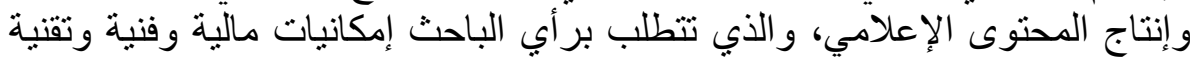

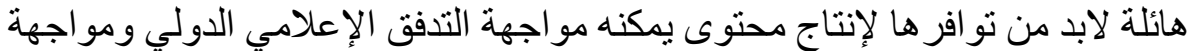

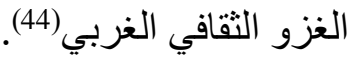

و على الجانب الآخر نجد أن هناك بعض التحديات الخارجية التي يمكن للباحث

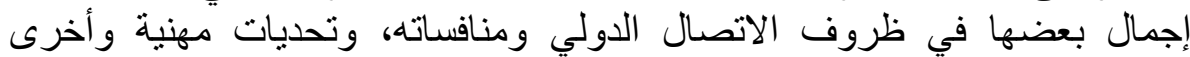
تكنولوجية من حيث مقدرة بعض مؤسسات القطاع الإعلامي السعودي المرئية

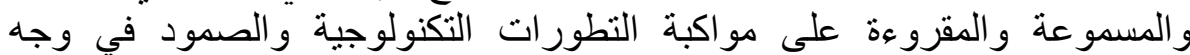

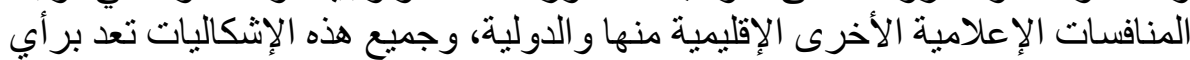

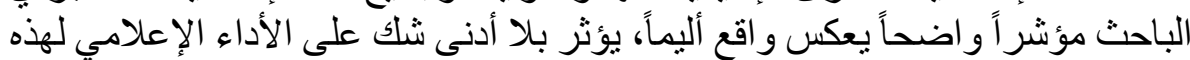

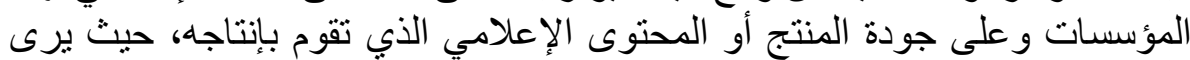
الباحث أن إشكاليات عملية صناعة المحتوى الإعلامي في القطاعات الإعلاع الإعلامية العربية

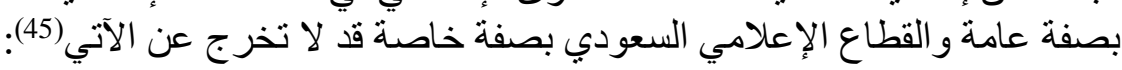
- قد تعاني بعض مؤسسات قطاع الإعلام السعودي من محدودية الإمكانيات وضعفها على المستويين المادي و التقني و البشري.

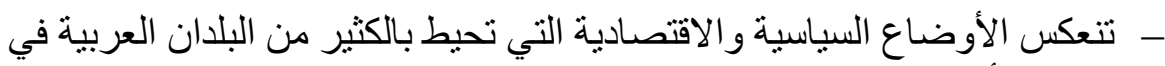

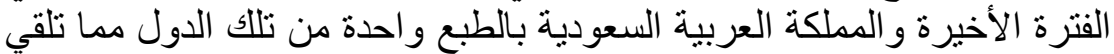

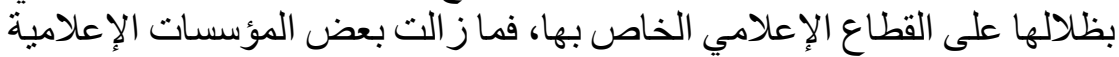

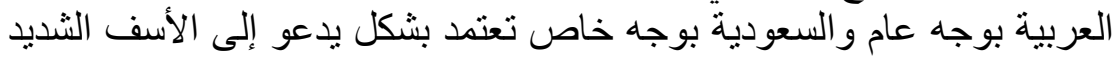

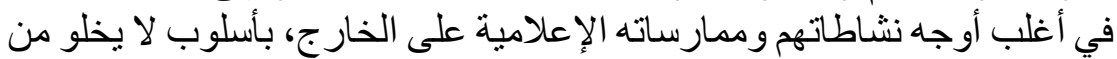

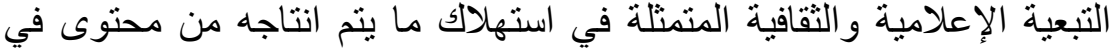

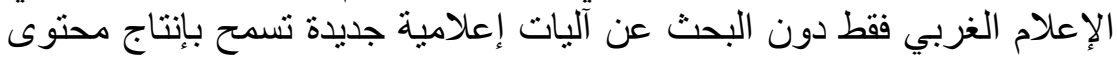

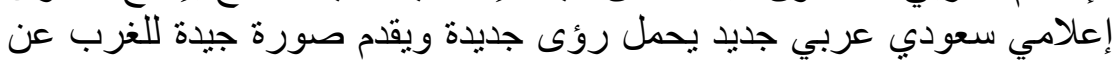
و اقع المجتمعات العربية بصفة عامة و المجتمع السعودي بصفة ودة خاصة. 


\section{المؤتقر العلمي اللدولي السادس والعشرين}

(الإعلام الرقمى والإعلام التقليدى : مسارات للتكامل والمتافسة)

- ندرة الكوادر في مجالات صناعة المحتوى وعملية الإنتاج الإعلام المتطورة المعتمدة على التقنيات الرقمية الحديثة و الوسائل الإلكترونية و المعلو ماتية الجديدة.

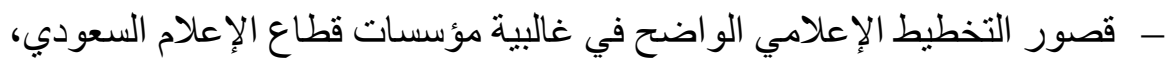

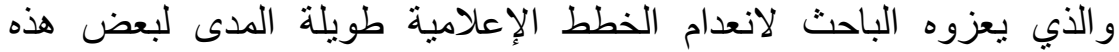
المؤسسات و التي ير اها الباحث تعزف منفردة بعيدة عن أهداف السياسة الإعلامية الإنة

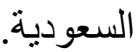

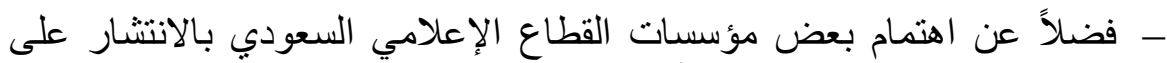

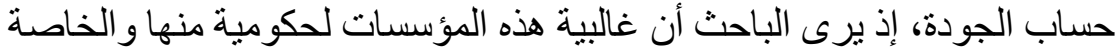

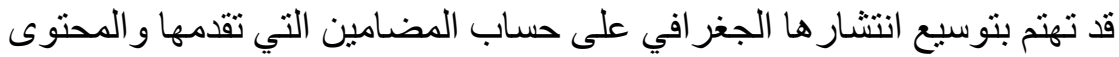
الإعلامي الذي تنتجه.

وبالرغم من كل تللك الظروف الصعبة الإنه والعقبات والإشكاليات السابق الإشارة

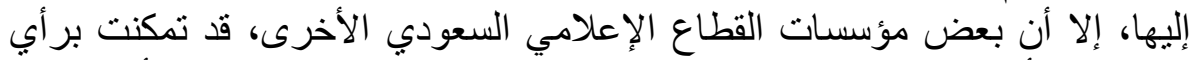

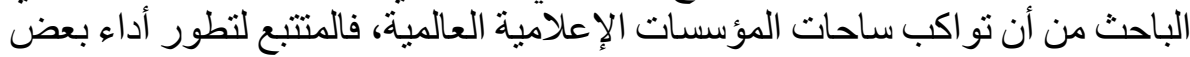

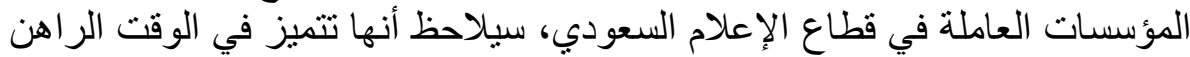

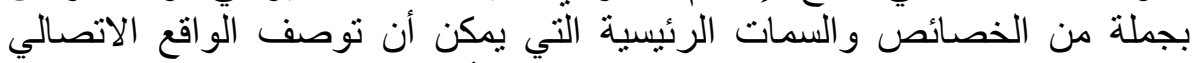

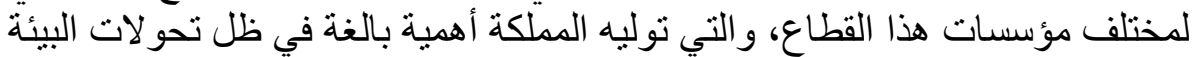

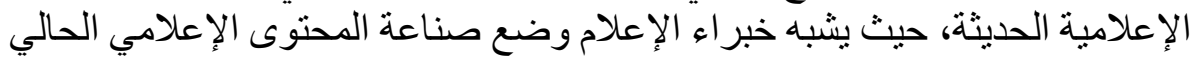

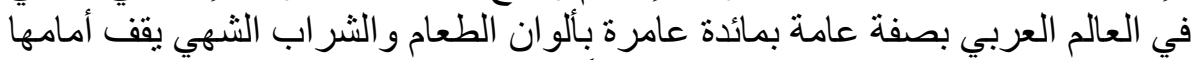

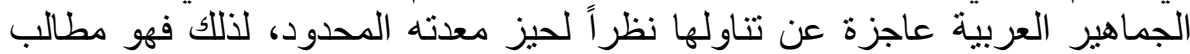

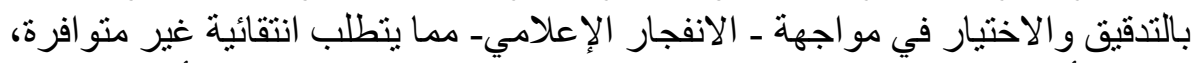

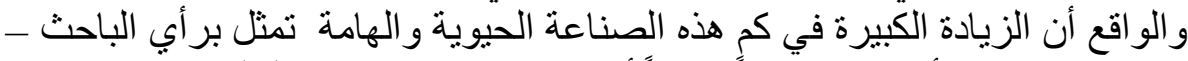

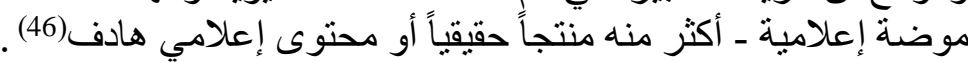

و هذا ما بدفع الباحث وقبل أن ينتقل للمحور الثاني من المنطلق الفكري لهذه إنها

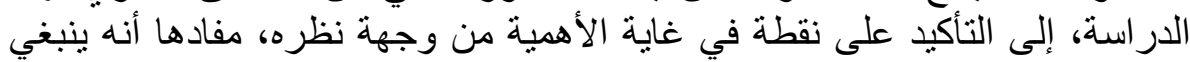

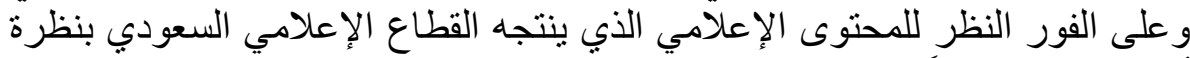

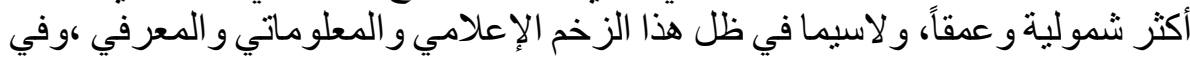

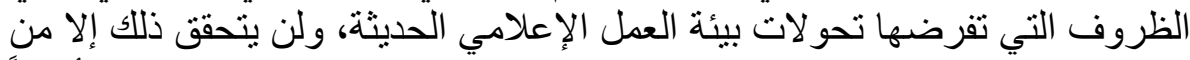

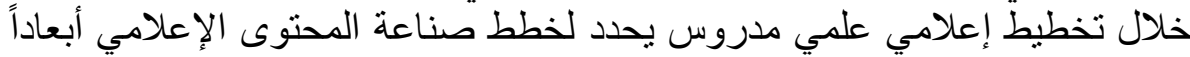

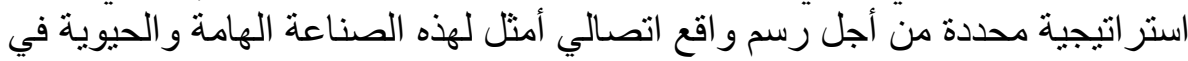

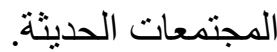




\section{المؤتقر العلمي اللدولي السادس والعشرين}

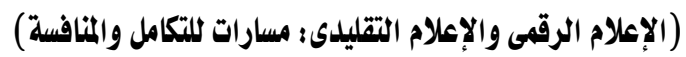

المحور الثالث: متطلبات صناعة المحتوى الإعلامي في ظل متغيرات البيئة الرقمية

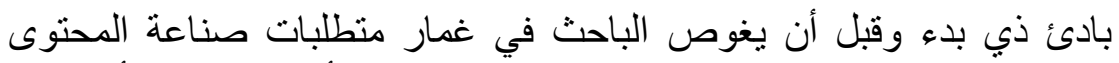

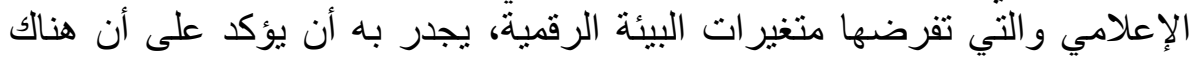

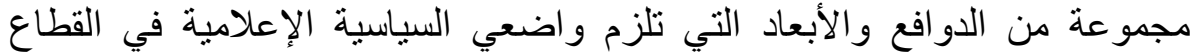

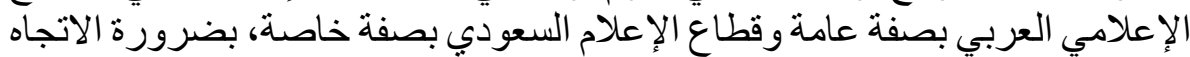

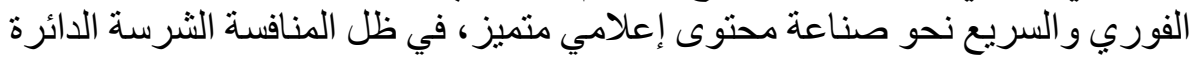

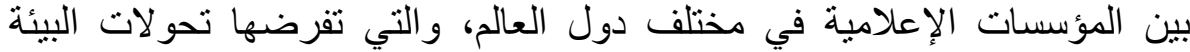

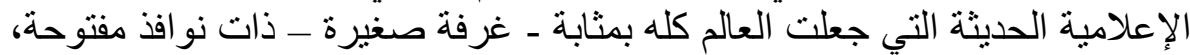

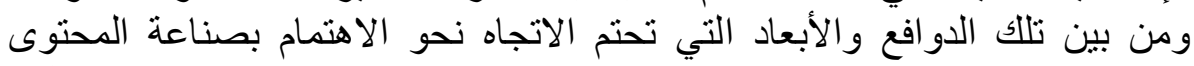

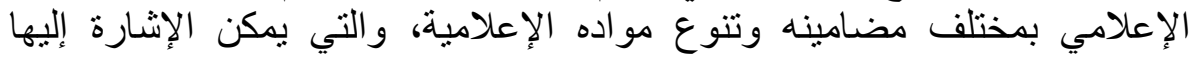
باختصار على النحو التالي (47):

• البعد الاقتصادي: حيث يمكن أن تحقق صناعة المحتوى الإعلامي بر أبي الباحث

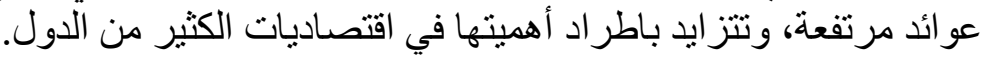

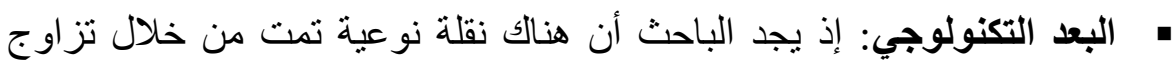

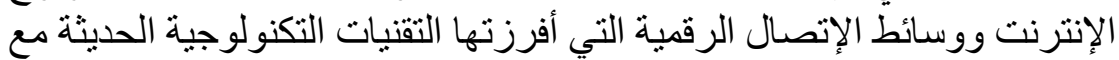

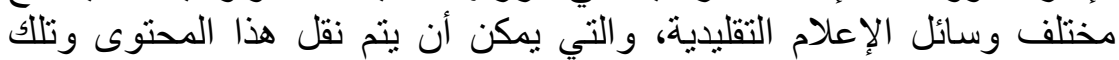

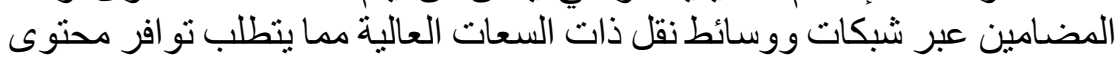

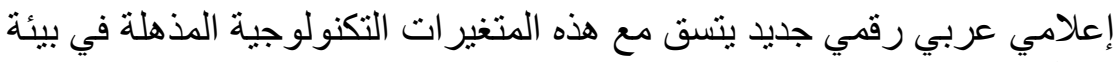

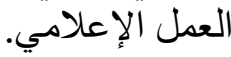

هالبعد التربوي: حيث أن صناعة المحتوى الإعلامي والاهتمام بها قد تمثل بر أي

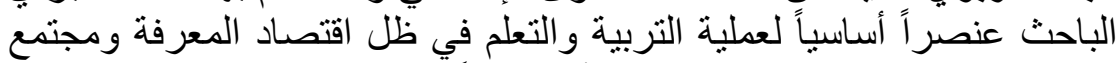

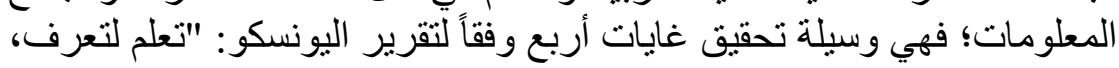

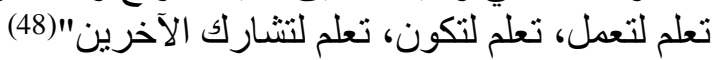

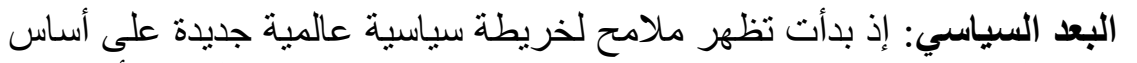

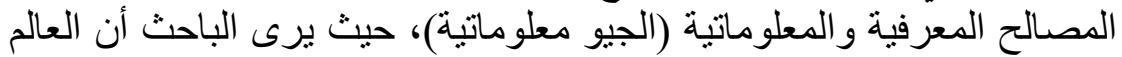

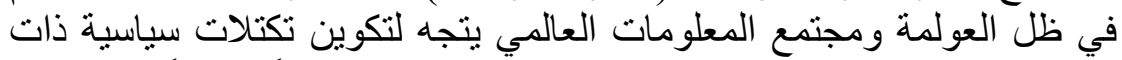

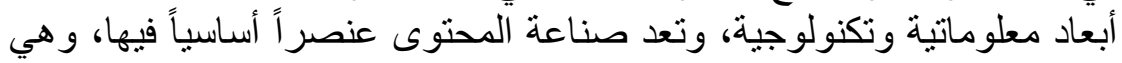

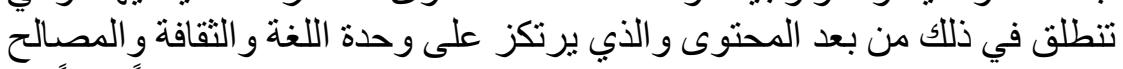

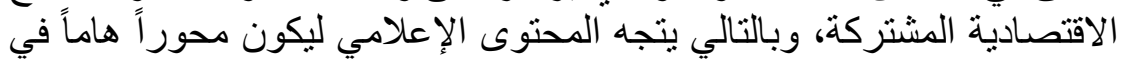
بنية الخريطة السياسية العالمية كونه منطلقاً هامًا للتحالفات لإنات السياسية والاقتصادية(49). 


\section{المؤتقر العلمي اللدولي السادس والعشرين}

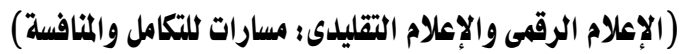

البعد الاجتماعي: فعملية صر اع التقافات في ظل العولمة وتحو لات البيئة الرقمية

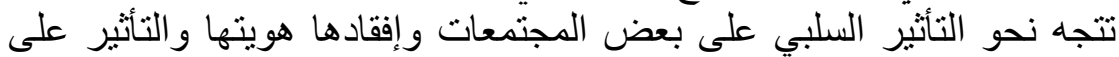

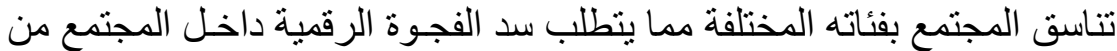

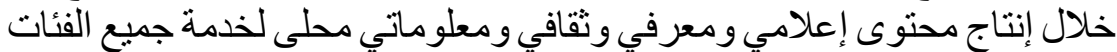

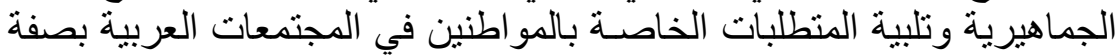
عامة و المجتمع السعودي بصفة خلاصنة

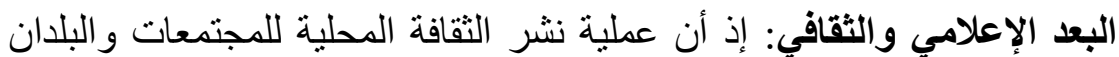

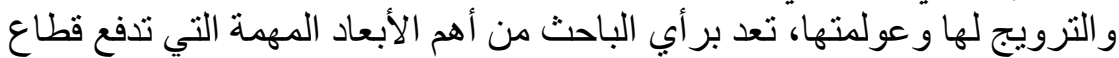

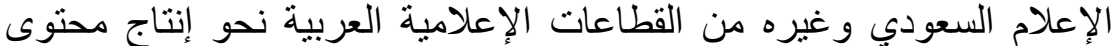

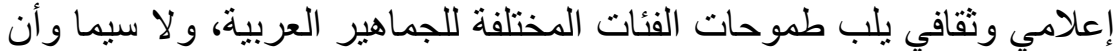

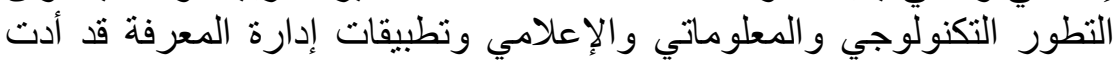

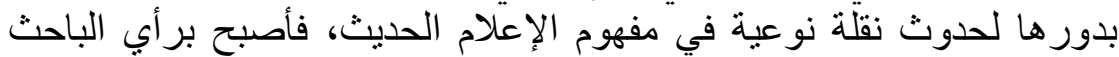

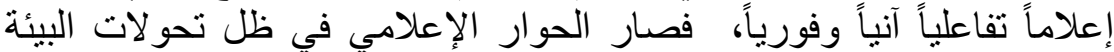

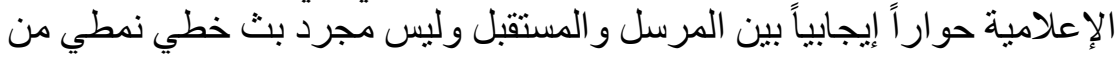

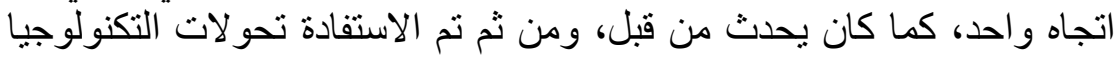

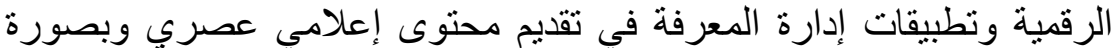
حديثة.

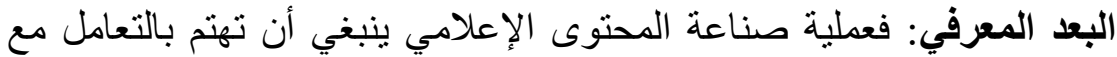

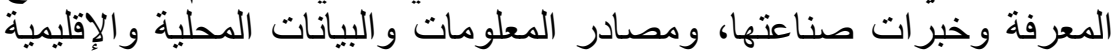

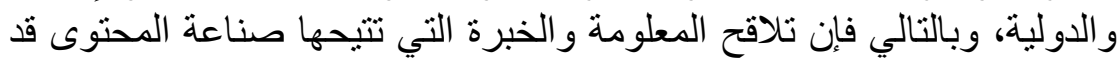

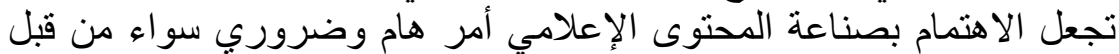

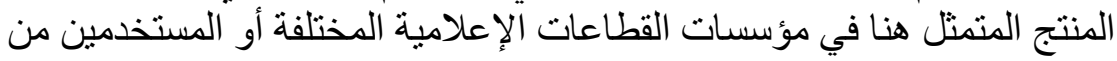
فئات الجماهير المتعددة(50).

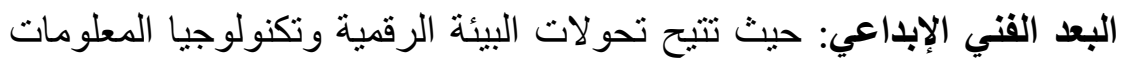

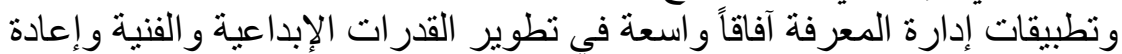

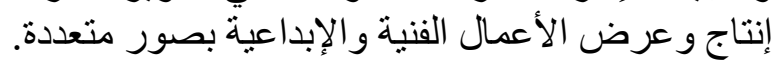

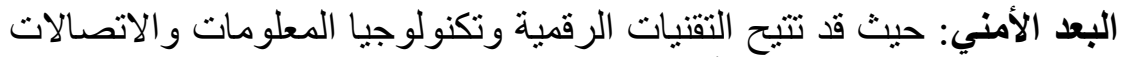

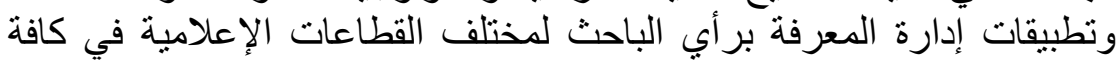

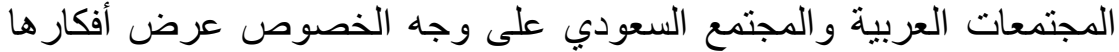

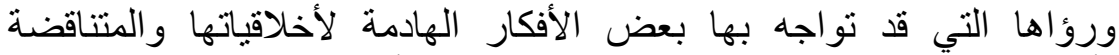

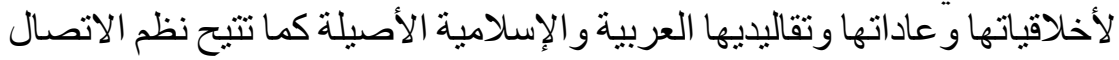

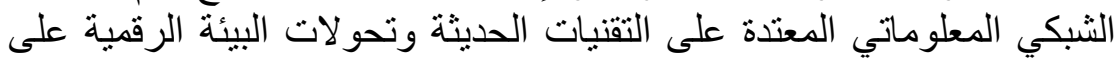




\section{المؤتقر العلمي اللدولي السادس والعشرين}

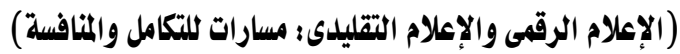

صناعة ونقل المحتوى الإعلامي الذي يمكن أن يو اجه بها تللك المضامين و الأفكار التي قد تهدد أمن المجتمعات الإعلاتوني

وفي ضوء هذه الأبعاد والدوافع السابق ذكرها والتي تحتم على القطاعات

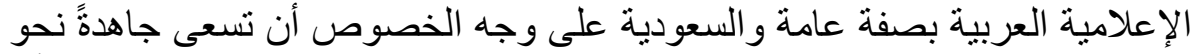

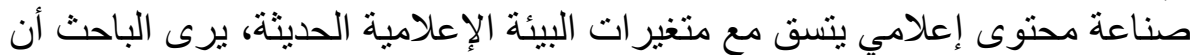

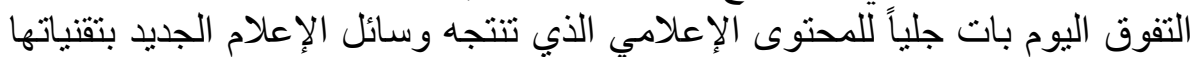

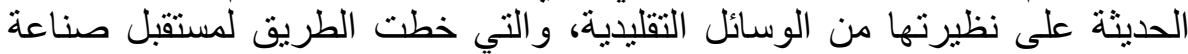

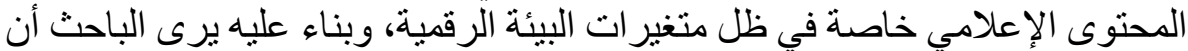

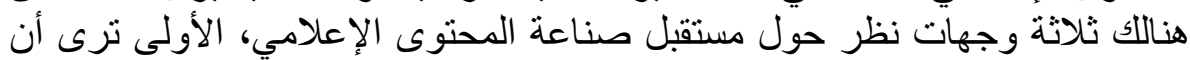

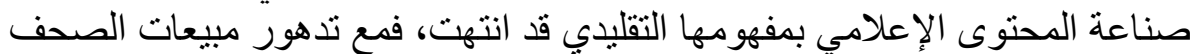

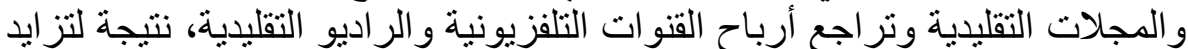

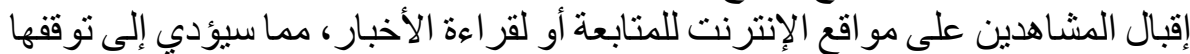

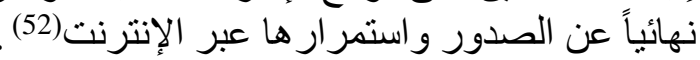

و هنالك وجهة نظر ثانية ترى أن صناعة المحتوى الإعلامي التقليدية باقية وهي الإني

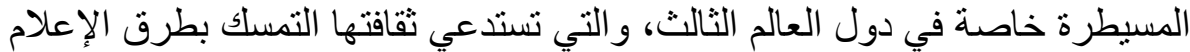

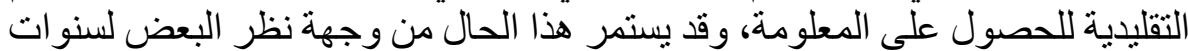

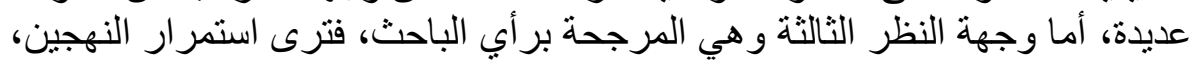

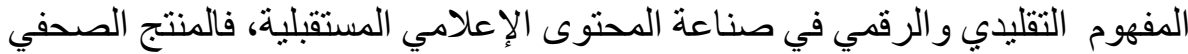

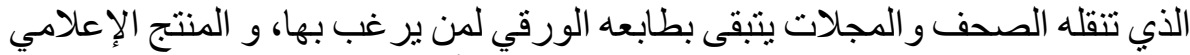

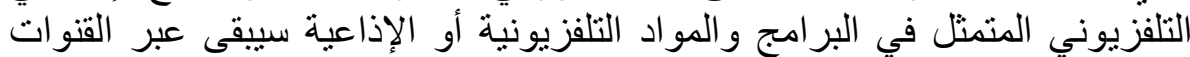

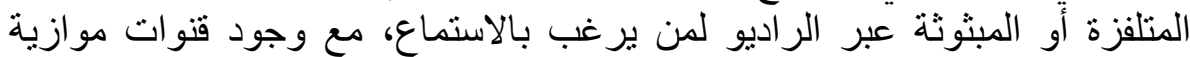
إلكترونية تدعم النشر الرقمي للأخبار و المعلومات كما هو قائم اليوم. (53)

الأمر الذي يؤكد ومن وجهة نظر الباحث أن البيئة التكنولوجية الرقمية عامة

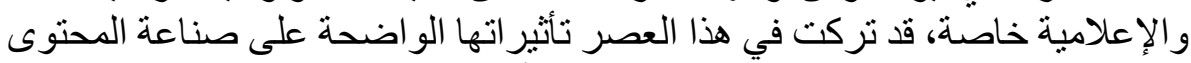

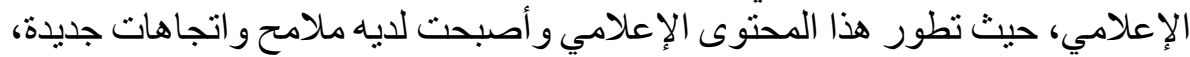
إذ يمكن وصف التطور المعاصر في المحتوى الإعلامي في ظل متغير ات البيئة الرقمية في مجمو عة النقاط التالية: آ التحول في نمط المحتوى الإعلامي من النمط المحتوى العام إلى المحتوى

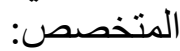
حيث كان الثكل التقليدي للمحتوى الإعلامي يتضمن كل القو الب من أخبار ، موسيقى، إناقية

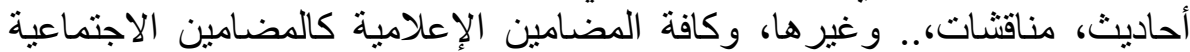

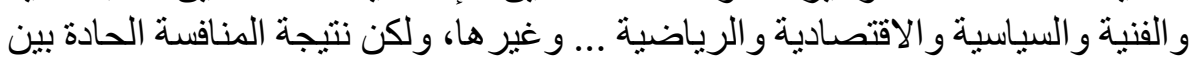
المؤسسات الإعلامية وبين وسائل الاتصال الجماهيرية الأخرى، اتجهات ولته خدمات 


\section{المؤتقر العلمي اللدولي السادس والعشرين}

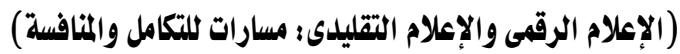

صناعة المحتوى إلى تطوير وإنشاء قنوات ووسائل ونوافذ ومنصات إعلامية

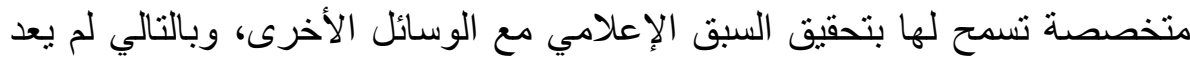

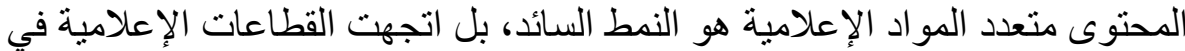

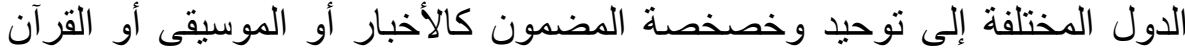

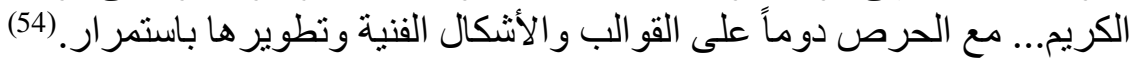
> تزايد الاتجاه نحو صناعة محتوى إعلامي تخاطب فئات متجانسة من الجمهور: حيث صاحب الاتجاه نحو إنشاء قنوات متخصصة في المضامين الإعلامية إعاءية

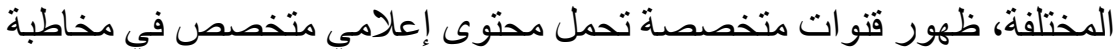

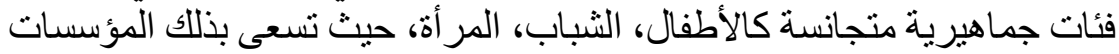

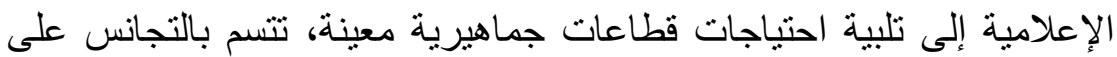

مستوى الخصائص الديمو غر افية، أو المهنية، أو الاجتماعية، أو العمرية(55).

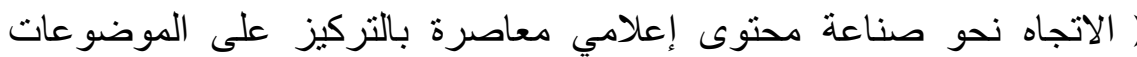

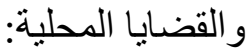

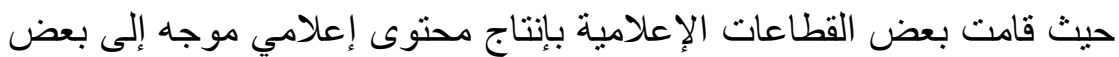

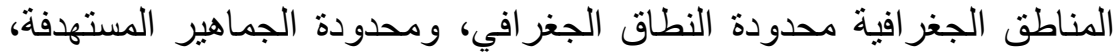

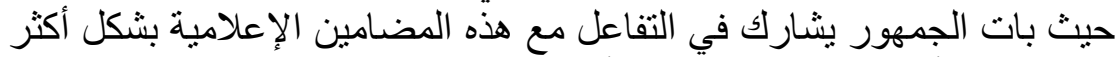

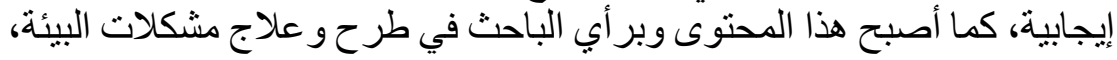
وتلبية احتياجات ورغبات الجماهير المستهدفة من الإعلام و الثقافة والترفيه. > التوسع في صناعة و إنتاج المحتوى الإعلامي الذي يتفاعل معده الجمهور : حيث ظهر اتجاه متز ايد في العديد من القطاعات الإعلامية في الكثير من البلدان

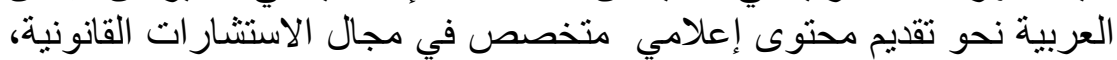

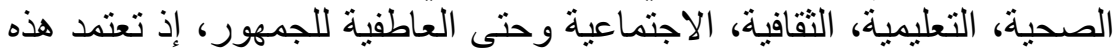

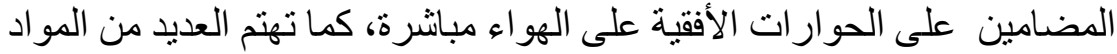

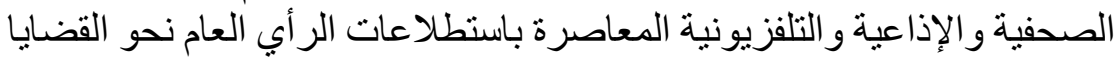

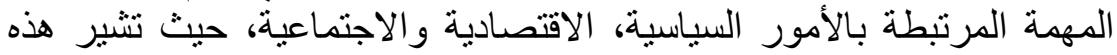

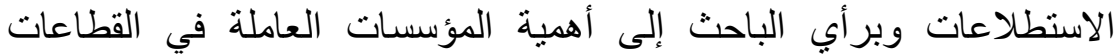

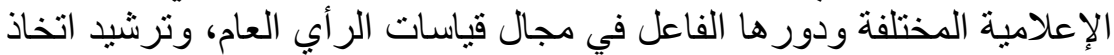

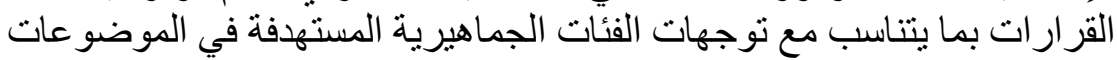
و القضنايا المختلفة(56).

وقد تمثلت إحدى الثمار الإيجابية لتكنولوجيا الاتصال الرقمية في تتمية التفاعل

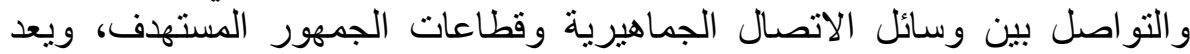

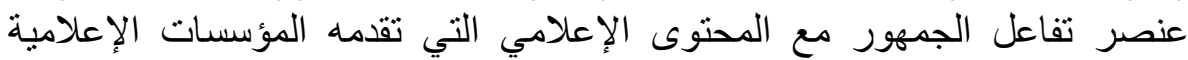




\section{المؤتتر العلمي الدولي السادس والعشرين \\ (الإعلام الرقمى والإعلام التقليدى : مسارات للتكامل والمذافسة)}

المختلفة أحد معالم الدور الفاعل للقطاعات الإعلامية في المجتمع المعاصر ، إضافة إلى إلى إنى

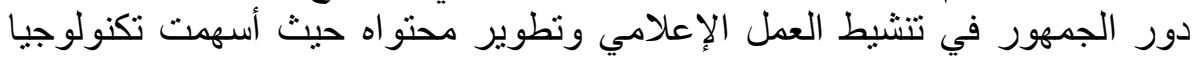

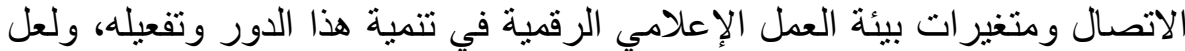

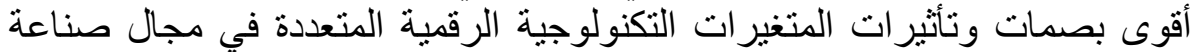

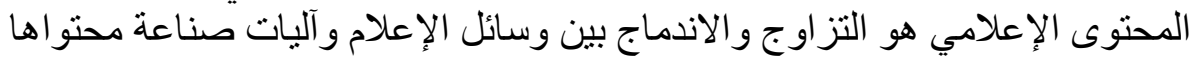

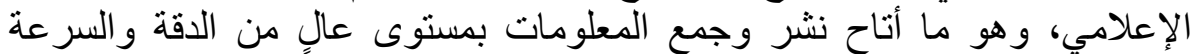

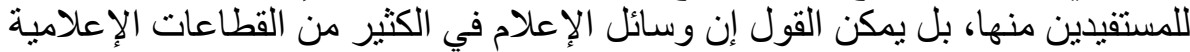

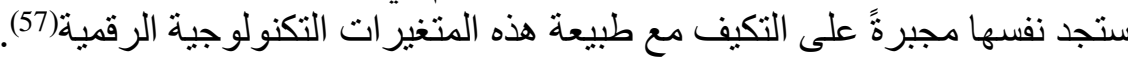
فتأثثرات هذه المتغير ات التكنولوجية الرقمية تجعل صانعي المحتوى الإعلامي

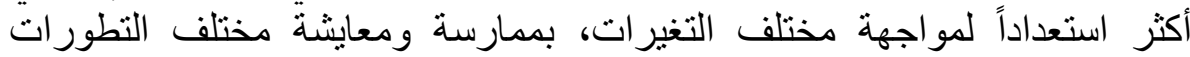

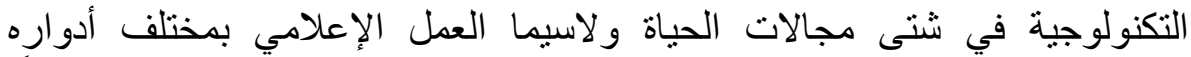

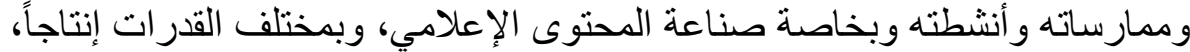

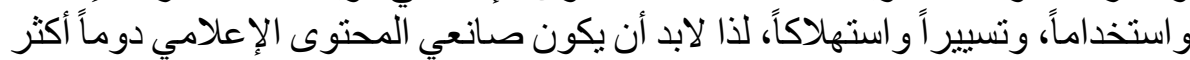

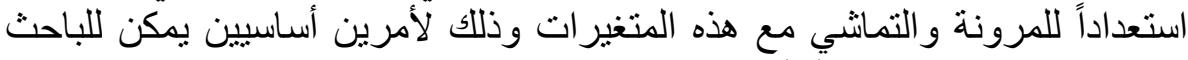
إجمالهما على النحو التالي (58):

• أولاً: أن التغير التكنولوجي الرقمي سوف يستمر في تأججه وثورته وسر عته

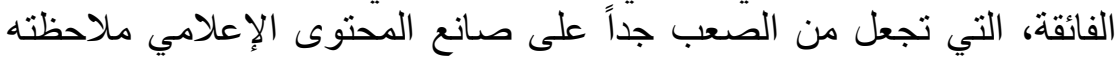

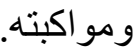

ثانياً: أن هذه التغييرات التكنولوجية الرقية سوف تؤدي إلى تغييرات إت إعلامية

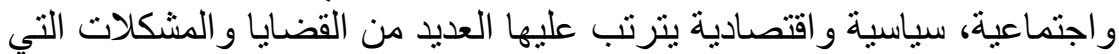

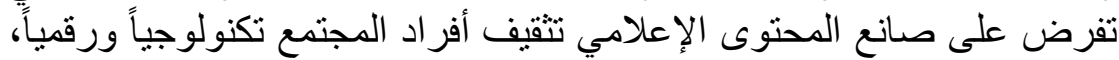

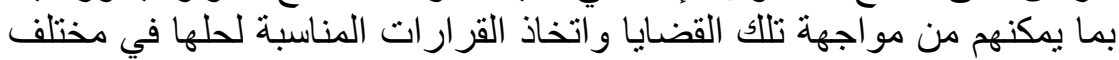
المجالات الحياتية.

وفي ضوء ما سبق يرى الباحث أن هناك مجموعة من المتطلبات الضرورية و الهامة

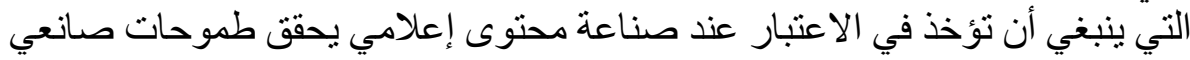

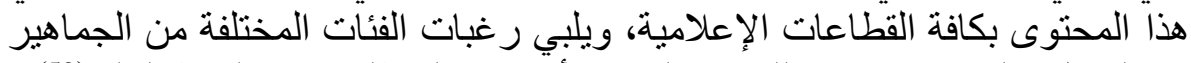
في الداخل و الخارج، ويمكن للباحث تلخيص أهم هذه المتطلبات في النقاط التالية(59):

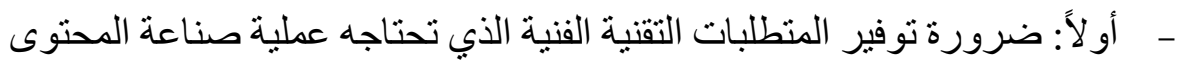
الإعلامي والمتمنل في تكنولوجيا الاتصال وتقنتيات المعلومات الاتلهات (الكمبيوتر و الانترنت) وجميع وسائل الاتصال الرقية الأنية الحديثة.

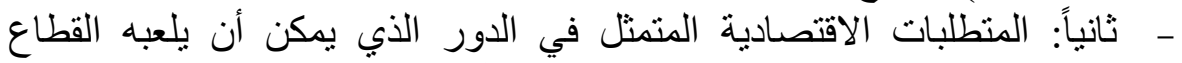
الإعلامي في خدمة الاستثمار وحركة السلع والخدمات الإعلامية ورؤوس الإن 


\section{المؤتقر العلمي اللدولي السادس والعشرين}

(الإعلام الرقمى والإعلام التقليدى : مسارات للتكامل والمتافسة)

الأمو ال التي يتم استثمار ها في هذا القطاع الحيوي، و هذا قد يتطلب بر أي الباحث

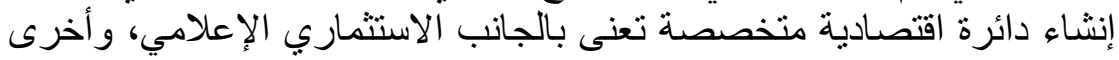

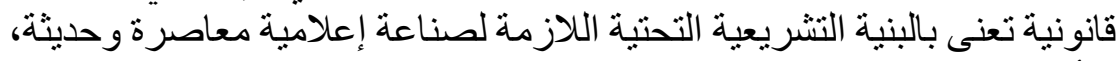

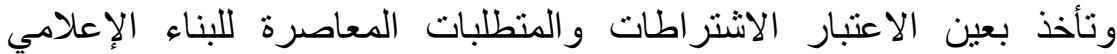

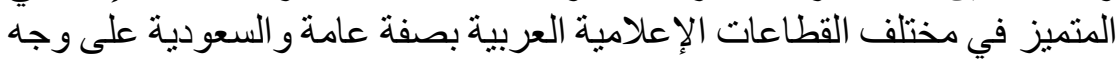

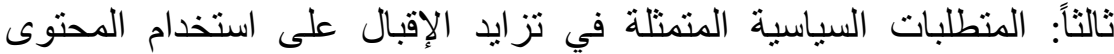

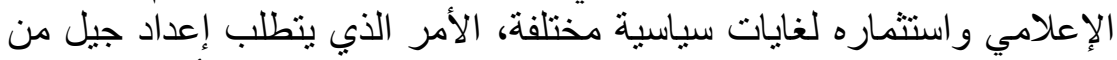

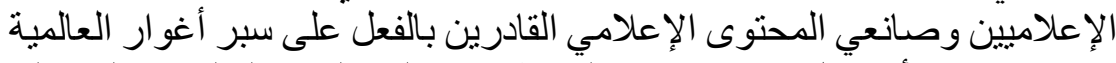

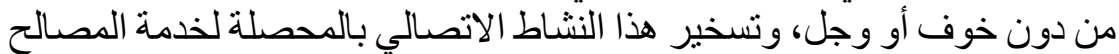

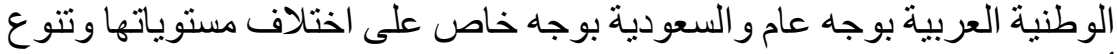

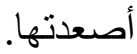

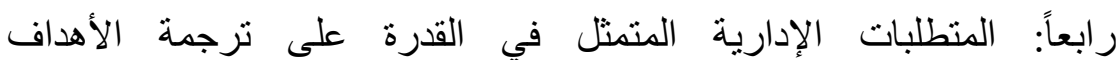

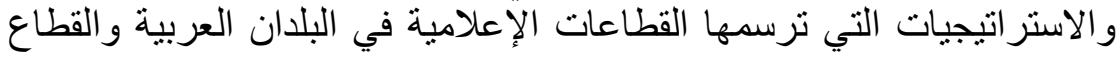

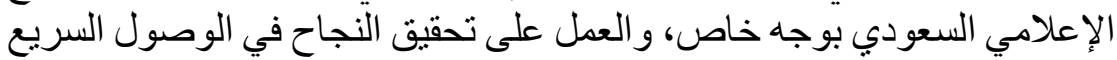

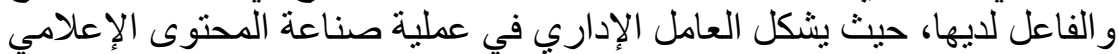

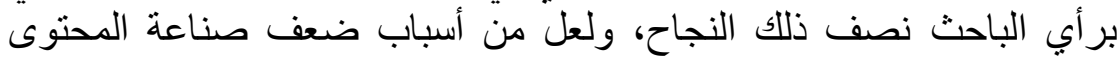

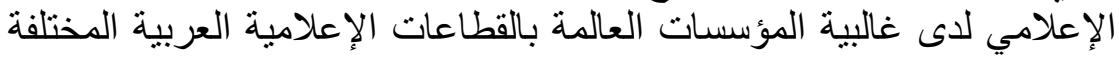

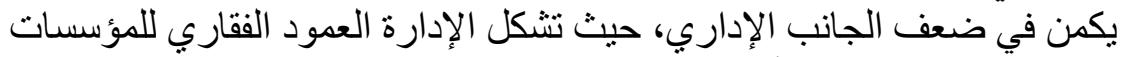

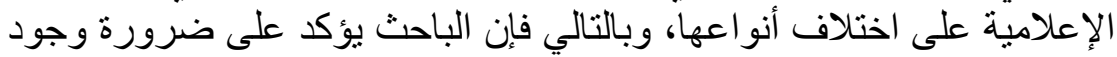

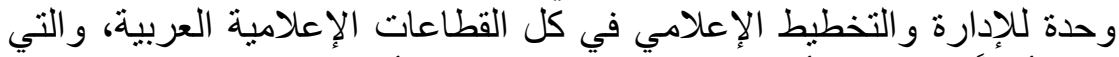

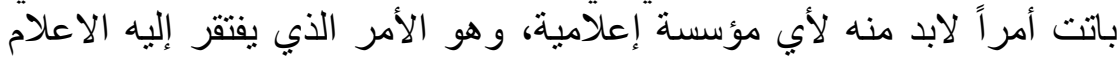

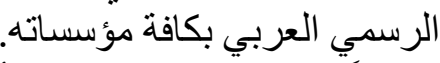

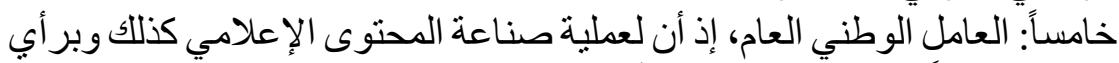

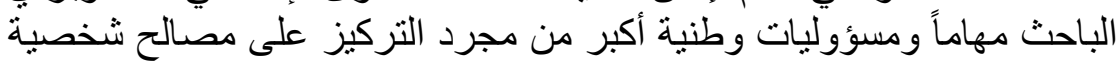

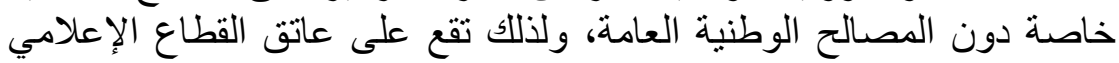

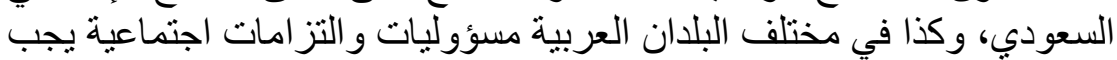

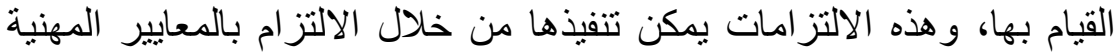

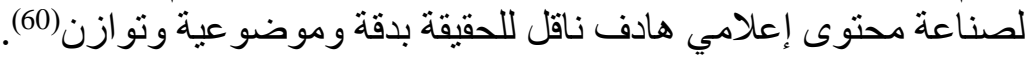

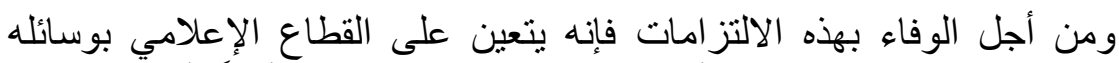

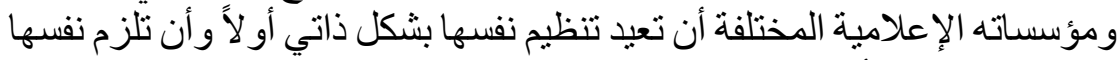

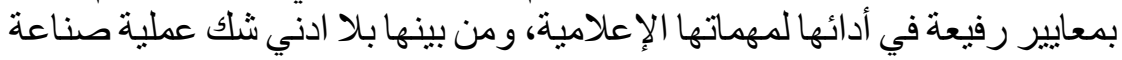
المحتوى الإعلامي التي ينبغي وعلى ألهي الفور العمل على تطويره بالاستفادة من 


\section{المؤتقر العلمي اللدولي السادس والعشرين}

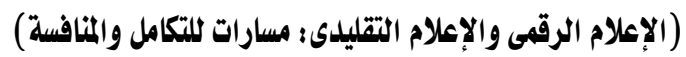

التقنيات التكنولوجية الرقمية وكذلك تطبيقات إدارة المعرفة والتي فرضت الإت نفسها

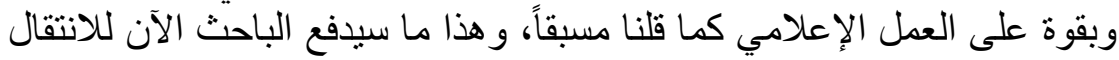

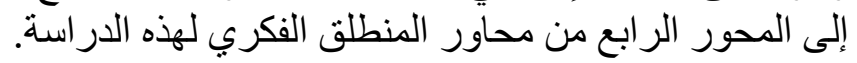

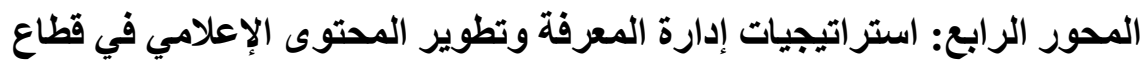

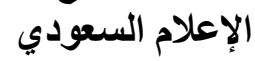

يشار إلى قطاع الإعلام في مختلف البلدان بأنه من أكثر القطاعات المعنية بالتغيير

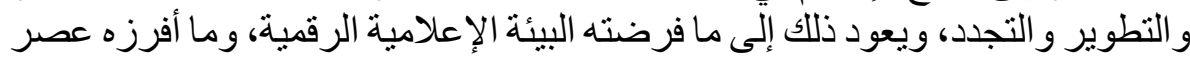

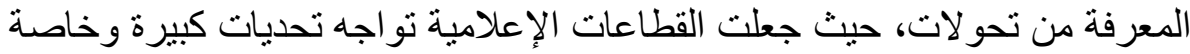

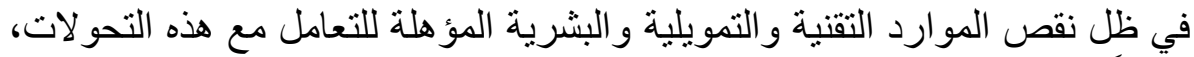

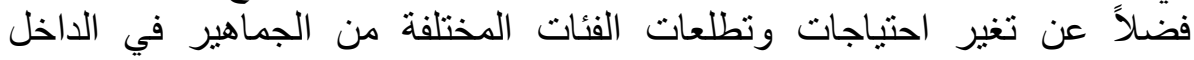
والخارج(61).

بالإضافة إلى ذللك يرى الباحث أن القطاع الإعلامي السعودي بمختلف مؤسساته

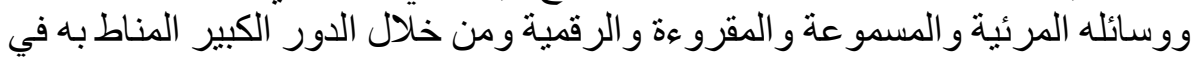

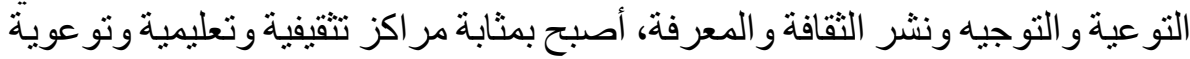

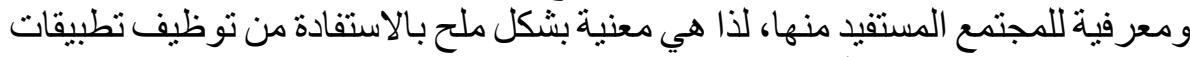

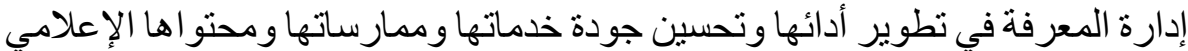
الذي تقدمه أو تنفله او تبثنه أو تذيعه.

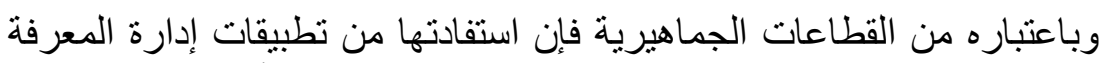

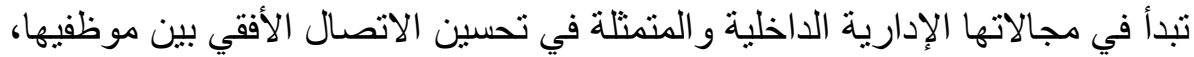

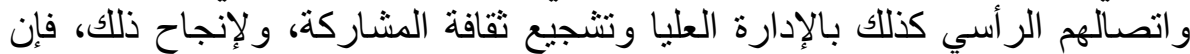

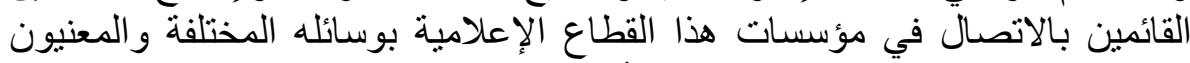
بصناعة المحتوى الإعلامي و إنتاجه، فالأساس

في نجاح العمل في هذا القطاع الحيوي في المجتمع يبدأ من توظيفها للتقنيات

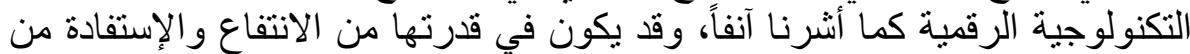

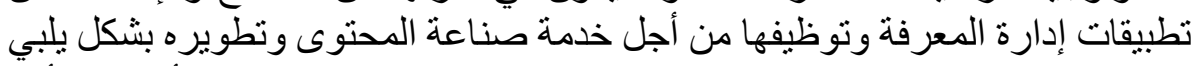

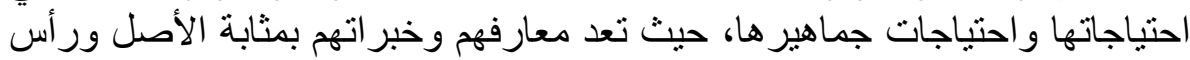

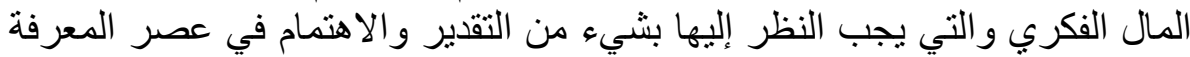
الذي فرضت متغيرات عمل حديثة على عملية صناعة المحتوى الإعلامي (62).

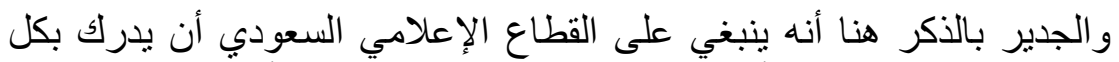

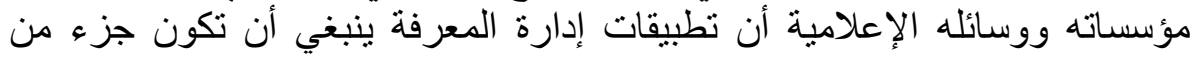
ممارساتها الإدارية والإعلامية، وبالتالي يمكن توظيفها بنطوير خدماتها ومحتوانها اهنا 


\section{المؤتقر العلمي اللدولي السادس والعشرين}

(الإعلام الرقمى والإعلام التقليدى : مسارات للتكامل والمتافسة)

الإعلامي سعيًا نحو إرضاء الفئات الجماهيرية المختلفة داخل المملكة وخارجها، كما

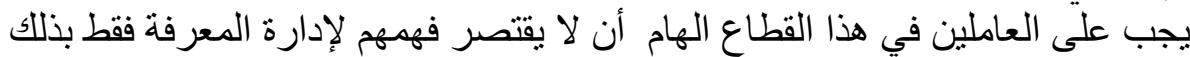

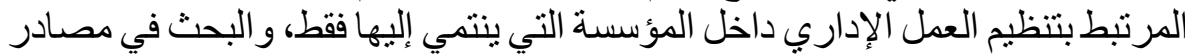

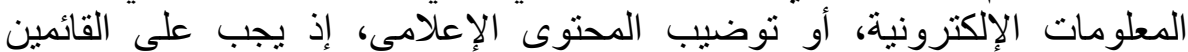

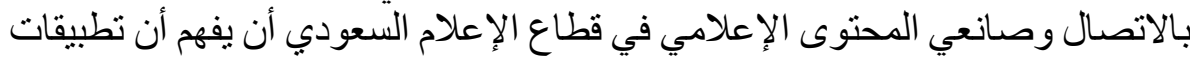

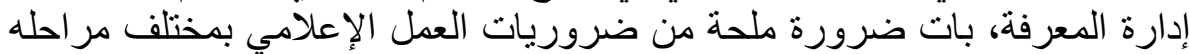

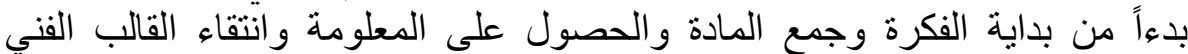

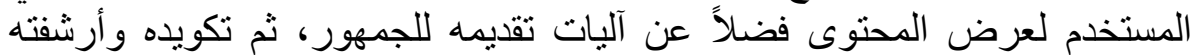

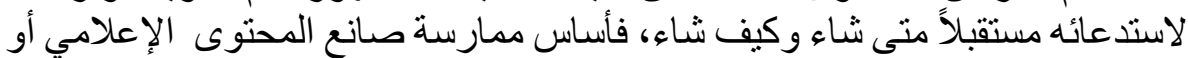

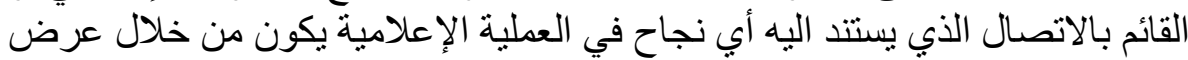

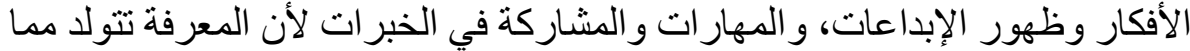

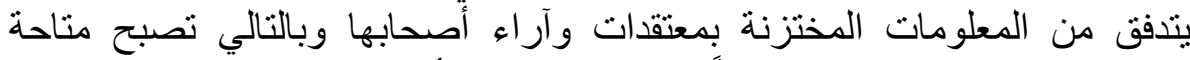

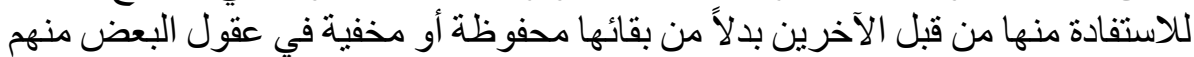

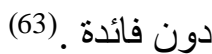

ويشير الباحث أن الاهتمام بتطبيق مفهوم إدارة المعرفة في تطوير المحتوى في

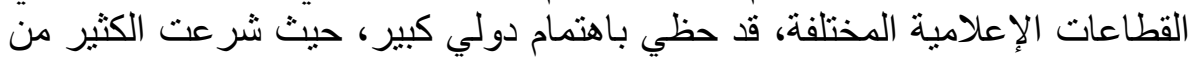

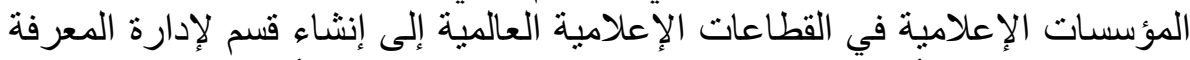

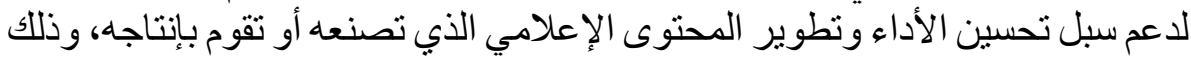

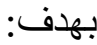

- دعم ثقافة تطبيق إدارة المعرفة في بيئة العمل الإعلامي الحديثة.

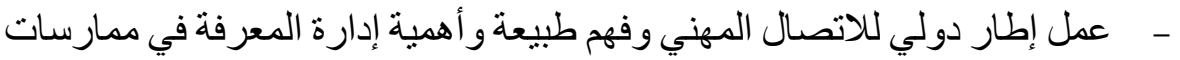
القطاع الإعلامي.

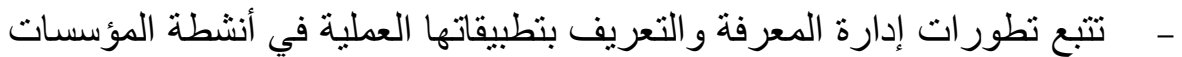
الإعلامية ومن بينها بالطبع إنتاج المحتوى الإعلامي (64).

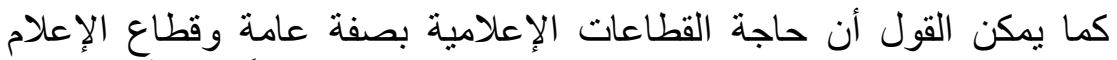

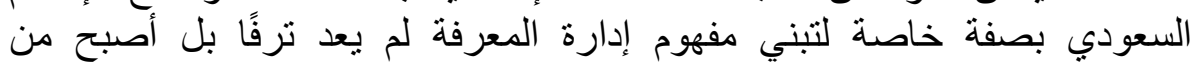

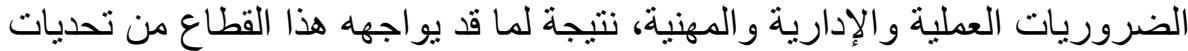

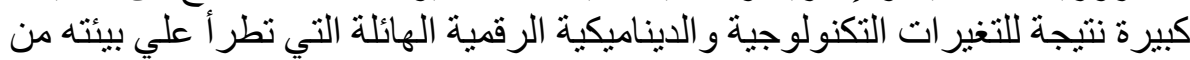

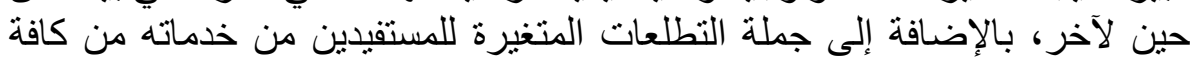

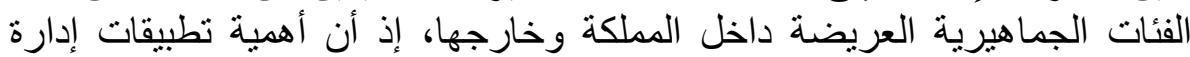

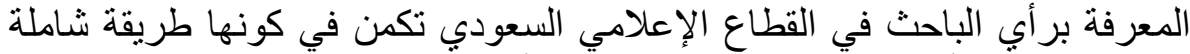

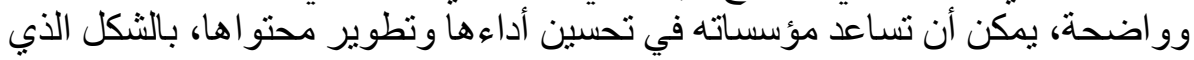




\section{المؤتتر العلمي الدولي السادس والعشرين \\ (الإعلام الرقمى والإعلام التقليدى : مسارات للتكامل والمذافسة)}

يمكن أيضاً أن يزيد من عوائدها المادية و المعنوية، إذ يرى الباحث أن إدارة المعرفة إنة إنها

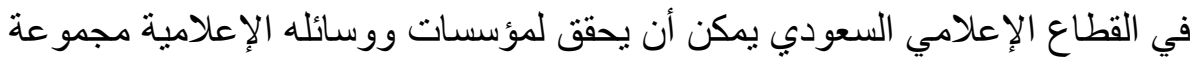

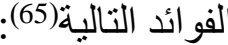

يمكنها أن تعمل على تحسين مستوى كفاءة وفعالية الخدمات الإعلامية التي يمكن

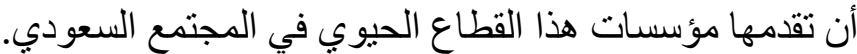

" يمكنها أن تزيد قدرة مؤسسات القطاع الإعلامي على تحديد جهود التحسين

و التطوير في الخدمات و الممارسات ولئ والأنشطة الإعلامية الإعية ومن بينها بالطبع عملية صناعة المحتوى الإعلامي بمر احلها المتعددة.

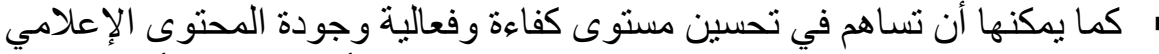
المقدم من خلال مؤسسات هذا القطاع الإعلامية سو اء أكانت مرئية أو مسمو عة الإعة

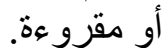

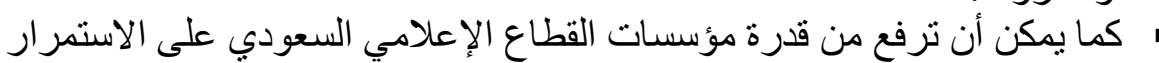

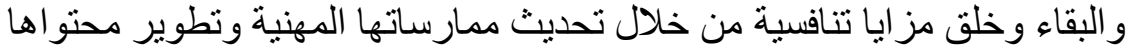

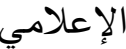

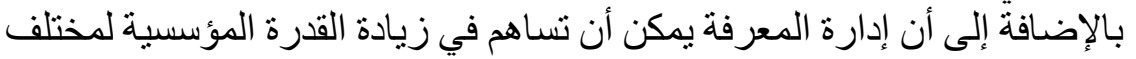

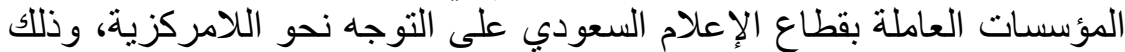

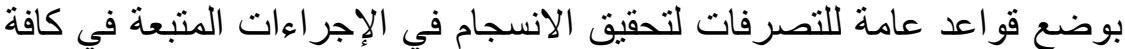

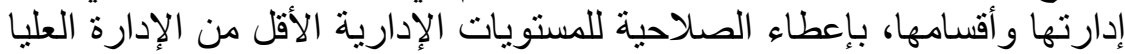

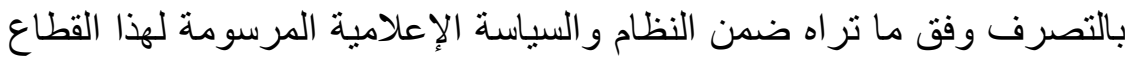

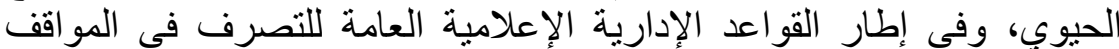
الطارئة التي تستدعى اتخاذ فورى، وما أكثر ها في ظل ما تفرضه الإدها طبيعة العمل

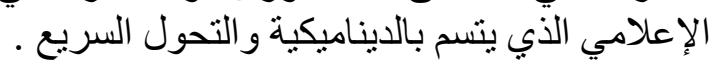

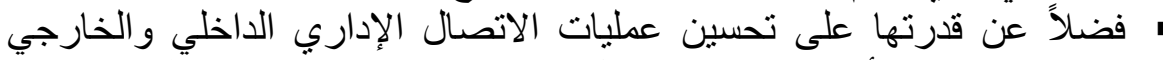

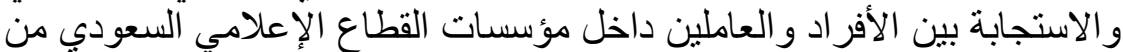
خلال توفير قاعدة معرفية كبيرة على كافة المستويات الإدارية المتعددة.

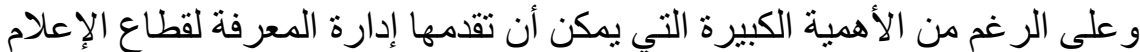

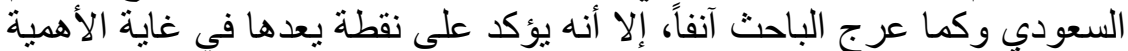

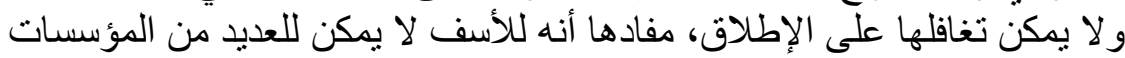

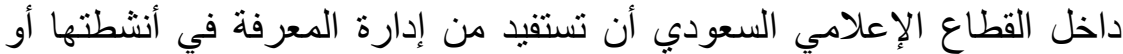

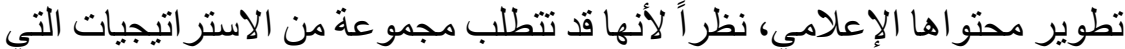

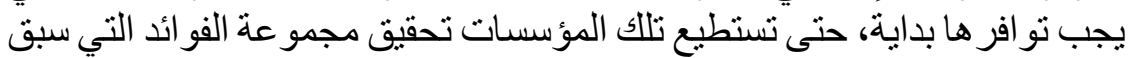

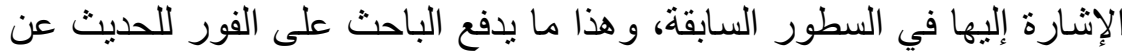
تلك الاستراتيجيات من خلال الأربعة نقاط التالية، والتي تمثل برأي التي الباحث 


\section{المؤتقر العلمي اللدولي السادس والعشرين}

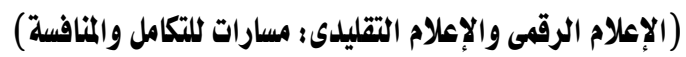

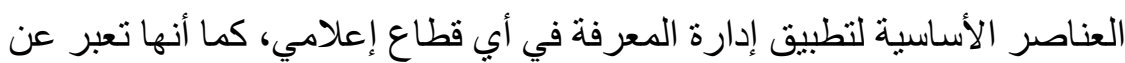

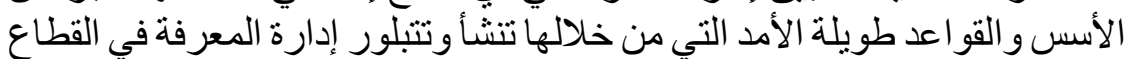

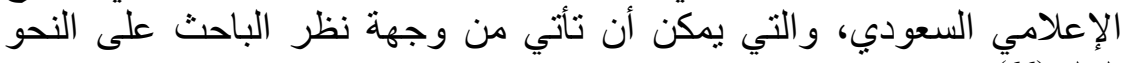

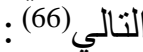

وجود استراتيجية محددة لتطبيق إدارة المعرفة: حيث تعتبر الاستر اتيجية أسلوب

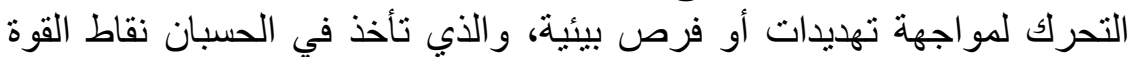
و الضعف الداخلية للمؤسسة الإعلامية التي ترغب تلبة تلبيق إدارة المعرفة في عملية تطوير محتواها الإعلامي، سعيا لتحقيق رسالة وأهداف هذه الإنة العملية الهامة

$$
\text { و الخطيرة. }
$$

والاستراتيجية في إدارة المعرفة، تختلف في معالجتها تبعا لنوعي المعرفة،

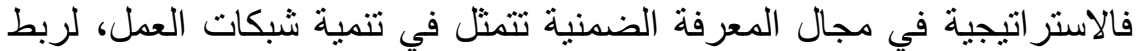

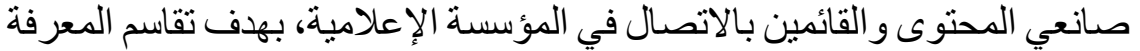

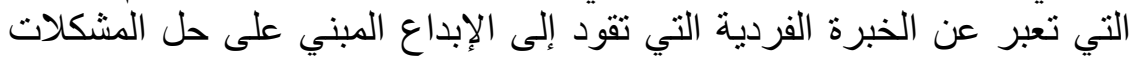

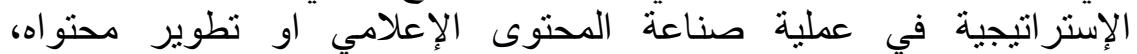
فالاستر اتيجية كإطار عمل لإدارة المعرفة في مؤسسات القطاع الإعلامي السعودي الإني

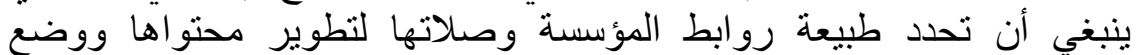

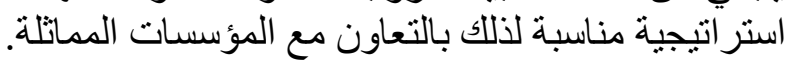

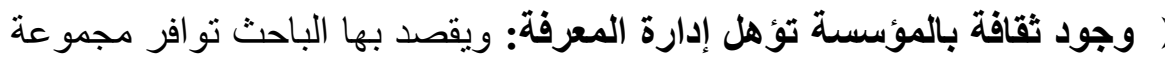

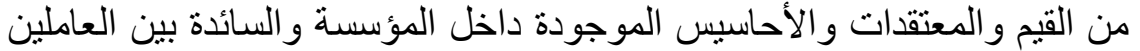

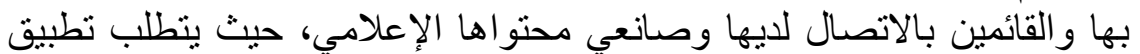

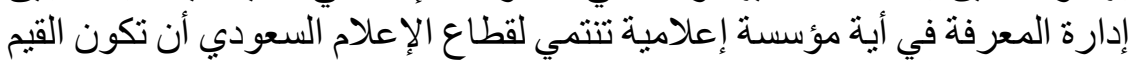

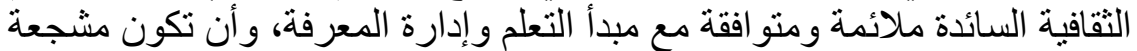

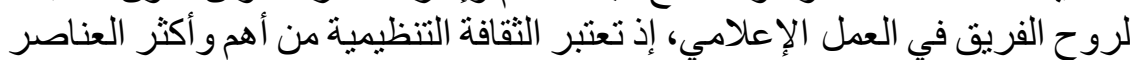

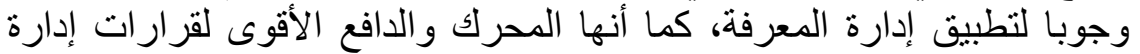

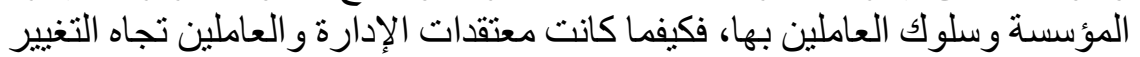
و التطوير و التكنولوجيا و المشاركة وفرق العمل ومنهجية الأداء و غيره من مسبيات

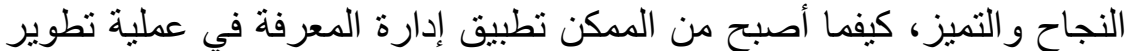

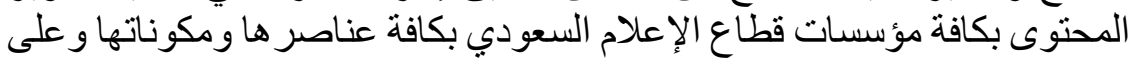

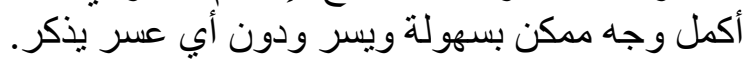

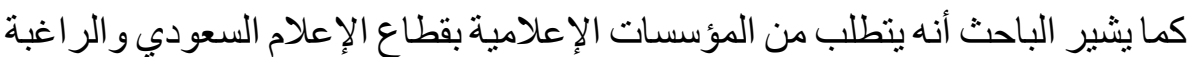

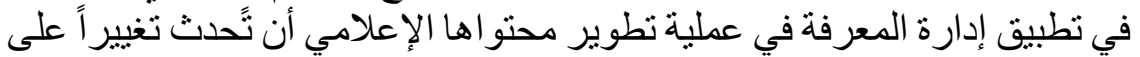




\section{المؤتقر العلمي اللدولي السادس والعشرين}

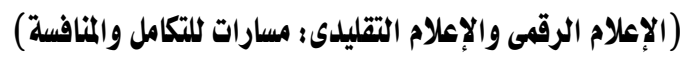

ثقافة موظفيها إلى الأفضل بعيدا عن الأنانية والكسل، وينحصر تغيير الثقافة هذه

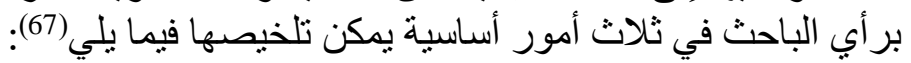

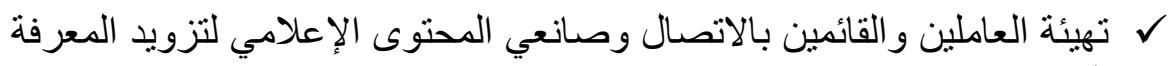
الخاصة بهم. ل $\checkmark$

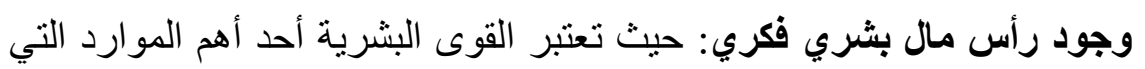

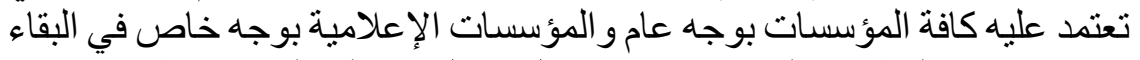

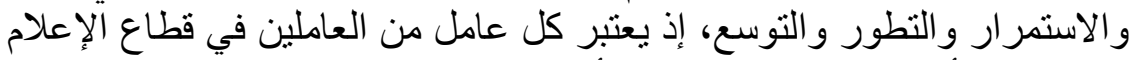

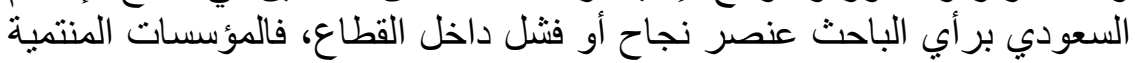

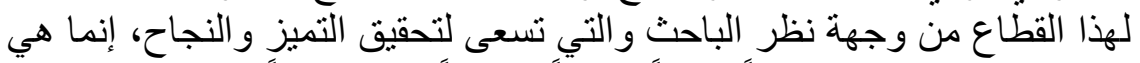

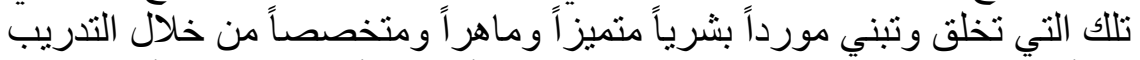

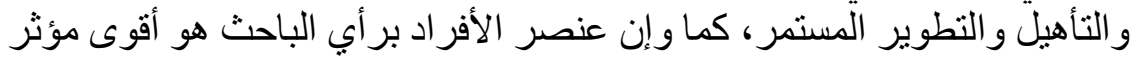

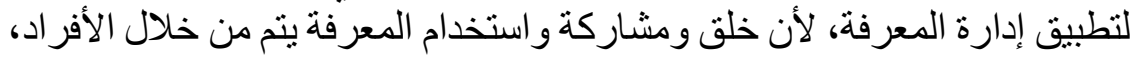

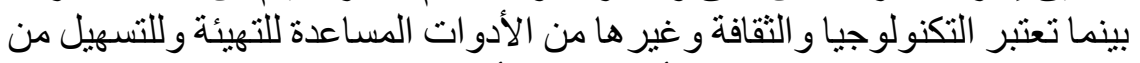

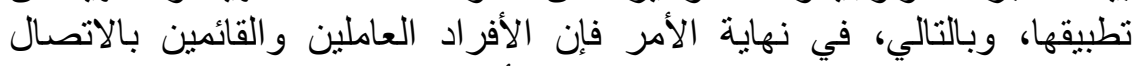
وصانعي المحتوى الإعلامي هم من يملكون بأنفسهم قرار تطبيق إدارة المعرفة من فالأن

$$
\text { عدمه(68). }
$$

> و وجود بنية تكنولوجية لتنفيذ نظام إدارة المعرفة: حيث تلعب التكنولوجيا الرقمية

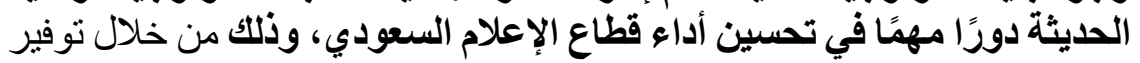

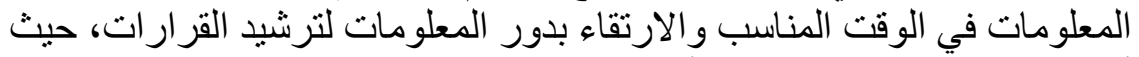

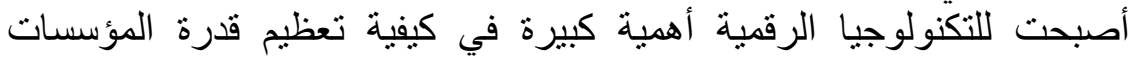

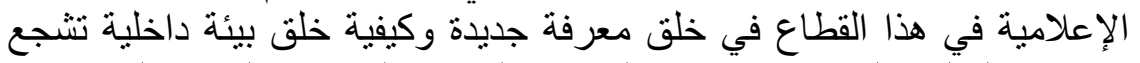

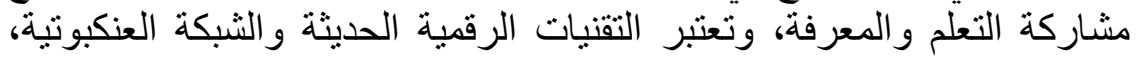

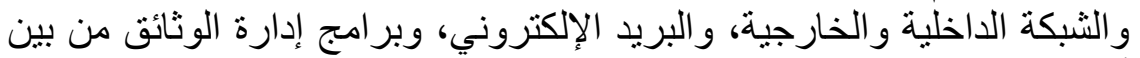

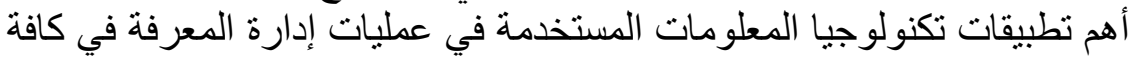

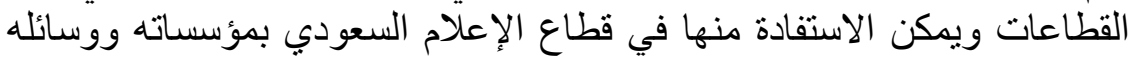
المختلفة(69).

وفي ضوء ما سبق ينبغي أن يقوم المسؤولون عن قطاع الإعلام السعودي

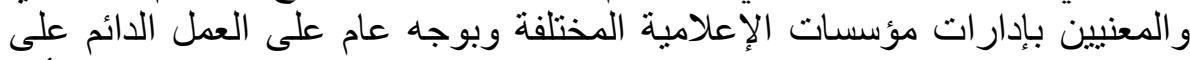

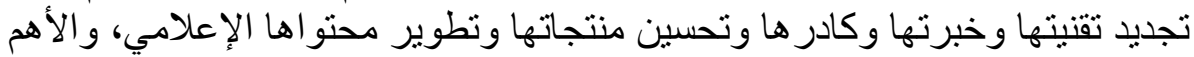

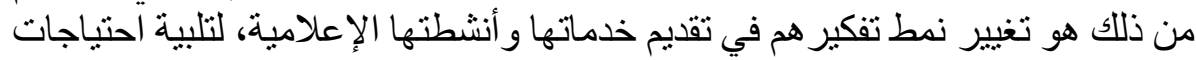




\section{المؤتقر العلمي اللدولي السادس والعشرين}

(الإعلام الرقمى والإعلام التقليدى : مسارات للتكامل والمتافسة)

الفئات المختلفة من الجماهير داخل المملكة وخارجها، و العمل الدؤوب على مو اكبة

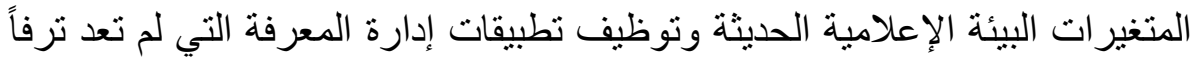

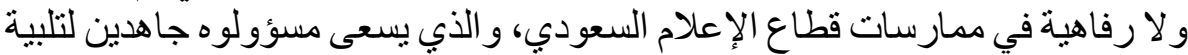

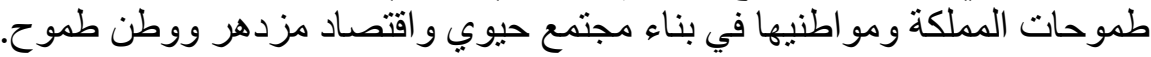

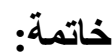

مع تعاظم اهتمام كافة الدول بإدارة المعرفة في مختلف القطاعات السعودية يتز ايد

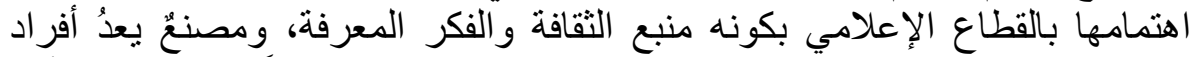

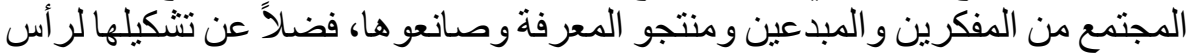

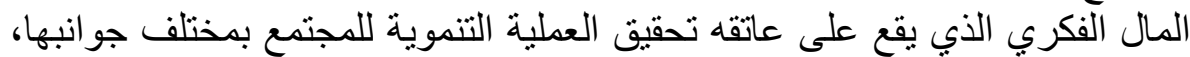

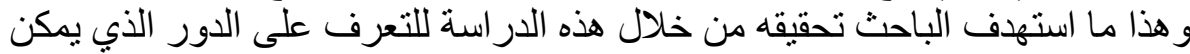

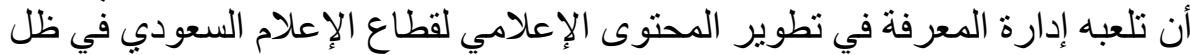

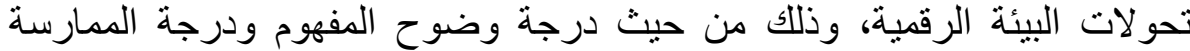
ومتطلبات تطبيقها في تطوير المحتوى الإعلامي لكافة مؤسسات وروسئ وسائل هذا القطاع

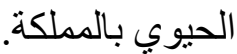

و أثنارت الدر اسة إلى أن تطبيقات إدارة المعرفة قد تتبح حلو لاً مبتكرة وتخطيطاً

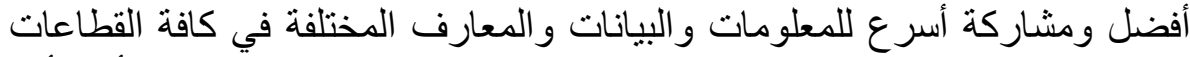

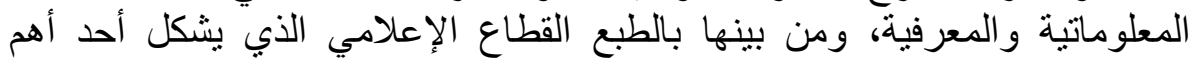

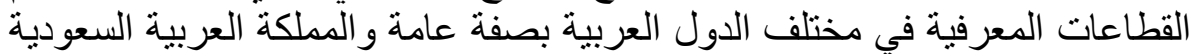

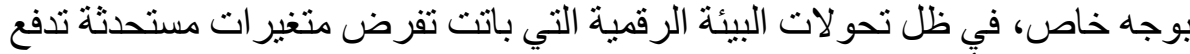

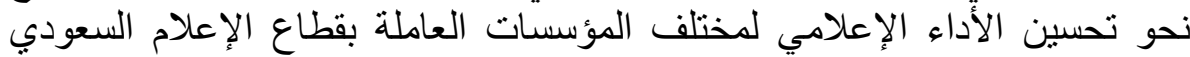

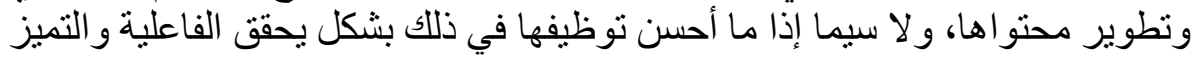

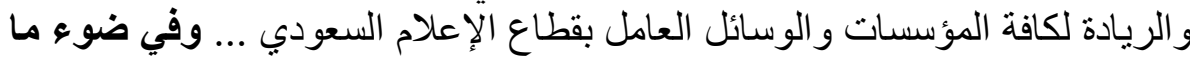

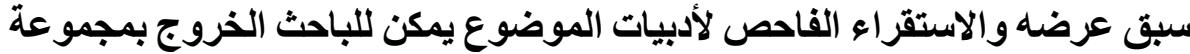

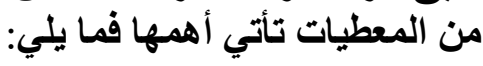

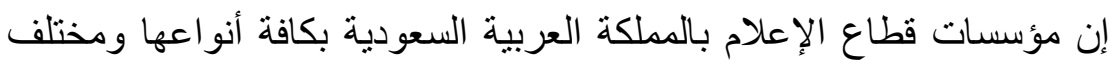

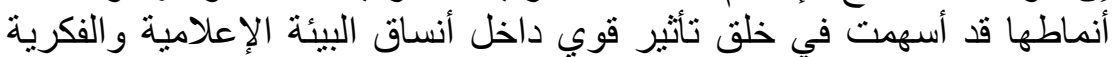

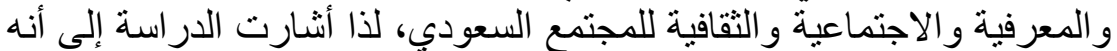

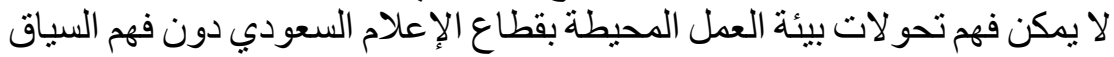

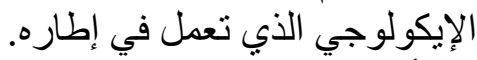

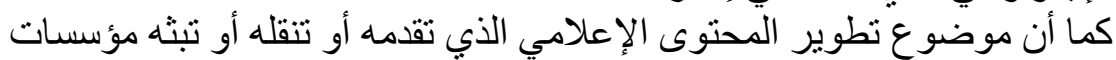

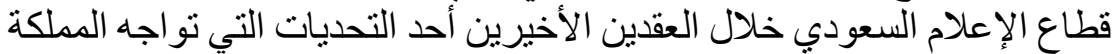
كغير ها من الكثير من البلدان العربية، فبات من الضروبن الضروري توفير محتوى إعلامي 


\section{المؤتقر العلمي اللدولي السادس والعشرين}

(الإعلام الرقمى والإعلام التقليدى : مسارات للتكامل والمتافسة)

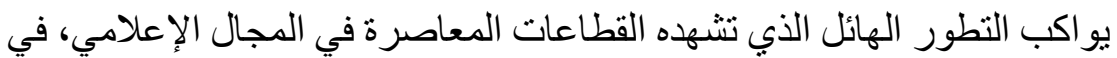

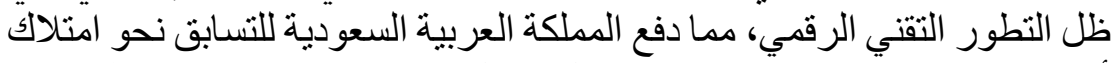
أحدث التقنيات في مجالات الاتصال ونقل المعلومات وصلئ وصناعة المحتوى

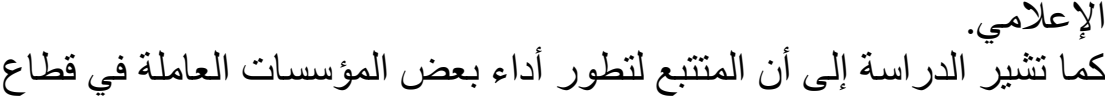

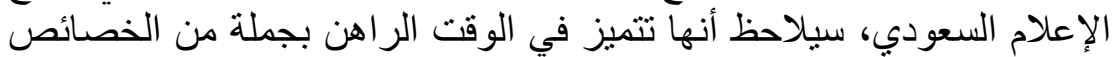

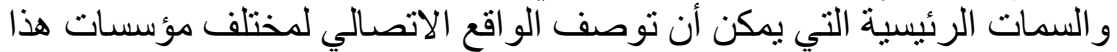

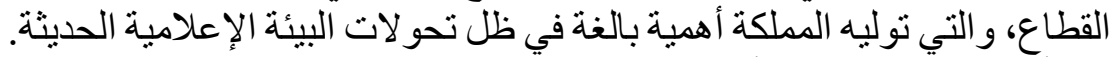

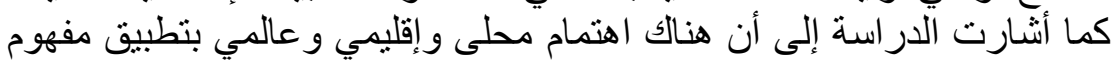

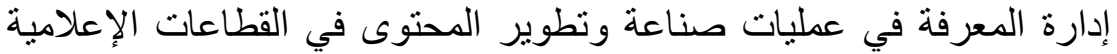

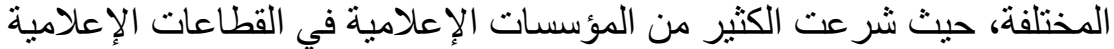

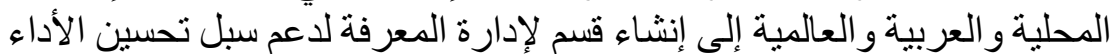

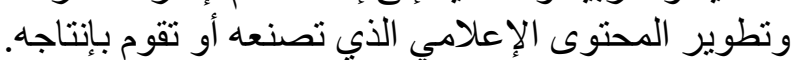

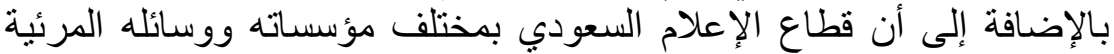

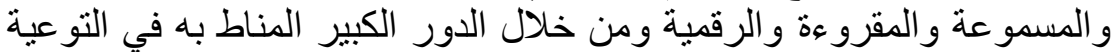

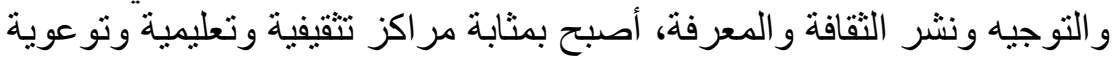

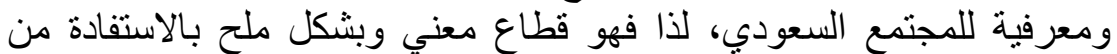

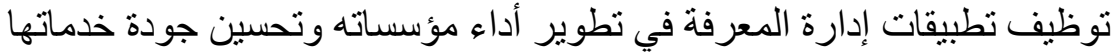

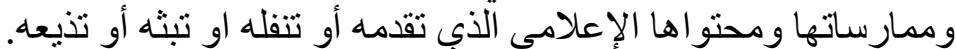

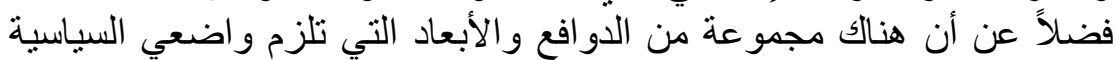

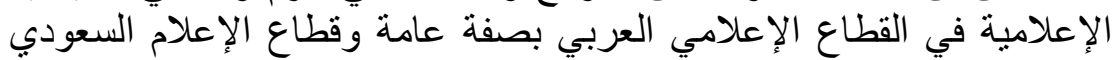

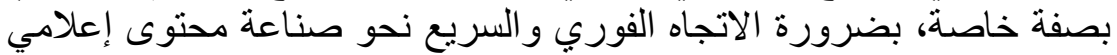

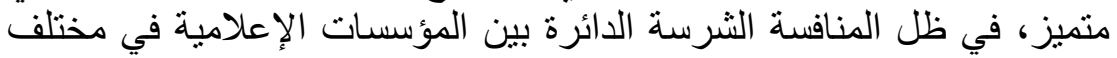

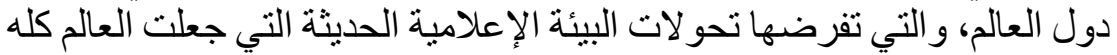

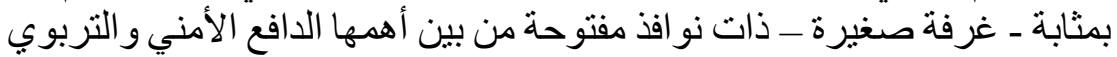

$$
\text { و السياسي و التكنولوجي وغني و المعرفي .... و غير ها. }
$$

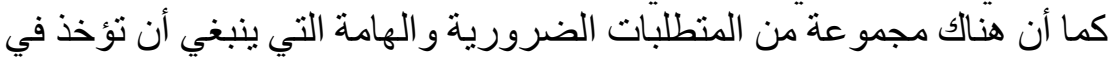

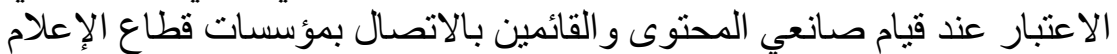
السعودي بعملية إنتاج وصناعة محتوى إعلامي ينبغي أن تؤخذ في الاعتبار حتى الأنى

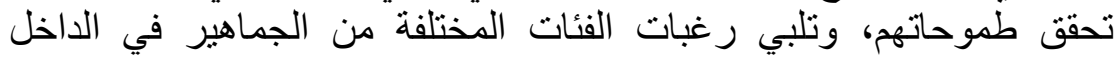

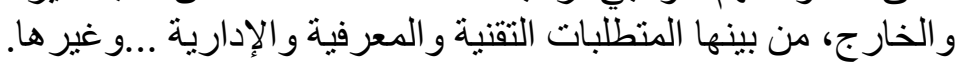

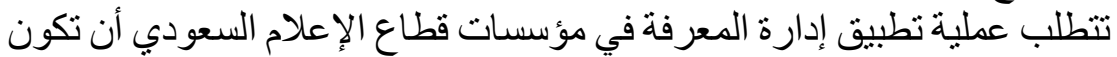

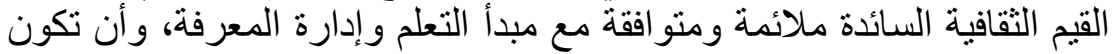

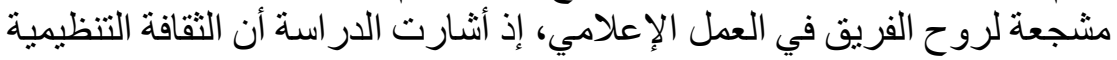




\section{المؤتقر العلمي اللدولي السادس والعشرين}

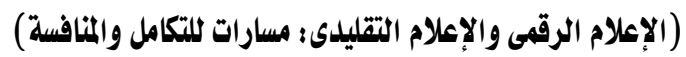

من أهم وأكثر العناصر وجوباً لتطبيق إدارة المعرفة، كما تعد المحرك و الدافع

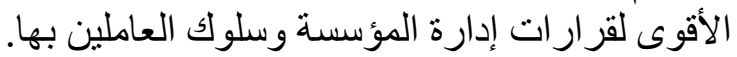

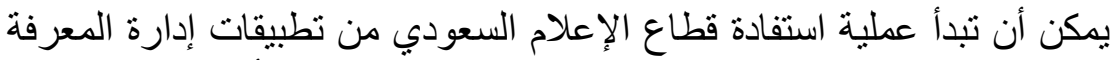

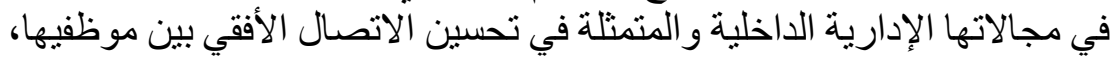

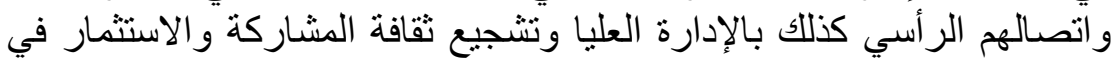

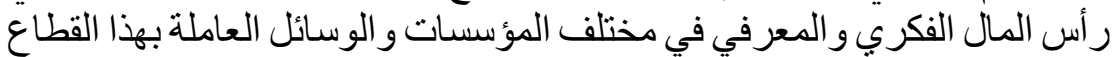

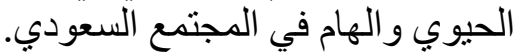
كما يمكن لإدارة المعرفة أن تساهم في زيادة القدرة المئي المؤسسية لمختلف المؤسسات

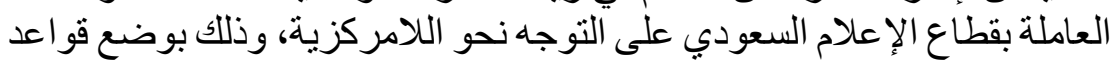
عامة للتصرفات لتحقيق الانسجام في الإجراءات الإدات المتبعة في كافة إدارتها

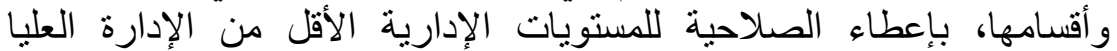
بالتصرف وفق ما تر اه ضمن النظام والسياسة الإعلامية التي رسمتها المملكة الإدة الإدة

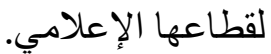
ويمكن أن ترفع تطبيقات إدارة المعرفة في قطاع الإعلام السعودي من قدرة

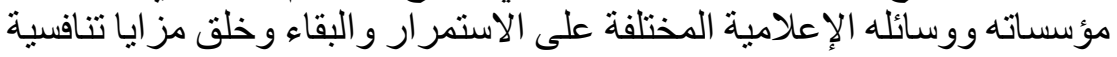

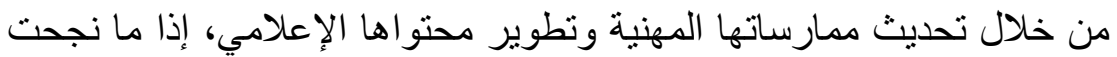

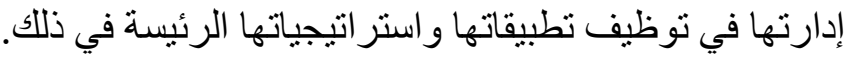

وفي ضوء ما خرج به الباحث من معطيات يمكن طرح بعض المقترحات والتوصيات

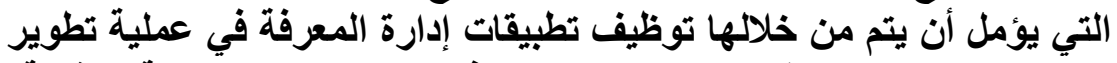

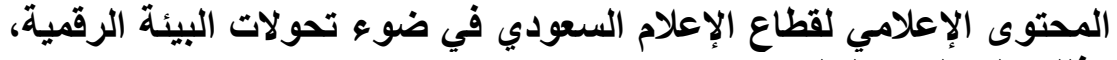
وذلك على النحو الآتالي:

ضرورة زيادة الاهتمام بموضوع تطبيق إدارة المعرفة في قطاع الإعلام

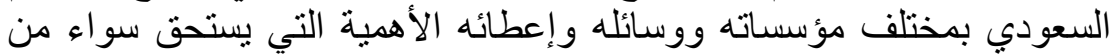

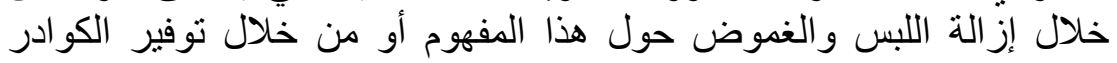

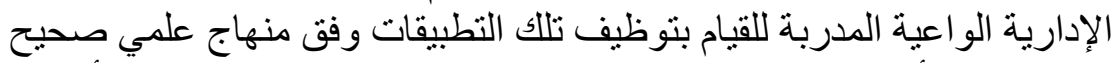

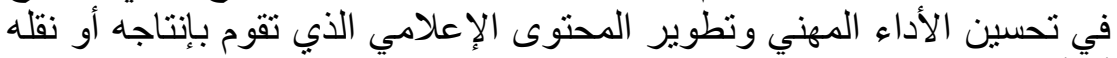

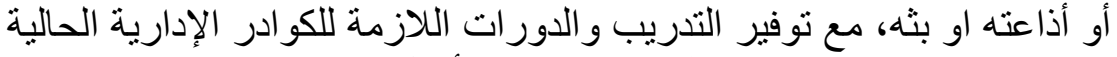

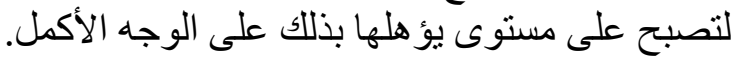

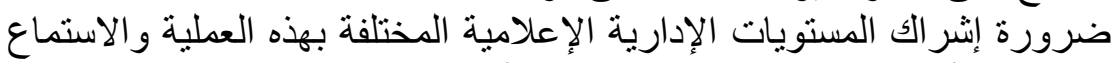

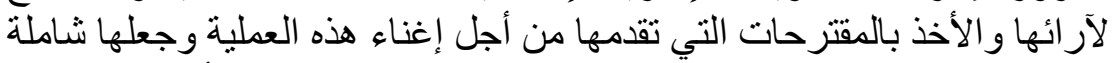

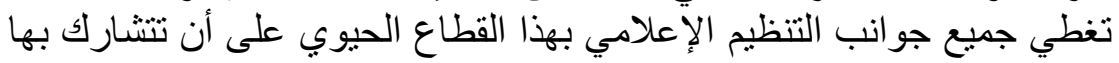
كافة المستويات لزيادة فرص نجاحها. 


\section{المؤتتر العلمي الدولي السادس والعشريز}

(الإعلام الرقىى والإعلام التقليدى : مسارات للتكامل والمنافسة)

ينبغي أن يقوم المسؤولون عن قطاع الإعلام السعودي والمعنيين بإدارات

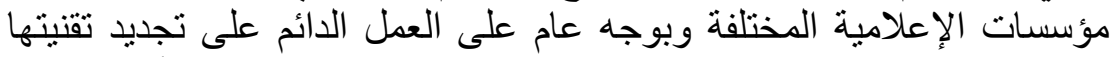

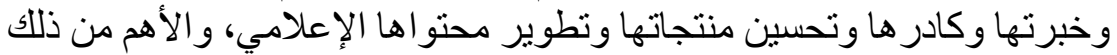

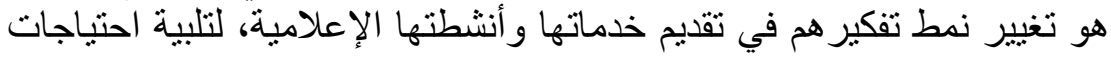
الفئات المختلفة من الجماهير داخل المملكة وخار فئرها.

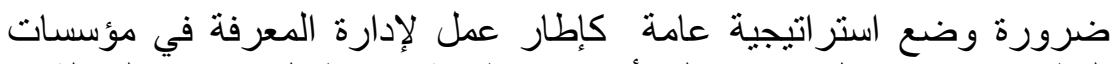

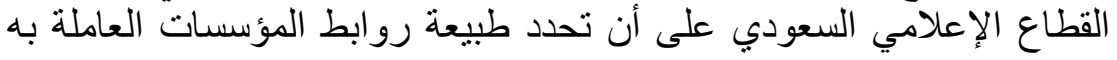

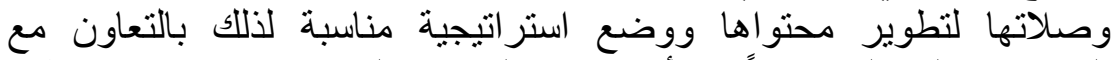

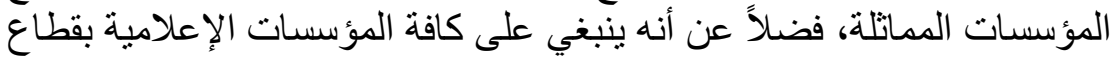

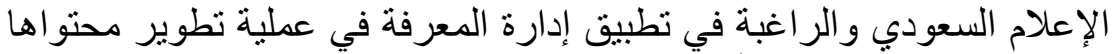

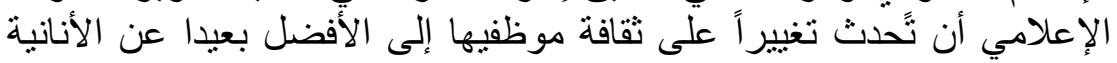

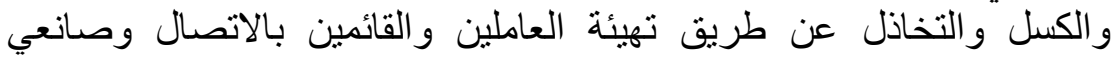

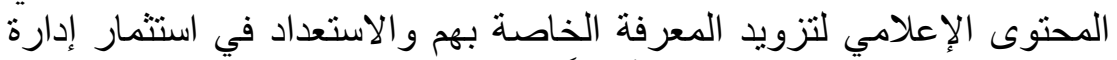

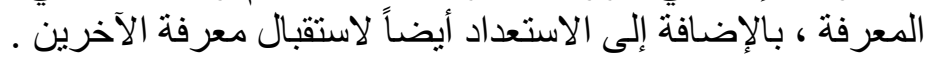

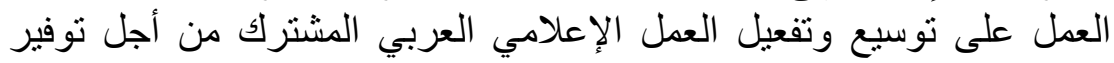

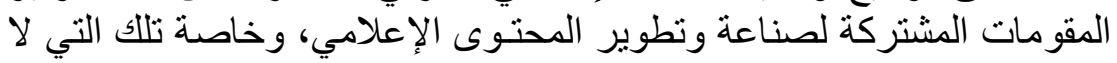

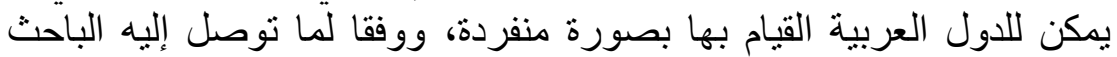

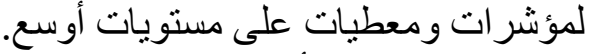

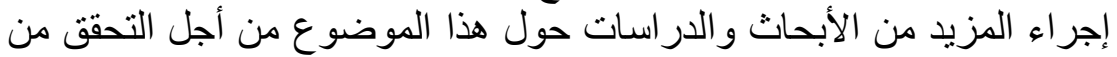

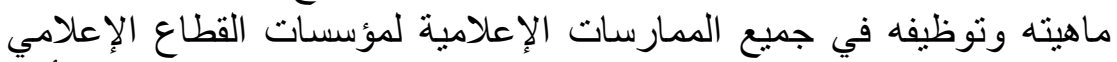

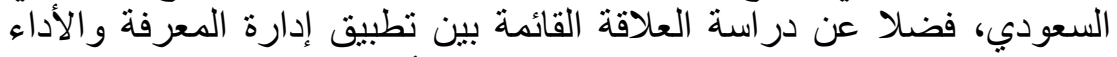

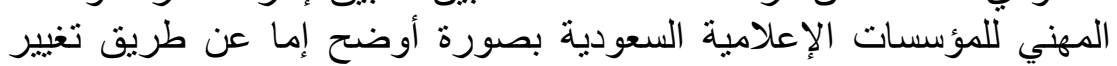

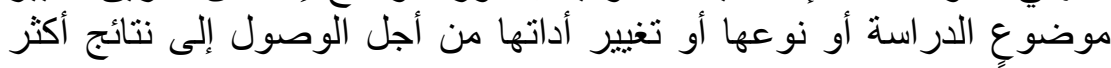
وضوحاً. 
1- أمين عبد الغني، المؤسسات الإعلامية في عصر اقتصاد المعرفة، الطبعة الأولى، (القاهرة: ايتر اكت

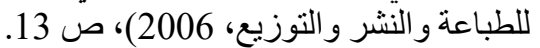
2- محمد عبد الحمبد، البحث العلمي في الدراسات الإعلامية، (القاهرة:عالم الكتب، الطبعة الأولى،

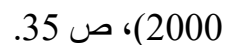

3- عامر قنديلجي، البحث العلمي واستخدام مصادر المعلومات التقليدية والإكترونية، (عمان: دار

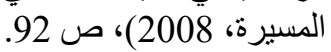

4- إسماعيل إبراهيم، مناهج البحوث الإعلامية، القاهرة: دار الفجر للنشر والتوزيع، 2017) ، ص

5-Lee, Hwa-Wei. Knowledge management and the role of libraries, 2005.

Retrieved November, 6, 2013, from http://www.whiteclouds.com/iclc/cliej/cl19lee.htm.

6- توفيق سريع علي، تكامل إدارة المعرفة و إدارة الجودة الثاملة وأثره على الأداء، رسالة دكتور اهاه،

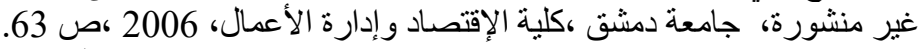

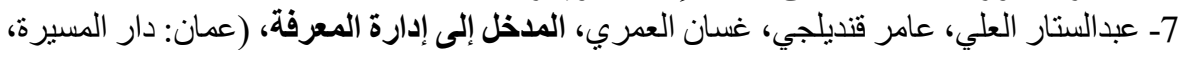

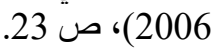
8- ماجد جعفر الغامدي، صناعة المحتوى الإعلامي، ( الرياض: دار تشكيل للنشر، 2017) ، ص

9-سعد محمد الهجرسي ، الاتصالات والمعلومات والتطبيقات الرقمية،(الإسكندية: دار الثقافة

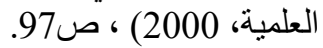

10- سيد حسب الله، أحمد محمد الثامي، الموسوعة العادية العربية لمصطلحات علوم المكتبات والمعلومات

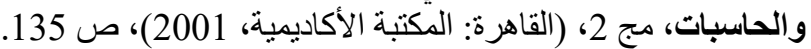

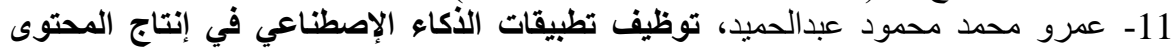

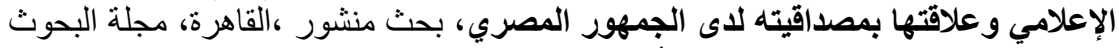

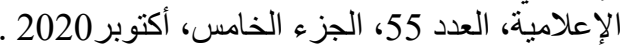

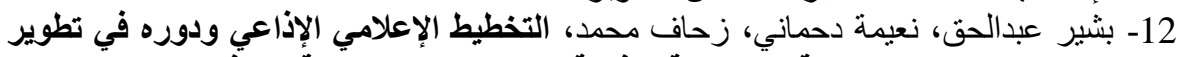

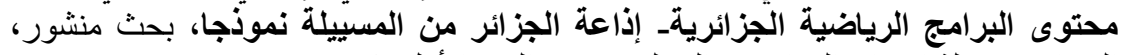

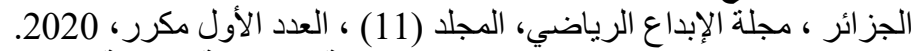

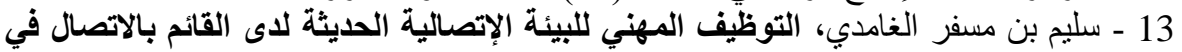

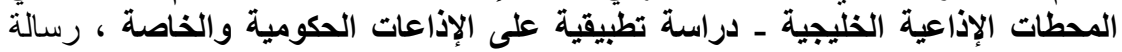

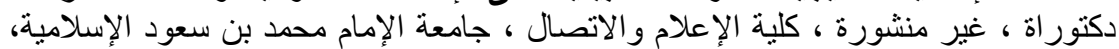
.2019

14-Chan ,Olmsted, Sylvia M. "A Review of Artificial Intelligence, Knowledge management Adoptions in the Media Industry. "International Journal on Media Management 21.3-4 (2019): 193-215. 15- علي عبداللطيف، حذيفة عبدالكريم، أثر التخطيط الإستراتيجي في أداء المؤسسات الإعلامية

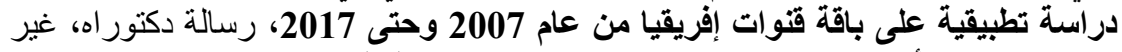

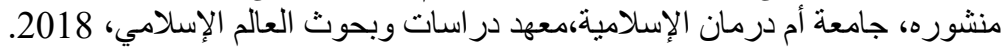


16- Adra Bencharef ,Knowledge Management approach for improve the quality of Scientific knowledge productivity in university institution : an Empirical Study with faculty members of the departments of library science Algerian universities, Cybrarians Journal, vol 48,Decamber 2017.

17-إكرام الصادق بشرى، التخطيط الإستراتيجي الإعلامي والإذاعي وأثره في الإنتاج الإخباري-

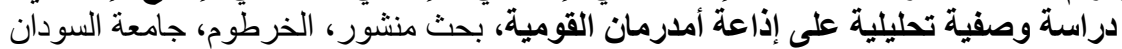

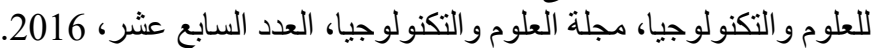

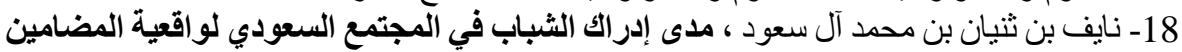

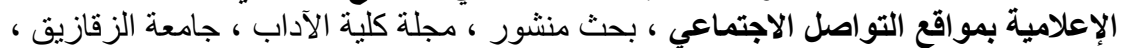

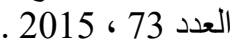

19-محمود عبدالهادي، التخطيط الاستراتيجي للمضمون الإعلامي، ورقة علمية مقدمة للمتلتقى الثالث

للقنو ات الفضائية، اسطنبول،

20- Aidemark, J.(2010) "Knowledge Management Paradoxes." The Electronic Journal of Knowledge Management Volume 7 Issue 1 2009, pp. 1 - 10, available online at www.ejkm.com.

21 - Khandekar, A \& Sharma, A , "the role of knowledge management atManaging Human Resources Capabilities For Sustainable Competitive Advantage: An Empirical Analysis From Indian Global Organizations "Education \& Training, V.48,2009

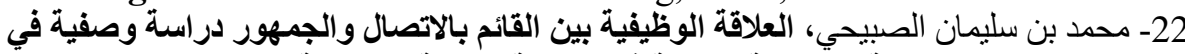

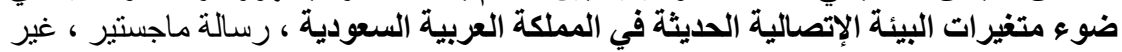

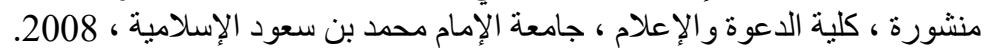

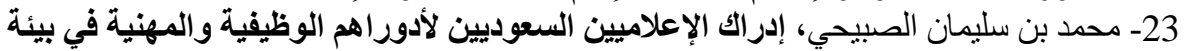

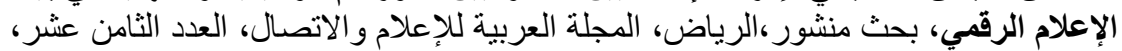

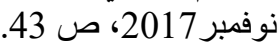

24- de Franco, Chiara, "Media Ecology and the Blurring of Public and Private Practices: A Case from the Middle East", (Politick, Vol. 19, No. 4, 2016).

25- Islas, Octavio and Bernal, Juan David, Media Ecology: A Complex and Systemic Met discipline, (Philosophies, 2016, 1).

26- McLuhan, M. Understanding Media: The Extensions of Man, McGraw-Hill, New York, 1964). P 39.

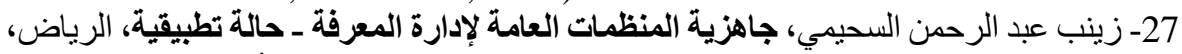

جامعة الملك عبد العزيز بجدة، المؤتمر الدولي للتنمية الإدارية ـ نحو أداء متميز في العية القطاع

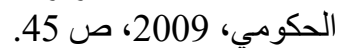

28-محمد عو اد الزيادات، اتجاهات معاصرة في إدارة المعرفة، الطبعة الاولى، (عمان: دار صفاء

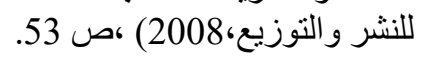




\section{المؤتقر العلمي اللدولي السادس والعشرين}

(الإعلام الرقمى والإعلام التقليدى : مسارات للتكامل والمذافسة)

29- سامي بن ابراهيم بن عبد العزيز الغنيمي، عمليات إدارة المعرفة وعلاقتها بتطوير مستوى الماري

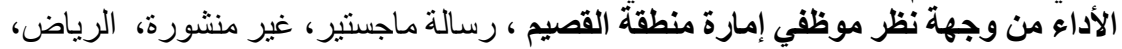

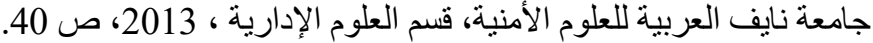

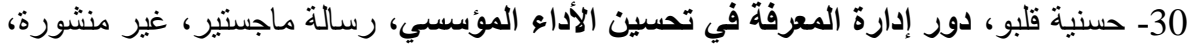

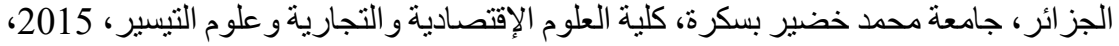

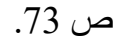

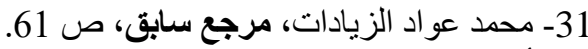

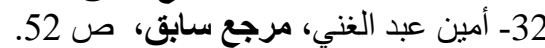

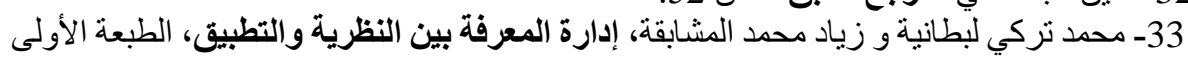

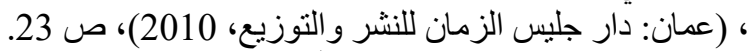

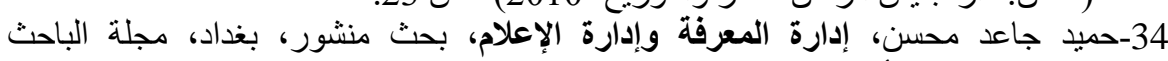

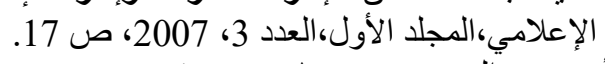

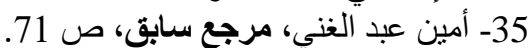

36- حمدى عبدالظكاهر، ، القتوات الفضائية المتخصصة، (الجز ائر : دار ضمة للنشر و التوزيع، 2020)

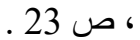

37- محرز حسين غالي، اقتصاديات المعرفة وصناعة الإعلام - من أزمة التمويل إلى النماذج

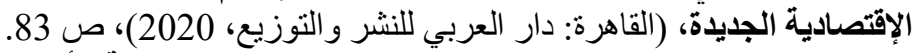

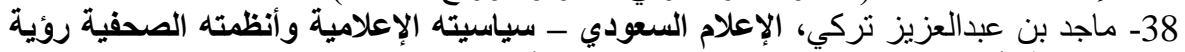

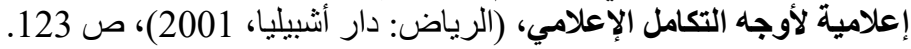

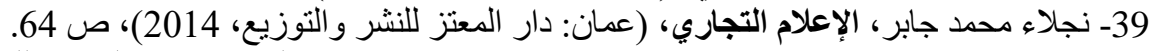

40- صابر حارص، الاتصال الإعلامي وتحديث المجتمع العربي، (القاهرة: دار العربي للنشر

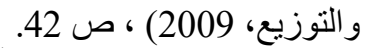

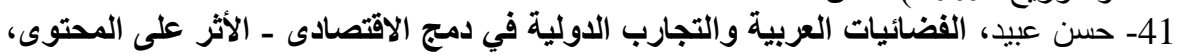

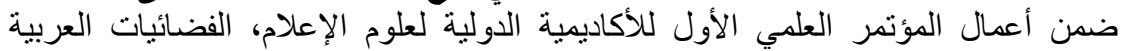

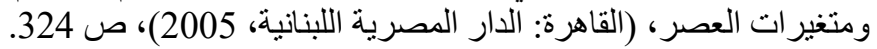

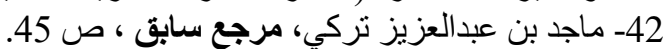

43- أمين سعيد عبدالغني، الثقافة العربية والفضائيات - روئية إعلامية من منظور منهجية التحليل

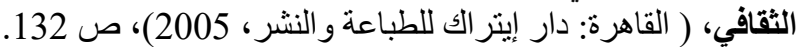

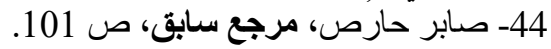

45- عبدالر ازق محمد الدليمي، إثكاليات الإعلام والاتصال في العالم الثالث، ط 3، ( عمان : مكتبة

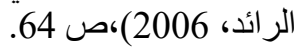

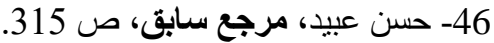

47- فاطمة الزهر اء عبدالفتاح، الإندماج الإعلامي وصناعة الأخبار، (القاهرة: دار العربي للنشر

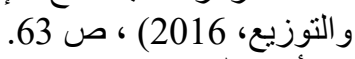

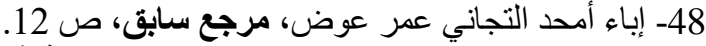

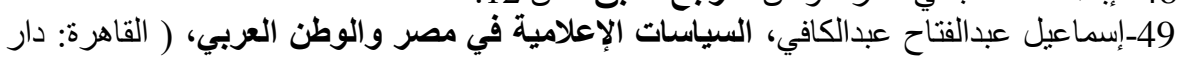

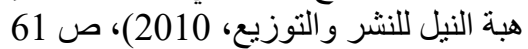

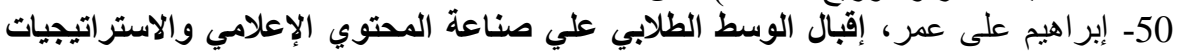

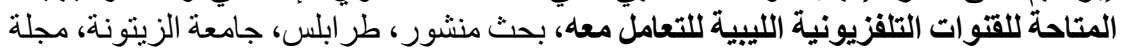

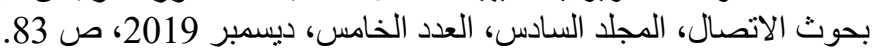




\section{المؤتقر العلمي اللدولي السادس والعشرين}

(الإعلام الرقمى والإعلام التقليدى : مسارات للتكامل والمذافسة)

51- عبدالر ازق الاليمي، آفاق الإعلام في القرن الواحد والعشرين، (عمان: دار اليازوري، 2019)

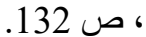

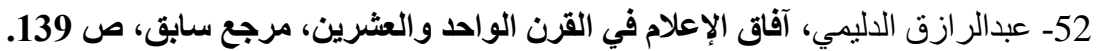

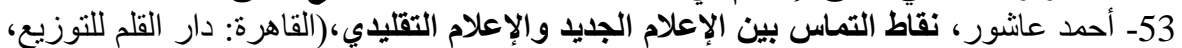

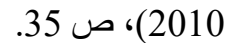

54- محمد عبد الحميد، التربية الإعلامية والوعي بالأداء الإعلامي، ط1، (القاهرة: عالم الكتب،

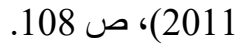

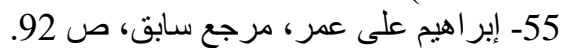

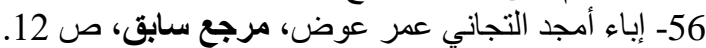

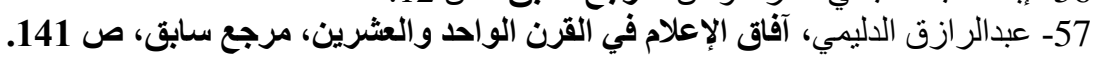

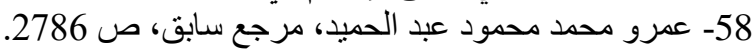

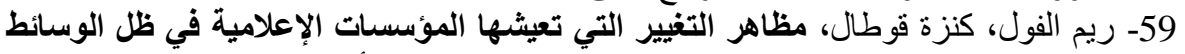

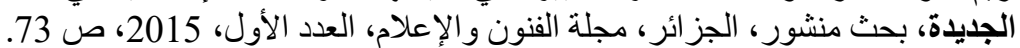
60- عبدالرازق محدد الدليمي، إثكاليات الإعلام والاتصال في العالم الثالث، مرجع سابق، صل صل صل 143

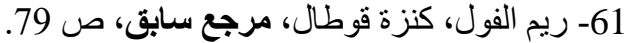

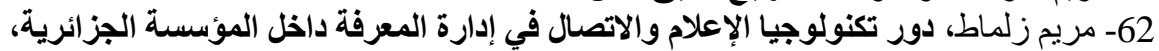

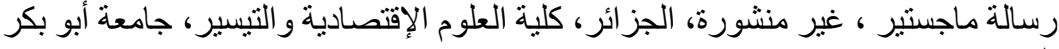

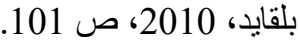

63- محرز حسين غالي، مرجع سابق، ص صن 89.

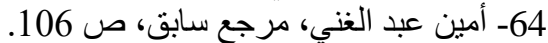

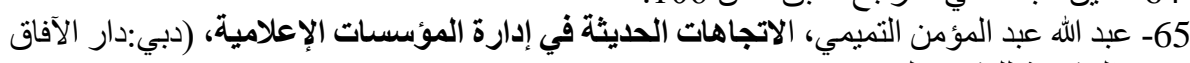

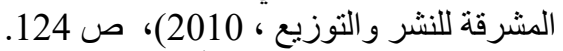

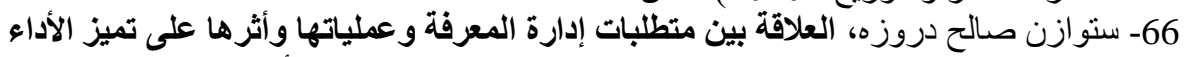

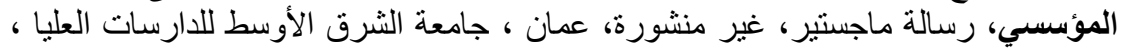

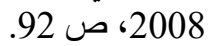

67-صباح حسن عثمان، إدارة المؤسسسات الإعلامية وتأثيراتها على إنتاج الرسالة التلفزيونية

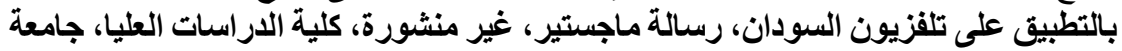

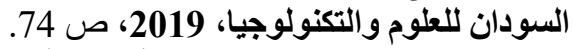

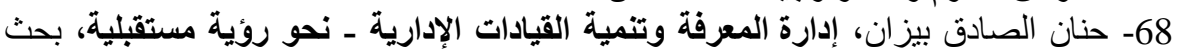

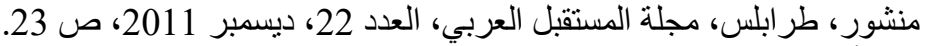
69-- إباء أمحد التجاني عمر ، مرجع سابق، صل لـ 12. 